\title{
Psychosocial needs of breast cancer patients and their relatives
}

Citation for published version (APA):

Schmid Büchi, S. (2010). Psychosocial needs of breast cancer patients and their relatives. [Doctoral Thesis, Maastricht University]. Datawyse / Universitaire Pers Maastricht. https://doi.org/10.26481/dis.20101022ss

Document status and date:

Published: 01/01/2010

DOI:

10.26481/dis.20101022ss

Document Version:

Publisher's PDF, also known as Version of record

\section{Please check the document version of this publication:}

- A submitted manuscript is the version of the article upon submission and before peer-review. There can be important differences between the submitted version and the official published version of record.

People interested in the research are advised to contact the author for the final version of the publication, or visit the DOI to the publisher's website.

- The final author version and the galley proof are versions of the publication after peer review.

- The final published version features the final layout of the paper including the volume, issue and page numbers.

Link to publication

\footnotetext{
General rights rights.

- You may freely distribute the URL identifying the publication in the public portal. please follow below link for the End User Agreement:

www.umlib.nl/taverne-license

Take down policy

If you believe that this document breaches copyright please contact us at:

repository@maastrichtuniversity.nl

providing details and we will investigate your claim.
}

Copyright and moral rights for the publications made accessible in the public portal are retained by the authors and/or other copyright owners and it is a condition of accessing publications that users recognise and abide by the legal requirements associated with these

- Users may download and print one copy of any publication from the public portal for the purpose of private study or research.

- You may not further distribute the material or use it for any profit-making activity or commercial gain

If the publication is distributed under the terms of Article $25 \mathrm{fa}$ of the Dutch Copyright Act, indicated by the "Taverne" license above, 


\section{Psychosocial needs of breast cancer patients and their relatives}

Silvia Schmid Büchi 
(C)2010 Silvia Schmid Büchi, Zürich, Switzerland silvia.schmid@bluewin.ch

All rights reserved

Published by Datawyse | Universitaire Pers Maastricht ISBN 9789052789385 


\title{
Psychosocial needs of breast cancer patients and their relatives
}

\author{
DISSERTATION \\ to obtain the degree of Doctor at the Maastricht University, \\ on the authority of the Rector Magnificus, Prof. dr. G.P.M.F. Mols \\ in accordance with the decision of the Board of Deans, \\ to be defended in public on Friday 22 October 2010, at 10.00 hours
}

by

Silvia Schmid Büchi

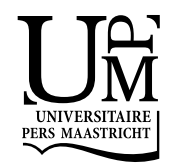




\section{Supervisors}

Prof. dr. H.W. van den Borne

Prof. dr. R.J.G. Halfens, Universität Witten/Herdecke, Germany / UM

Prof. dr. T. Dassen, Charité-Universitätsmedizin Berlin, Germany

\section{Assessment Committee}

Prof. dr. L. Curfs (chairman)

Prof. dr. R. de Bie

Prof. dr. J.P.H. Hamers

Prof. dr. G. Kok

Prof. dr. C. Lohrmann, Universität Graz, Austria

Funding was provided in part by the Cancer League Zürich, Switzerland. 


\section{CONTENTS}

Chapter 1

Introduction

Chapter 2

Experiencing breast cancer and getting life under control again

Chapter 3

A review of psychosocial needs of breast cancer patients and their relatives

\section{Chapter 4}

Psychosocial problems and needs of post-treatment patients with breast cancer and their relatives

\section{Chapter 5}

Factors associated with supportive care needs of patients under treatment for breast cancer

Chapter 6

Factors associated with psychosocial needs of close relatives of women under treatment for breast cancer

Chapter 7

Discussion

Summary

Samenvatting (Summary in Dutch)

Zusammenfassung (Summary in German)

Acknowledgements

Curriculum vitae 

Chapter One Introduction 


\section{INTRODUCTION}

This dissertation addresses the psychosocial needs of breast cancer patients and their relatives. The diagnosis of an illness like cancer frequently results in a complex set of issues that the individual must confront (Holland 2003). Cancer treatment causes a lot of health problems and treatment-related symptoms which may persist for a long time and may add distress to patients who are under great pressure to cope with the demands of their disease and treatment (Cleeland 2000). Family members also are deeply affected when one of their relatives has cancer (CarrollJohnson et al. 2006, Northouse 2005). Relatives are often in conflict between their own suffering and the concern for the patient (Carroll-Johnson et al. 2006). Patients and their relatives are also challenged in their interpersonal relationship, dealing with the stress and the demands caused by cancer (Fergus \& Gray 2009, Northouse 2005). The main focus of this dissertation is the experience of women who live with breast cancer, their supportive care needs and their treatment-related symptoms, as well as the relatives' psychosocial needs. Furthermore, this thesis investigates the patients' and their relatives' emotional problems and the perception of their interpersonal relationship.

This dissertation consists of a qualitative study and a literature review, providing a tentative model as a basis for three quantitative studies.

\section{Cancer and the Swiss Health Care System}

\section{Cancer population}

Switzerland has a population of 7.7 million (BFS 2009). Every year, more than 5200 women are newly diagnosed with breast cancer and more than 1350 die from it. Approximately one-third of all female cancer patients (32.2\%) suffer from breast cancer, which is the most frequently occurring cancer in women. The yearly incidence rate of breast cancer was 111.6 newly-diagnosed women per 100'000 females (NICER 2003-2006). The proportion of breast cancer patients surviving at least 5 years was 81\% for those diagnosed between 1993 and 1997 (Fisch et al. 2005).

\section{The Swiss Health Care System}

Switzerland has 26 cantons. The health care system has a liberal and federal structure. The financing and the competences for health care and health care institutions are mostly in the authority of the 26 cantons. The federal government has no comprehensive regulatory function in this respect (Onccosuisse \& Krebsliga-Schweiz 2005a). The variations in the health care system reflect the self-image of the country and its population. Cantonal, regional and cultural diversity are deeply rooted and are actively cultivated. Cultural borderlines demarcate the country not only along the linguistic dividing line but also between city and countryside, large and 
small cantons, and between different regions (Onccosuisse \& Krebsliga-Schweiz 2005a).

Oncosuisse is the national Swiss cancer umbrella organization for strategicpolitical concerns regarding cancer and consists of two associations, the SAKK (Swiss Group for Clinical Cancer Research) and the Swiss Cancer League (Onccosuisse \& Krebsliga-Schweiz 2005a). Oncosuisse was mandated by the Swiss Federal Office of Public Health to develop a National Cancer Program for 2005-2010. One aim in this program is to improve psychosocial cancer care. Because of insufficient data on cancer patients' psychosocial problems and needs and how these problems and needs were addressed by the health care system, Oncosuisse and the Swiss Cancer League assessed the current status of psychosocial oncology in Switzerland (Onccosuisse \& Krebsliga-Schweiz 2005b).

Results of this survey were: patients and their relatives still do not have much of a voice, and neither their satisfaction nor their quality of life care clearly defined goals in the health care system. Problems most often mentioned were: a lack of explanation received from the doctor when the illness is communicated; a lack of attention from healthcare workers; a lack of psychological and practical support and a lack of coordination of nursing and medical care (Onccosuisse \& Krebsliga-Schweiz 2005b).

Today, and even more in the coming years, psychosocial care for cancer patients is subject to substantial financial pressures, because subsidy financing decreases every year and health insurances are reluctant to pay such services or nurseinitiated counselling and education for cancer patients and their relatives. However, one of the goals formulated for further development in the National Cancer Program is: "cancer patients' and their relatives' needs must be assessed systematically", (Onccosuisse \& Krebsliga-Schweiz 2005a, page 63). Important partners on the way to patient-centred and holistic care are those who directly help cancer patients and their relatives. Health care professionals, e.g. nurses, play an important role in guaranteeing a consistent and patient-centred approach (Onccosuisse \& KrebsligaSchweiz 2005a).

\section{THEORETICAL FRAMEWORK}

\section{Background}

The general objective of the research reported in this dissertation is to identify opportunities for improvements in nursing care for cancer patients and their relatives. The domain of oncology nursing is the cancer patients' and their relatives' unique responses and reactions to cancer and cancer treatment. Oncology nursing care tries to minimise the patients' cancer and cancer treatment-related physical reacti- 
ons and symptoms. Further, it tries to reduce distress and suffering of cancer patients and their relatives and to enable them to understand and cope with the disease, the treatment and the consequences. Nursing care should occur in a context of a mutually respectful and confidential relationship and incorporate physical, psychological, social, spiritual and existential dimensions. It seeks to help the patient find a tolerable meaning to the presence of the serious illness and threat to the future and to life itself (Holland 2003, RCN 2007). Nurses want to individualize care by using knowledge of the patients' experiences, behaviours, feelings and perceptions (Radwin \& Alster 2002). Nursing is an intellectual, physical, emotional and moral process which includes the identification of the patients' needs, nursing interventions, personal care, information, education, advice, advocacy, and physical, emotional and spiritual support (RCN 2007). Patients expect nurses to provide care while acknowledging the patients' experiences with the illness, preferred coping behaviours in dealing with difficulties, feelings, and patients' perceptions on how the illness affects their life (Radwin \& Alster 2002). In general, cancer patients experience nurses as knowledgeable and caring professionals who can help patients satisfy their needs and achieve a desired outcome (Radwin et al. 2005).

\section{Needs}

Breast cancer patients' and their relatives' supportive and psychosocial needs are the main focus of this dissertation. A purpose of nursing is to meet the patients' needs (Endacott 1997) and activities of nursing take place within the territory of basic human needs (Yura \& Walsh 1983). Therefore, the concept of needs is also the main focus of the theoretical framework of this dissertation.

Needs can be viewed as a theoretical construct which consists of general principles of human existence (Holmes \& Warelow 1997). A need can be defined as an internal directional force that determines how people seek out or respond to objects or situations in the environment. A need is an internal state or condition, a lack of something that is necessary for well-being and motivates behaviour (Murray, 1938 in Carver \& Scheier 2008). Some needs are based in the biological nature (needs for food, water, air, sexuality and pain avoidance). Psychological or social needs are secondary needs. Needs work through motives (Carver \& Scheier 2008). Motives refer to internal states that arouse and direct behaviour toward specific objects or goals. A motive is often caused by a deficit, by a lack of something. Motives differ from each other in type, amount and intensity, depending on the person and her or his circumstances. Motives are based on needs and propel people to perceive, think, and act in specific ways (Larsen \& Buss 2008).

A disease such as cancer represents a threat to the patient's continued ability to reach her or his goals. All goals are threatened by a cancer diagnosis. The most salient goal is the continuation of one's life. Other goals are the desire to maintain the 
self-image of a healthy person, the desire to continue being engaged in a wide range of specific activities, and the ability of the patient to live out his or her future with loved ones (Carver 2005). However, according to their individual differences in personality, people have different needs which may vary in intensity (Carver \& Scheier 2008). The threats which are most salient to a person in case of cancer vary with each patient (Carver 2005).

\section{Maslow's hierarchy of needs}

According to Maslow (1968), needs are hierarchically organized in five levels, with more basic needs found at the bottom of the hierarchy and the need for selfactualisation at the top. Individuals will usually be motivated to meet higher need levels when lower order needs are satisfied. The first level basic, biological or physiological needs are of prime importance for the survival of the individual, like the need for air, food, water and sleep; further clothing and shelter, and sexuality for the long-term survival of human beings. At the next level, when physiological needs are relatively satisfied, the needs for safety and security, such as finding safe circumstances, stability and protection, a need for structure and order and predictability of life become important. The third level consists of belonging needs. Humans as social beings have a need for affectionate relationships and love, to belong to a group, to have friends, a family and a sense of community. Esteem needs constitute the fourth level. There are two related types of esteem. The lower esteem is the need for respect from others, recognition, reputation, and status. The higher one is self-esteem. Humans have a need for self-respect. They want to feel good about themselves, valuable, competent, confident, independent and free. Maslow (1968) called the lower four levels of needs (physiological needs, security and safety, belongingness and esteem needs), deficiency needs or D-needs. Satisfying these needs is important in order to avoid unpleasant feelings or consequences. The fifth and highest level is self-actualisation which is based on a need to grow, to become what one is meant to be, and to develop one's potentials and capacities. Therefore Maslow (1968) called them growth needs. Growth is defined as the various processes which bring the person towards ultimate self-actualisation. (Maslow 1968, page 26). The five levels of Maslow's hierarchy of human needs are often presented in the shape of a pyramid (figure 1). How Maslow's hierarchy of needs has been applied in analyses of patients' needs in nursing is addressed in the next paragraph. 


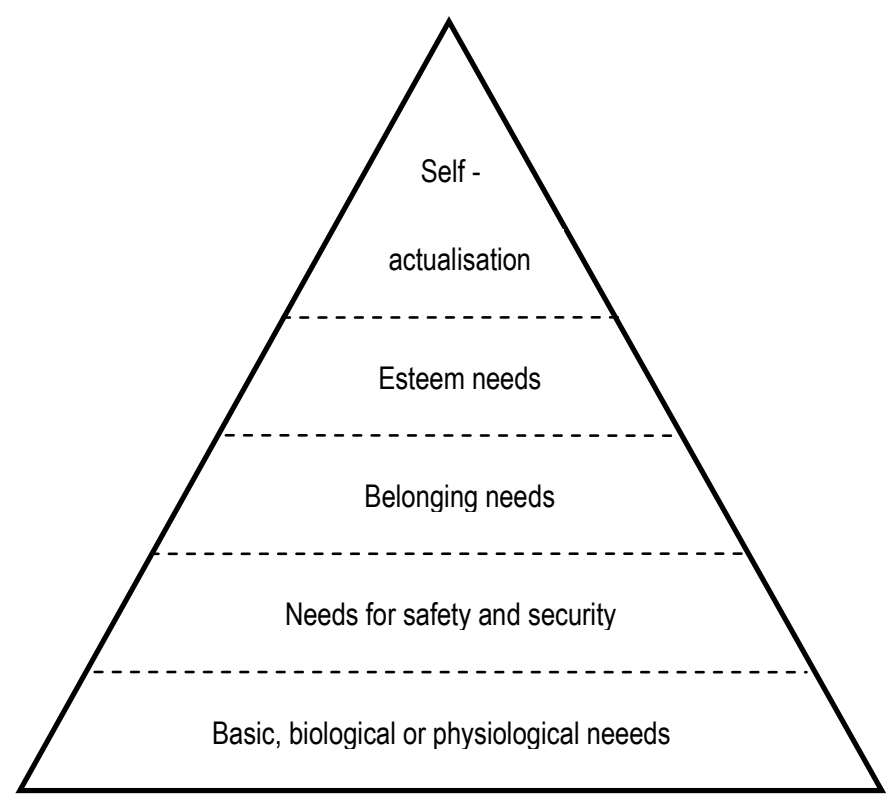

Figure 1: Maslow's hierarchy of human needs

\section{Needs of cancer patients and their relatives in the context of nursing}

Needs in nursing care

Analyses of specific patients' needs reported in most of the nursing literature is usually based on Maslow's work and hierarchy (Holmes \& Warelow 1997). Minshull et al. (1986) translated Maslow's model of human needs to the human need model of nursing. In their opinion, the model is capable of serving nursing practice. The human need model serves to identify areas in nursing care and therefore guides nurses in assessing and meeting human needs. In this context, unmet needs can also be seen as nursing problems which require specific nursing interventions to resolve or alleviate the problems of patients and their relatives (Minshull et al. 1986). Cancer may influence the patients' and their relatives' basic needs, but also their need of self-actualisation (Maslow 1968).

Needs of cancer patients and their relatives in nursing care

Cancer patients and their relatives are faced with existential issues of life and death (Holland 2003). Cancer and cancer treatment may influence the patients' basic biological or physiological needs, and patients may have a need for help in managing the effects of cancer and cancer treatment (Ferrell \& Hassey Dow 1997, SansonFisher et al. 2000). Cancer may cause emotional feelings of anxiety, distress and uncertainty, fear of loss of control, changes in daily routine and stability and fear of 
recurrence in patients as well as in their relatives. To feel free from fear is important to satisfy needs for safety and security and vital for psychological stability. Unmet needs can lead to disorientation, instability and mental crisis (Minshull et al. 1986). Patients and their relatives may need help to gain a sense of control, psychological stability, to develop hope, confidence and a positive outlook for the future (Bonevski et al. 2000, Ferrell \& Hassey Dow 1997, Soothill et al. 2003). Cancer may change the patients' and their relatives' interpersonal relationships, sexuality, everyday, social and work activities and may cause feelings of social isolation. Such unmet belonging needs may result in loneliness, rejection, friendlessness, rootlessness and alienation (Minshull et al. 1986). Patients and relatives have to deal with the health care system. They may need help in obtaining information, counselling and in their adjustment process (Bonevski et al. 2000, Ferrell \& Hassey Dow 1997, Holland \& Reznik 2005, Soothill et al. 2003). Cancer may lead to feelings of inadequacy, worthlessness and dependence, changes in family or social roles, functions and loss of motivation (Minshull et al. 1986). Patients perceiving changes in body appearance and body image may have concerns about attractiveness and fear of social rejection. Patients and their relatives may sense an increased vulnerability and feelings of personal inadequacy (Holland \& Reznik 2005). They may need help to satisfy their esteem needs and to improve self-efficacy for their adjustment process, and to integrate the cancer experience into their life (Morse \& Carter 1996). An illness such as cancer confronts the patients and their relatives with existential issues of life and death. Seeking comforting philosophical, spiritual and religious belief structures or values may help to give a tolerable meaning to life and death and to the new world of illness (Holland 2002, 2003). Nurses cannot directly meet needs of selfactualisation (Minshull et al. 1986), but they can support patients and their relatives in self-actualisation processes. A cancer experience may, in fact, bear a chance for growth (Morse \& Carter 1996, Weiss 2004).

Needs of breast cancer patients and their relatives

Based on a literature-review (chapter 3), we have developed a tentative model (figure 2) of the psychosocial needs of breast cancer patients and their relatives. This tentative model guided our research and may also provide a potential basis for the development of support interventions for breast cancer patients and their relatives and may support clinical practice.

The model addresses the needs of women suffering from breast cancer, the needs of the women's partners and the interaction between the women and their partners. The results of the literature showed that women's needs were influenced by cancer treatments and their long-lasting side effects, and by resulting physical and social impairment. The life-threatening condition of breast cancer may have an impact on psychological needs and challenges of both the women and their partners. Women need to deal with distress, such as anxiety and depression, and need 
information and professional support helping them to maintain control and to manage their illness. Partners may need help in protecting themselves from threats and emotions. They also want information concerning the patients' condition, and need information about the prognosis and the possible future outcome of treatment. The model reflects the interrelationship between women's and their partners' needs. The breast cancer diagnosis per se may affect the interaction between the women and their partners. However factors, such as familial or marital support, the women's as well as the partners' mental or physical health and their emotional distress could also affect the interaction between the women and their partners. Concordance or discordance in communication and satisfaction with the communication between the women and their partners might influence the mutual interaction (chapter 3).
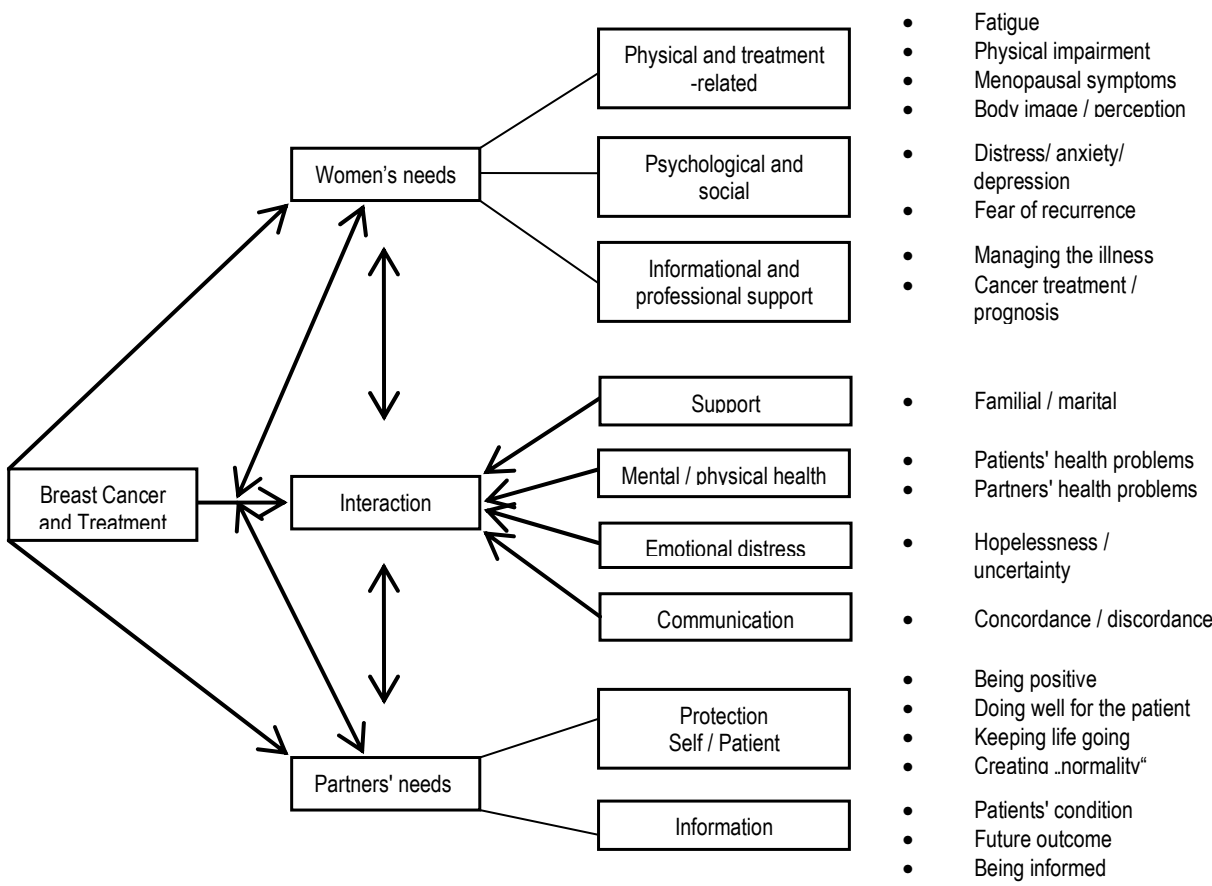

Figure 2: A model for breast cancer patients' and partners' needs during and after treatment

The tentative model in the context of Maslow's hierarchy of human needs The psychosocial needs of the tentative model (figure 2), organised according to the five hierarchical levels of Maslow's model of human needs appear as follows: 


\section{Basic, biological or physiological needs}

- Patients: physical and treatment-related problems, such as fatigue, physical impairment and menopausal symptoms

- Patients: health problems not related to cancer and the treatment

- Relatives: health problems

\section{Needs for safety and security}

- Patients: psychological and social problems, such as distress, anxiety, depression and fear of recurrence

- Patients: informational and professional support needs such as how to manage the illness, concerning cancer-treatment and prognosis, how to maintain control over information and decisions

- Relatives: needs to protect the patient and themselves, to be positive, to do well for the patient, to keep life going and to create "normality"

- Relatives: needs such as to be informed in general and about the patient's condition and the future outcome

- Patients and relatives: distress through hopelessness and uncertainty

\section{Belonging needs}

- Patients and relatives: familial and marital support

- Patients and relatives: concordance or discordance in communication

\section{Esteem needs}

- Patients: body image problems and changed body perception

- Patients: role limitation

\section{Self-actualisation}

- Patients and relatives: adjustment to the patients' illness

Ordering of the patients' and relatives' psychosocial needs according to Maslow's model reflect that patients and relatives have their own needs but also needs which they share. Most of the patients' and the relatives' problems are related to needs for safety and security. Patients suffer from cancer treatment-related problems which cause their basic, biological or physiological needs. Information about breast cancer, cancer treatment and prognosis may help patients and relatives to manage the patients' illness and the cancer-related problems. Patients' and relatives' familial and marital support and concordance in communication may boost belonging needs, and discordance in communication may complicate the satisfaction of belonging needs. The patients' body image problems and their cancer and treatmentrelated role limitations may raise their needs for esteem. Self-actualisation may occur through the patients' and relatives' adjustment process. 


\section{RESEARCH QUESTIONS}

The dissertation addresses the following research questions:

1. What are the experiences of breast cancer patients with recently-diagnosed breast cancer?

2. What are the cancer and cancer treatment-related symptoms of breast cancer patients?

3. What are the needs of breast cancer patients and their relatives?

4. What are the psychological problems of breast cancer patients and their relatives?

5. How do breast cancer patients and their relatives evaluate their mutual relationship?

6. What factors are associated with breast cancer patients' supportive care needs and their relatives psychosocial needs?

\section{OUTLINE OF THE DISSERTATION}

The dissertation starts with a qualitative study (chapter 2). This study describes the experiences of living with breast cancer from the perspective of ten recentlydiagnosed women. The findings provided a basis for the subsequent studies (research question 1).

Chapter 3 presents a literature review. The review evaluates the psychosocial needs of breast cancer patients and their relatives and identifies factors affecting the patients' and relatives' satisfaction with care and support. Based on this review, a tentative model for need assessment has been developed which guided the subsequent quantitative studies (research question 3).

Chapter 4 focuses on the patients' and their relatives' needs and on factors during the post-treatment phase. This study assessed and compared the supportive care needs of breast cancer patients and the psychosocial needs of their relatives; the patients' and relatives' burden of illness, anxiety, depression and distress; assessed the patients' illness and treatment-related symptoms; and identified factors influencing the patients' and relatives' needs (research questions 2, 3, 4).

Chapter 5 evaluates the supportive care needs, cancer and cancer treatmentrelated symptoms, anxiety, depression and distress of breast cancer patients during their medical treatment, and evaluated how patients perceived their interpersonal relationship. Further, the study defined factors associated with the patients' supportive care needs, which may identify patients with unsatisfied needs in compa- 
rison to patients with satisfied needs, factors which may identify patients at risk, who are more vulnerable and have higher needs for support (research questions 2, $3,4,5,6)$.

Chapter 6 is directed to the relatives of the patients. It gives insight into psychosocial needs, anxiety, depression and distress of close relatives of patients under treatment for breast cancer, and evaluated how the close relatives perceived their interpersonal relationship with the patient. The study defined factors associated with the relatives' psychosocial needs, which may identify relatives with unmet needs, who are more vulnerable and have a higher need for support (research questions 3, 4, 5, $6)$.

In chapter 7, the main findings are discussed, methodological limitations are critically reflected and recommendations are presented for nursing care and future research. 


\section{REFERENCES}

BFS (2009) Swiss Statistical Federal Office. www.bfs.admin.ch.

Bonevski B, Sanson-Fisher R, Girgis A, Burton L, Cook P \& Boyes A (2000) Evaluation of an instrument to assess the needs of patients with cancer. Cancer 88, 217-225.

Carroll-Johnson R, Gorman L \& Bush N (2006) Psychosocial Nursing Care: Along the Cancer Continuum. Oncology Nursing Society, Pittsburgh, Pennsylvania.

Carver CS (2005) Enhancing adaptation during treatment and the role of individual differences. Cancer 104, 2602-2607.

Carver CS \& Scheier MF (2008) Perspectives on Personality. Pearson International Edition, Boston, New York, San Francisco.

Cleeland CS (2000) Cancer-related symptoms. Semin Radiat Oncol 10, 175-190.

Endacott R (1997) Clarifying the concept of need: a comparison of two approaches to concept analysis. J Adv Nurs 25, 471-476.

Fergus KD \& Gray RE (2009) Relationship vulnerabilities during breast cancer: patient and partner perspectives. Psychooncology.

Ferrell BR \& Hassey Dow K (1997) Quality of life among long-term cancer survivors. Oncology 11, 565576.

Fisch T, Pury P, Probst N, Bordoni A, Bouchardy C, Frick H, Jundt G, De Weck D, Perret E \& Lutz JM (2005) Variation in survival after diagnosis of breast cancer in Switzerland. Ann Oncol 16, 1882-1888.

Holland JC (2002) History of psycho-oncology: overcoming attitudinal and conceptual barriers. Psychosom Med 64, 206-221.

Holland JC (2003) American Cancer Society Award lecture. Psychological care of patients: psychooncology's contribution. J Clin Oncol 21, 253-265.

Holland JC \& Reznik I (2005) Pathways for psychosocial care of cancer survivors. Cancer 104, 2624-2637.

Holmes CA \& Warelow PJ (1997) Culture, needs and nursing: a critical theory approach. J Adv Nurs 25, 463-470.

Larsen RJ \& Buss DM (2008) Personality, Psychology: Domains of Knowledge about Human Nature. McGraw-Hill International Edition, Boston.

Maslow AH (1968) Toward a Psychology of Being. D. Van Nostrand Company, New York, Cincinnati.

Minshull J, Ross K \& Turner J (1986) The human needs model of nursing. J Adv Nurs 11, 643-649.

Morse JM \& Carter B (1996) The essence of enduring and expressions of suffering: the reformulation of self. Sch Inq Nurs Pract 10, 43-60.

NICER (2003-2006) The National Institute for Cancer Epidemiology and Registration, and the Swiss Statistical Federal Office (NICER \& FSO). www.nicer-swiss.ch.

Northouse L (2005) Helping families of patients with cancer. Oncol Nurs Forum 32, 743-750.

Onccosuisse \& Krebsliga-Schweiz (2005a) Nationales Krebsprogramm für die Schweiz 2005 - 2010.

Onccosuisse \& Krebsliga-Schweiz (2005b) Psychosoziale Onkologie in der Schweiz: Schlussbericht der Bestandesaufnahme.

Radwin LE \& Alster K (2002) Individualized nursing care: an empirically generated definition. Int Nurs Rev 49, 54-63.

Radwin LE, Farquhar SL, Knowles MN \& Virchick BG (2005) Cancer patients' descriptions of their nursing care. J Adv Nurs 50, 162-169.

RCN (2007) Defining Nursing. Royal College of Nursing www.rcn.org.uk.

Sanson-Fisher R, Girgis A, Boyes A, Bonevski B, Burton L \& Cook P (2000) The unmet supportive care needs of patients with cancer. Cancer 88, 226-237.

Soothill K, Morris SM, Thomas C, Harman JC, Francis B \& Mclllmurray MB (2003) The universal, situational, and personal needs of cancer patients and their main carers. Eur J Oncol Nurs 7, 5-13.

Weiss T (2004) Correlates of posttraumatic growth in husbands of breast cancer survivors. Psychooncology 13, 260-268.

Yura H \& Walsh MB (1983) Human needs 3 and the nursing process. Appleton-Century, Crofts, New York. 


\section{Chapter Two}

\section{Experiencing breast cancer and getting life under control again}

A slightly revised translation of a paper originally published in German as:

Schmid-Büchi S, Dassen T, Halfens RJG (2005). Die Erfahrung an Brustkrebs zu erkranken, und wie die betroffenen Frauen ihr Leben wieder unter Kontrolle bringen. Pflege 18, 345-352 


\section{ABSTRACT}

Women experiencing breast cancer are confronted with a life-threatening disease and find themselves in a situation that changes and restricts their life psychologically, physically and socially. This qualitative investigation examined the experience of living with breast cancer from the perspective of newly-diagnosed women. Ten women were interviewed at the end of their radiotherapy. The interviews were analysed using content analysis. The findings show three domains. First domain: From living in fear of having breast cancer to the confirmation of its diagnosis. These women perceive the confirmation of the diagnosis as a shock and initially plunge into an existential crisis. The life-threatening disease with an unpredictable future, feelings of vulnerability, uncertainty, hopelessness and anxiety often leads to depressive feelings. The women need energy to maintain control over their life and sometimes for to suppress emotions to protect themselves from overwhelming feelings and suffering. Second domain: Experiencing therapy. The women undergo weakening, aggressive and invasive treatment regimes, leaving them in a condition worse than before. Physically exhausted, they sometimes don't know how to go through and overcome this time. Lack of energy, tiredness and fatigue are ongoing problems. On being diagnosed with breast cancer, they suddenly become patients, having to cope with a complex healthcare system. They expect empathy, caring and expertise from doctors and nurses. When in contact with health care providers, they often hide their suffering, though in fact they are extremely vulnerable and in deep despair. Third domain: Endure and live. Women living with breast cancer have no choice but to go through this situation. By motivating themselves, they regain and mobilise their vital energy. They try to suppress their suffering and threatening, intrusive memories. Support from relatives is very important, at the same time women have the tendency to protect them from their suffering. The definition of the role of these relatives and their suffering remain unclear. More research is needed to determine precisely which psychosocial variables and processes are effective in promoting greater health for women with breast cancer and their families, taking into consideration the dynamics of the relationship between women with breast cancer and their relatives as well as the influence of their mutual support. 


\section{INTRODUCTION}

Breast cancer is a relevant topic in the Swiss health care system. Every year, more than 5000 women are newly-confronted with this diagnosis (NICER 1986-2005). Cancer is perceived by most people as an existential threat, they become aware of their mortality, which often elicits fear and emotional distress (Mast 1998). The psychosocial distress of the disease and its treatment demand enormous coping efforts from both the person afflicted and from her family members (Kissane et al. 1998, Lev 1992). Women who get breast cancer are confronted with a lifethreatening disease; they must learn to cope with fear and uncertainty (Cimprich 1999, Verres \& Klusmann 1997). The treatments, which are invasive, stressful and associated with numerous side-effects, may be greatly detrimental to the quality of life and social contacts (Buick et al. 2000, Dow \& Lafferty 2000). Fatigue, emotional distress and an altered body image and physical perceptions are problems under which the women suffer during treatment and usually thereafter as well (De Jong et al. 2002). In their comparative study, Gottesman \& Lewis (1982) speak of short-term stress situations in women who must undergo surgery, but also of genuine crises in women undergoing surgery for breast cancer. The goal of nursing and medical care, in addition to treatment, is to support affected women, to support them along the way, and give them orientation in their adjustment process to therapy and disease (Herth 2000, Palsson \& Norberg 1995, Samarel et al. 1999). It is important to understand how affected women experience their altered life situation and thus to know their real problems and needs. In this way, women and their families can be offered support that really helps them (Freedman 2003, Landmark \& Wahl 2002, Mclllmurray et al. 2001).

In this study, women suffering from breast cancer, treated in Swiss health institutions, were to be questioned from a practice perspective. The objectives of this research were to describe the experiences of women with breast cancer, how they experience the consequences and problems of cancer treatment, and their coping strategies.

\section{METHODS}

In this study, women with newly-diagnosed breast cancer were asked at the end of their outpatient radiation therapy about their experiences and needs, using qualitative, problem-centred interviews. The problem-centred interview was described by Witzel (1982) and has been classified by Flick (2002) among the category of guided interviews. The problem-centred interviews can be characterized as a combination of an inductive and deductive approach, which may provide opportunities for modi- 
fying theoretical concepts. Structuring the meaning of social reality remains solely up to the person interviewed (Lamnek 1995).

\section{Interviews}

The women who were under treatment at the Radio-Therapeutic Clinic of the University Hospital Zurich at the time of the investigation were asked by the nurses of the clinic whether they would be willing to participate in the study. Nearly all women who were approached agreed to participate. The researcher informed those interested about the study both verbally and in writing. The women confirmed their participation by providing written informed consent. Ten women were interviewed. The interviews took between 40 and 90 minutes. In the interviews, women were asked about their experiences and problems, about their fears and their need for support. The interviews were recorded on tape, transcribed by the researcher and translated from Swiss dialect (only a spoken language) into standard German.

\section{Data analysis}

Analysis of the interviews was made largely by qualitative content analysis (Mayring 2003), which is characterized by adherence to systematic analytical procedures in a pre-defined procedural model. An analysis scheme (coding guideline) was worked out in several steps by which corresponding text passages could be arranged (Downe-Wamboldt 1992, Lamnek 1995, Mayring 2003, Schmidt 2000). Then the material was summarized and a manageable body created by abstraction. In an explication step, questionable text segments were clarified, explained and interpreted (Mayring 2003). Finally, a structure was filtered out of the material by means of structured content analysis. This was done by making a cross-section through the material: The dimensions and intensities were collated to a category system to reveal typical variants of collective behavioural patterns and to develop a consistent overall pattern (Lamnek 1995, Mayring 2003, Schmidt 2000).

During the entire research process, concrete steps were taken to comply with the quality criteria of qualitative research (Lincoln \& Guba 1985). Plausibility was attained by analysis and discussion of the research process and the knowledge therein gained by experts in oncology and of the interviews by three qualified experts who possess the required methodological and professional knowledge, but were not directly involved in this research project (peer debriefing). The research results were submitted to one of the interviewed women to check authenticity and statement validity (member checking). The comprehensibility and the confirmatory power of the research were increased by regular audits with a supervisor and continuous evaluation of the research process by supervisory persons (confirmability audit). An information basis was obtained with detailed presentation of context- 
specific conditions and interview excerpts (thick description) upon which the transferability can be evaluated.

Ethics approval was obtained from the Institutional Review Board of the Canton of Zurich, Switzerland.

\section{RESULTS}

Nine of the ten women interviewed were at the end of their radiation therapy, one had suffered cancer of the other breast two years earlier. One other woman had completed therapy 1.5 years prior to the interview and remained in remission. The women were between 31 and 75 years old. All had undergone breast-conserving surgery, eight had chemotherapy, all ten radiation therapy and nine an endocrine therapy. Eight women were living with a partner, three had no children, five had grown children and two had under-age children.

Analysis of the interviews led to three domains with two subtopics each. First: From living in fear of having breast cancer to the confirmation of its diagnosis with the subtopics shock and crisis. The second domain deals with: Experiencing therapy with the sub-topics impact of treatment on the body and psyche, and being a patient and the relationship to health care professionals. Endure and live is the third domain. It has the two subtopics strengthen and protect yourself, and mobilising strength and finding coping strategies.

\section{From living in fear of having breast cancer to the confirmation of its diagnosis}

The suspicion of having breast cancer and the inescapable certainty of being afflicted with the disease elicited a state of shock in the women. They experienced the disease as an existential threat. They designated the resulting strain and stress as a crisis.

Shock

The confirmed diagnosis of cancer was experienced as a shock. The women were deeply shocked as they either felt the tumour in their breast themselves or were confronted with the fact that they might have breast cancer. The women reacted differently to the cancer diagnosis. Some of them accepted their fate, or turned feelings off, others were calm and suppressed intrusive thoughts and some women associated the disease immediately with death.

"I had no idea that it might not be benign. It happens, you have heard about it, but that you might get it yourself - the idea just doesn't occur to you" (Interview 2). 
The time before and after the diagnosis, in which several appointments for examinations and sometimes painful procedures had to be kept, in which one was swept up in machinery, was experienced as very stressful. The time until the diagnosis and the extent of the disease had been clarified, was experienced as short, but often also as the most difficult time. Waiting for the diagnosis was described as horror.

\section{Crisis}

The crisis was characterized by fear, threat, insecurity, uncertainty, emotional and physical exhaustion.

The women often realized the full meaning of their breast cancer after the first shock of the diagnosis or after coming well through the operation. They became aware that this disease was more than a flu, an appendectomy, or a broken leg and that the surgical procedure was only the beginning of a usually long-lasting treatment. The disease attacked suddenly, they hadn't felt ill. The women reacted violently to the threat; they experienced panic attacks, fear of death, were on the brink of a nervous breakdown, and felt themselves in an extreme situation. They themselves spoke of a crisis, of a catastrophe - of an absolutely existential experience. They reached the limits of their resistance, complained of a total lack of energy, powerlessness, fatigue, emptiness; they often doubted whether they would have strength enough to get through this. They experienced being in a rollercoaster of emotions, were distressed and felt insecure.

"Such a little lump that you can hardly feel, and it can do practically everything" (Interview 9).

"You're full of strength, you don't feel anything, that's awful. - That's the trage$d y$ of this disease, that it is nasty and insidious, so gradual that you don't notice it at all, or you don't feel at all different" (Interview 7).

The disease can destroy entire life plans, especially for younger women. They spoke of losing their joy in life, their nonchalance, that a free life was no longer possible, or that the world had fallen apart. In order to bring their fears and the situation under control, they expended enormous energy to create strategies in which they consciously tried to protect themselves against influences, withdraw into themselves and consciously suppressed feelings. But they remained very vulnerable, easily irritated and sensitive. Sometimes little things or physical exhaustion caused "everything" to collapse, led to emotional releases or to paradox reactions.

"And then I noticed that I have to go to bed in the evening before I get to the point where I have the feeling that I can't go on. When I waited, I was so tired, I began to be cold, I shivered, then my house of cards collapsed. And then I 
thought, no, I can't do it. This is how my life will go on, just endure and at some point seeing there is no hope. That's cruel, cruel" (Interview 2).

"If you had wanted to start a family and you think then, why am I struggling now, when I really don't know what's smart. If you get it at sixty - o.k., at sixty you don't have this energy for life, but maybe at least you have children and grandchildren and that is at least something" (Interview 4).

The women were convinced that only people who have experienced the same illness in their own bodies could understand what it really means to get this disease.

\section{Experiencing Therapy}

Beginning cancer therapy means submitting to invasive, aggressive and toxic treatment methods like operations, chemotherapy, radiotherapy and endocrine therapy, which have potent effects on body and psyche. The diagnosis of breast cancer makes the afflicted women into patients. They are confronted nearly every day with a complex health system, in which they must find their way.

Impact of treatment on body and psyche

The women experienced therapy as drastic, endless and debilitating. They did not designate the operation as the most difficult part of treatment. Rather, they suffered under the subsequent therapies. Thanks to breast-conserving operation techniques, the procedure was experienced as minor and usually without problems. At the time of the interview, the women expressed no dissatisfaction with the appearance of the breast. It was usually not the change in body image which was stressful for the women, but the unusual and unknown sensations and violent reactions of the body to the subsequent treatment. Treatment in general takes its toll on energy and substance and often brings the women to the brink of physical exhaustion, which may have a marked effect on their emotional well-being. Crises may break out again, or the threatening, dark thoughts increase again, which may lead to depressions. The women correlated their emotional state with their physical state and felt very definitely that they were not suffering an emotional disorder, but that their psyche would recover along with their physical recovery. This applied especially to the period of chemotherapy. The women reached their endurance limits in this time and later didn't know how they had managed to live through it.

"When I got to a pedestrian crossing and the light was green, I waited until it was red and then green again so that I had the whole green phase to cross the street; otherwise I wouldn't have made it across" (Interview 1). 
"I was completely beside myself, my body was somehow not my body. I simply think that my body was so violated by drugs and by everything that I simply had to endure it" (Interview 9).

The impairments caused by radiation were experienced as less stressful than those of chemotherapy. The women appeared to recover somewhat physically in this time period. Nonetheless, the women spoke of great fears, sometimes of feelings of horror, which they had at the beginning of therapy. Radioactive rays and the environment to which they were exposed, were experienced as something eerie. The women didn't know what was happening to them. In the radiotherapy waiting room, they also met other people who were greatly marked by their disease, people accompanying patients who spoke of recurrences in their family members, or people who needed to tell their stories. This was stressful for the women. They could hardly bear it, because it elicited their own, otherwise well-controlled fears. They protected themselves by reading, by not looking around, or by saying that, by comparison, they were well off.

"I had a horror of the first radiation session. That was again something unknown, and the huge machine that came towards you. And then, logically, I was afraid, and I burst into tears" (Interview 3).

"The first couple of times, I wanted nothing so much as to get off the table" (Interview 4).

The endocrine therapy apparently was better tolerated by older women than by younger ones who, because they took the medications, suddenly no longer menstruated and found themselves in a state similar to menopause - and that at a time which didn't correspond to their natural life cycle. They felt very debilitated by the sudden change, the unaccustomed bodily sensations, complaints and the mood swings in particular were stressful. They suffered from extreme hot flashes, couldn't sleep because they sweat so much at night that they had to change their bedding and nightwear several times. But the side effects could also be far worse for older women than their foregoing menopause. Younger women with endocrine therapy worried about the effects of therapy on their fertility. Some of the women spoke spontaneously about problems with sexuality, expressed as loss of libido and marked physical impairment. In general, the women were poorly informed about endocrine therapy. They felt abandoned and didn't know which of the many specialized doctors they could turn to with their questions.

"I stopped menstruating immediately. The hot flashes are extreme, I can't sleep, I sweat enormously at night, I have to change bedding and nightwear twice every night. And as for sexuality, the effects are enormous, even though 
no one said so. The dryness makes it painful, and that's really serious" (Interview 4).

Usually, the women didn't look sick. If they didn't feel well, they therefore often had to fight that their relatives or health care professionals perceived their bad health condition.

Being a patient and the relationship to health care professionals

Suddenly the women became patients. They met a number of health-care workers. In cooperation with health care professionals, they had to make difficult decisions about their final therapy and treatment, based on examination findings and after they had been informed of the risks and chances of therapy. The women often felt overwhelmed, sometimes lost.

"I was overwhelmed by this decision: chemotherapy yes or no. - It's a cruel decision, like deciding whether you want to be punched on the right side or the left, a decision between bad and just as bad. - I couldn't do it and left it to the chance decision in the study (randomisation). - Of course, I drew the whole "package" with chemotherapy" (Interview 1).

On the one hand, the women wanted detailed information, on the other hand, they didn't want to know too much. Direct information from caregivers was preferred. In contact with doctors, not all women found it easy to obtain information and to ask questions. Sometimes they doubted that they really had been told everything. A trusting, constant relationship to at least one of the several doctors appeared to have an essential influence on coping with the disease. Some women had experienced difficult moments in contact with doctors, usually in phases in which they were very uncertain and upset or railed against their fate. If they were not taken seriously, they felt helpless, powerless, betrayed, miserable and abandoned. If the relationship didn't function, it became more difficult for them to bring their fears and lack of confidence under control. Many women tended to be good patients, who coped well with the disease and the therapy and presented their strong side to the outside world.

Nurses appeared to have a great influence on the atmosphere and on whether the women felt comfortable. The women were grateful if they always reencountered people they knew. That gave them a feeling of safety and of orientation. They demanded professional competence, concrete information, correction of information deficits, and a personal tone from the nurses. They expected the nurses to perceive if they were not feeling well, and they were very grateful if nurses had time for them and asked them in more detail about how they felt. 
"For me personally, it was important to be treated very gently, very very tenderly. And this is what happened to me. I think that's what you need in this situation" (Interview 2).

\section{Endure and live}

The women tried to attain control over their lives with the disease. They protected and strengthened themselves and developed enormous strengths that helped them to find ways of coping and having more confidence in the future.

\section{Strengthen and protect yourself}

The women consciously looked for ways to cope with the situation and to win control over fears, their bodies and over the threatening situation. They concentrated increasingly on their own person and attempted to strengthen themselves, to not be confounded on their own route and to listen to and trust their own feelings. In addition, they attempted to orient themselves to the good days, to think positively and to believe in a good prognosis. Hope and trust that things would work out, forget, divert oneself, protect oneself and intentionally withdraw were important strategies to keep from falling into a bottomless pit. Reading and sleeping were good means of not always having to deal with the disease, or protecting oneself against the influences and threatening thoughts.

"Just try to please myself, look and see what lifts my spirits and do it. And to put aside the other way, with whatever drives one mad and destroys one completely" (Interview 4).

"I believe that one very important point is to concentrate on oneself, or to try to take the responsibility for oneself in hand, to listen to oneself and one's feelings. Yes, that one is alive, I think that's definitely very important" (Interview 9).

Only seeing the positive and always emphasising that one has no emotional problems, no breakdown and no bad thoughts also appeared to be a coping strategy.

"Emotional problems, I really have to say honestly, I have none at all. I said, OK, what should I do? Cry? Go to bed? Or should I go on living? Then I said: "Go on living". It took no more than a minute, and then I got up and did what I usually do, as normal.' - "When other women talked about their difficulties with chemotherapy, I had the feeling that I had a different disease" (Interview 5).

Through the confrontation with the disease, the women often experienced new inner strength and power that they wanted to show the outside world. And it did them good to be admired for how well they dealt with the situation. 
Mobilising strengths and findings coping strategies

Strengthening one's own person helped to mobilise strengths to get through the therapy. They had no choice, they simply had to deal with it. Somehow they developed strength for themselves, they fortified themselves because they wanted to live. Not giving up appeared to be an important principle. The women pulled themselves together, they dressed well, put on makeup and arranged their hair and kept their household in order as always, or took their bicycle to radiotherapy. And sometimes they worked as much as possible. They struggled to go upstairs, although hardly possible, but the idea never occurred to them to take the elevator. Later, their efforts seemed almost a little absurd to them. But they gave them the feeling of not giving up, of still believing in themselves.

The support from family, sympathy and understanding from friends gave a hold and help in coping. The women reported how the diagnosis of breast cancer deeply shocked and affected partners and family members and activated great fears in them. Sometimes the women felt that it was worse for their loved ones than for themselves as the afflicted person who was in the midst of the situation. So they attempted to recreate normality as quickly as possible and to alleviate fears in their environment by their emphatically positive behaviour. Or they consciously spared their relatives from the beginning, since they were not healthy themselves or could not deal well with the stress. If they showed that they wanted to go on living, could cope with the situation and were strong, they felt that things would improve for their relatives.

I always had the feeling that I was the strongest in the whole family. I sort of felt like the knight in shining armour: show everyone that I can deal with it. That gave my husband a lot of strength, too" (Interview 8).

"The biggest problem was telling my husband. I told him I have everything under control, but he couldn't sleep. He is a little unstable emotionally and when I told him, he really was completely dejected. Now, if I laugh again, that helps him, too" (Interview 5).

The disease caused the women to think about existential questions. In this, the attitude to life may undergo basic change. They remembered other life processes which made them stronger and encouraged themselves with these experiences. Cancer was not always the worst thing which women had experienced.

"Yes, you know this and should adapt to it, these years you have been given that may be before you, and those which are past, and that you can be together. The 
relationship to the children, grandchildren and sons-in-law is good. Yes, one hopes, and I really believe, that the disease is over" (Interview 6).

"Looking back, I have to say that this disease was necessary for me personally, for my own growth. It saved my marriage, I get along better with the children. That's because I have changed. I have to emphasise that for me, personally, faith is the greatest point" (Interview 10).

It took time to gain new confidence. One of the women described accurately the change she underwent and the process by which she turned her dark, threatening thoughts to positive ones.

"At the beginning, I didn't sleep at all, and I remembered all the people among my acquaintances who had cancer and had died. And I thought, they all had hope once - and look what came of it. During the time of chemotherapy, I suddenIy realized that I could remember at night those who had cancer and who are now well, who survived. And I think that's an amazing change. You have to encourage yourself with them" (Interview 2).

At the end of the treatment period, the women were proud of themselves that they made it through this difficult time, and they looked forward to the time without treatment, and maybe to living with fewer worries and taking things easier, not to be constantly confronted with the disease. They usually looked hopefully to the future.

\section{DISCUSSION}

The results of this study showed: Breast cancer usually hits women who are healthy, without any feeling of illness beforehand, and confronts them with a lifethreatening disease which quickly and deeply changes their lives and the lives of their relatives. The diagnosis of cancer elicits shock, sadness, insecurity, fear and a feeling of loss of control among those affected. The existential threat and the emotional and cognitive stress which results over the course of the disease, later due to physical exhaustion resulting from treatment, may plunge the women into a crisis. With enormous strength, they attempt to bring their situation under control, to create protective mechanisms, and not to give in to physical exhaustion. The women suffer from the symptoms of therapy and from the influence of treatment on their quality of life. Constant, trusting and personal relationships to health care professionals, from whom they expect empathy and professional competence, appear to have an essential influence on coping with the disease processes. Support 
from family and friends is even more important. This gives them strength and is central to coping. The role of family members, however, remains unclear. The women attempt to protect their relatives and often even to support them.

Control mechanisms are central to coping with breast cancer and the resultant existential threatening situation. This appears confirmed also by Morse \& Carter (1996). In their study they described how individuals in situations in which they have no choice but to go forward, struggle to gain control over the situation and the way in which they are able to express suffering only after a period of time. According to Arman et al. (2002), expressing suffering means freeing oneself somewhat from double suffering. This applies also to women with breast cancer; while on the one hand, they protect themselves or must protect themselves from their deepest feelings, on the other hand, they don't express their suffering in order to spare others. Coping with the disease, enduring the situation, costs enormous strength. If physical exhaustion due to cancer therapy is added, the women are threatened by crises. Nonetheless, they force themselves to perform physically and attempt not to give in. Kesselring (1994), called these phenomena "I can". They are accompanied by feelings of capability, of mastery and security. "I can' $t$ ", is characterized by fears and despair. The mood is more grey and dark, insecurity spreads and seeps into everything. This explains why these women have to force themselves even when they almost can't. And it clarifies the extent to which they feel threatened when it doesn't work out. For this reason, conservation of energy, along with relief of symptoms and complaints are central to the care and support of these women. The role of family members is many-sided. Family members are enormously important for support of the women, but they are also affected themselves. Family members often feel inadequate, they are unprepared for this life crisis and have too little information (Hilton et al. 2000, Kilpatrick et al. 1998). The husbands want to support their wives but often have difficulty reading the woman's signals and reacting appropriately (Samms 1999). As a consequence of the mostly outpatient treatment, family members are not only irreplaceable in the emotional support of the women, but also in the maintenance and management of everyday living during and between the therapy cycles.

With this practice-oriented study, we were able to present the process of coping with disease on the one hand and on the other to illuminate important topics and problems in the treatment and care process. This is the strength of this research and that which makes it different from other studies. Although other studies found similar results for individual topics of this research, the results of this research cannot be generalized. The following conditions must be taken into account in interpreting the results: the women who participated in this study were not selected by any defined criteria. Most of them were middle-class women, usually living with a partner and were capable of differentiated expression. They were interviewed at the 
end of a long therapy phase, at the end of radiation therapy. That is, in a phase in which they were happy and justifiably a little proud of having coped so well with the recent past. For this reason, they were more likely in an optimistic mood. How the women and their family members cope with the situation after therapy and with their needs, as well as how they adapt to living with the disease remains unclear.

For nursing practice, the results of this study indicate that women with breast cancer and their families need concrete advice and assistance from caregivers which is applicable to everyday living, so that they can cope with the effects of the disease, the consequences of treatment, the emotional stress and with the changes in daily living and social relationships which often persist after treatment. The complexity of treatment and care, the hidden suffering of the women and their families require a high level of professional competence, experience, intuition and expertise from the nurses. Specialist and discipline-specific education for nurses, such as that demanded by the European Society of Mastology (EUSOMA 2000), and the development of a specialized nursing practice, in which the latest knowledge and research results are implemented and care offers can be developed and assessed, are needed.

For this reason, in addition to the subjective affliction of the women addressed in this research, a large, patient-oriented quantitative study with standardized and structured data collection methods should be performed to include more Swiss women with breast cancer and their families in phases of treatment as well as in phases after treatment. Such a study should address these psychosocial, disease and treatment-related factors which would contribute to improving the health and quality of life of those affected and their families, as well as influence the dynamics of mutual support between the afflicted women and their families. On this basis, broader integrative models, as well as concrete care and interdisciplinary concepts could be developed, oriented to the needs of the women and their families and also taking into account the culture and context of the Swiss health system.

\section{Acknowledgement}

I would like to thank the women for their valuable contribution who reported their personal experience of disease and therapy in the interviews and made this research possible. Thanks go to Dr. J. Eysell for the translation of the German publication. 


\section{REFERENCES}

Arman M, Rehnsfeldt A, Lindholm L \& Hamrin E (2002) The face of suffering among women with breast cancer-being in a field of forces. Cancer Nurs 25, 96-103.

Buick D, Petrie K, Booth R, Probert J, Benjamin C \& Harvey V (2000) Emotional and Functional Impact of Radiotherapy and Chemotherapy on Patients with Primary Breast Cancer. J Psychosocl Oncol 18, 3962.

Cimprich B (1999) Pretreatment symptom distress in women newly diagnosed with breast cancer. Cancer Nurs 22, 185-194.

De Jong N, Courtens AM, Abu-Saad HH \& Schouten HC (2002) Fatigue in patients with breast cancer receiving adjuvant chemotherapy: a review of the literature. Cancer Nurs 25, 283-297.

Dow KH \& Lafferty P (2000) Quality of life, survivorship, and psychosocial adjustment of young women with breast cancer after breast-conserving surgery and radiation therapy. Oncol Nurs Forum 27, 1555-1564.

Downe-Wamboldt B (1992) Content analysis: method, applications, and issues. Health Care Women Int 13, 313-321.

EUSOMA (2000) The Requirements of a Specialist Breast Cancer Unit: Position Paper. Eur J Cancer 36, 2288-2293.

Flick U (2002) Qualitative Sozialforschung: eine Einführung. Rowohlt, Reinbek bei Hamburg.

Freedman TG (2003) Prescriptions for health providers: from cancer patients. Cancer Nurs 26, 323-330.

Gottesman D \& Lewis MS (1982) Differences in crisis reactions among cancer and surgery patients. $J$ Consult Clin Psychol 50, 381-388.

Herth K (2000) Enhancing hope in people with a first recurrence of cancer. J Adv Nurs 32, 1431-1441.

Hilton BA, Crawford JA \& Tarko MA (2000) Men's perspectives on individual and family coping with their wives' breast cancer and chemotherapy. West J Nurs Res 22, 438-459.

Kesselring A (1994) [Body image and the experience of illness--experience of women with breast cancer]. Pflege 7, 175-182.

Kilpatrick MG, Kristjanson LJ, Tataryn DJ \& Fraser VH (1998) Information needs of husbands of women with breast cancer. Oncol Nurs Forum 25, 1595-1601.

Kissane DW, Clarke DM, Ikin J, Bloch S, Smith GC, Vitetta L \& McKenzie DP (1998) Psychological morbidity and quality of life in Australian women with early-stage breast cancer: a cross-sectional survey. Med J Aust 169, 192-196.

Lamnek D (1995) Qualitative Sozialforschung: Methoden und Techniken Beltz Psychologie Verlangs Union, Weinheim.

Landmark BT \& Wahl A (2002) Living with newly diagnosed breast cancer: a qualitative study of 10 women with newly diagnosed breast cancer. J Adv Nurs 40, 112-121.

Lev EL (1992) Patients' strategies for adapting to cancer treatment. West J Nurs Res 14, 595-612.

Lincoln Y \& Guba E (1985) Naturalistic inquiry. Sage Publications, Newbury Park London, New Delhi.

Mast ME (1998) Survivors of breast cancer: illness uncertainty, positive reappraisal, and emotional distress. Oncol Nurs Forum 25, 555-562.

Mayring P (2003) Qualitative Inhaltsanalyse: Grundlagen und Techniken. Beltz Verlag UTB, Weinheim Basel.

Mclllmurray MB, Thomas C, Francis B, Morris S, Soothill K \& Al-Hamad A (2001) The psychosocial needs of cancer patients: findings from an observational study. Eur J Cancer Care 10, 261-269.

Morse JM \& Carter B (1996) The essence of enduring and expressions of suffering: the reformulation of self. Sch Inq Nurs Pract 10, 43-60.

NICER (1986-2005) The National Institute for Cancer Epidemiology and Registration, and the Swiss Statistical Federal Office (NICER \& FSO) www.nicer-swiss.ch.

Palsson MB \& Norberg A (1995) Breast cancer patients' experiences of nursing care with the focus on emotional support: the implementation of a nursing intervention. J Adv Nurs 21, 277-285. 
Samarel N, Fawcett J, Tulman L, Rothman H, Spector L, Spillane PA, Dickson MA \& Toole JH (1999) A resource kit for women with breast cancer: development and evaluation. Oncol Nurs Forum 26, 611618.

Samms MC (1999) The husband's untold account of his wife's breast cancer: a chronologic analysis. Oncol Nurs Forum 26, 1351-1358.

Schmidt C (2000) Analyse von Leitfadeninterviews. In Qualitative Forschung: Ein Handbuch (Flick U, von Kardorff E \& Steinke IH eds.). Rowohlt, Reinbek bei Hamburg.

Verres R \& Klusmann D (1997) Strahlentherapie im Erleben der Patienten. Ambrosius Barth Verlag, Heidelberg, Leipzig.

Witzel A (1982) Das Problemzentrierte Interview. In Qualitative Forschung in der Psychologie (Jüttemann J ed.). Beltz, Weinheim. 


\section{Chapter Three}

\section{A review of psychosocial needs of breast cancer patients and their relatives}

Manuscript published as: Schmid-Büchi S, Halfens RJG, Dassen T, van den Borne B (2008). A review of psychosocial needs of breast cancer patients and their relatives. Journal of Clinical Nursing 17, 2895-2909 


\section{ABSTRACT}

Aim. To identify the psychosocial needs of breast cancer patients and their relatives along with factors affecting these needs and to develop a tentative model to guide further research and need assessments in clinical practice.

Background. Women experiencing breast cancer must deal with the diagnosis of a life-threatening illness. Treatment and the recovery process can be demanding for patients and their relatives. Need assessment may help clinicians focus on providing appropriate help.

Method. A literature review was undertaken using electronic databases and specific research terms. Twenty articles were identified and analysed.

Results. The needs identified by patients involve 1) treatment-related physical and social impairment like fatigue, menopausal symptoms and a changed body image and 2) emotional distress like fear of recurrence, anxiety and depression. Partners need help to protect themselves and the patient from different threats. Women need information to maintain control and manage their illness. Partners want information concerning the patient's condition and both of them about prognosis and perspectives. There is a lack of knowledge of relatives' needs. Mutual familial support, women's and partners' health and emotional distress may affect the interaction between the patients and their partners.

Conclusions. A tentative family-based model to guide further research and clinical support is proposed. Further research is needed to determine precisely which psychosocial factors may influence fulfilment of the patients' and relatives' needs.

Relevance to clinical practice. The proposed model may provide a framework for health care professionals to evaluate the patients' and relatives' met and unmet needs and the real demand for help, to guide care planning, counselling and education. 


\section{INTRODUCTION}

Women with breast cancer experience a situation that changes their lives. They must deal with the emotional and physical consequences of being diagnosed with a life-threatening illness. They often undergo debilitating aggressive treatment regimens which usually leave them feeling worse than before diagnosis (Arman et al. 2002). Cancer also affects family members. The disease, treatment and recovery process can be demanding on patients and their families. Research describing the relationship between breast cancer and overall quality of life does not really identify the issues in which the patients and their relatives recognize their need for help (Bonevski et al. 2000). A need assessment covering the different phases patients and family members go through after diagnosis is needed to develop rehabilitation and care programs (Wen \& Gustafson 2004).

\section{The concept of needs}

Need can be defined as "the requirement of some action or resource necessary, desirable, or useful, to attain optimal well-being" (Sanson-Fisher et al. 2000). Most nursing literature addressing specific patients' needs is based on Maslow's human needs theory (Endacott 1997, Holmes \& Warelow 1997). Maslow (1968) identifies needs for life, safety and security, belongingness and affection, respect, self-respect and self-actualisation. Basic or biological needs may be considered as deficiencies which must be fulfilled by the environment. All needs or values are related in hierarchical and developmental ways, in order of strength and priority. All these basic needs may be considered as steps along the path to general self-actualisation under which all basic needs can be subsumed. Psychosocial needs should be understood as a bio-psychosocial framework of health and illness. Need assessment in oncology should include a direct and comprehensive assessment of the multidimensional impact of cancer on the lives of patients and should address important domains of physical, functional, emotional, social and spiritual well-being (Ferrell \& Hassey Dow 1997, Bonevski et al. 2000) as well as practical needs (Soothill et al. 2001). Need assessment is a direct measure of the divergence between the patients' experiences and expectations (Bonevski et al. 2000). If a need has been identified, action is recognized as desirable whether by the individual, by professionals or by society. Inaction will result in dissatisfaction and a persistence of the need. Need assessment and a fuller understanding of the patients' and relatives' needs helps clinicians and nurses focus their care on the most relevant needs (Holmes \& Warelow 1997, Wen \& Gustafson 2004). 
Aim

The aim of this paper is to review the research on psychosocial needs of breast cancer patients and their relatives and to identify the factors affecting patients' and partners' satisfaction with care and support. Based on this review, a tentative model for need assessment has been developed considering both cancer patients' needs and the needs of their relatives. This model could be used as a guide for further research and clinical practice.

\section{OBJECTIVES AND METHODS}

\section{Search strategy}

An electronic literature search was conducted using the database MEDLINE (PUBMed online) and Cumulative Index of Nursing and Allied Health Literature (CINHAL). For the patient's needs, the two key terms "needs" and "breast cancer" were used in combination with "psychosocial" excluding the terms "risk", "genetics", "palliative" and "end of life". This search was limited to the period between 1995 through March 2007 because treatment regimens for breast cancer changed decisively in the mid-nineties, which had an impact on the needs of the women concerned. For the partners' needs, we used the key terms "needs" and "breast cancer" in combination with the terms "support", "spouses", "family" and "relatives" and "caregivers". The search was limited to English-language studies.

\section{Selection criteria}

Studies were included which described specific needs of women with breast cancer or of their relatives living only in countries with a Western lifestyle, because needs are context-dependent. Studies involving patients with a variety of tumours, other target populations, specific interventions and articles that reviewed the literature were excluded.

\section{Selection process}

The electronic search strategy identified a total of 142 articles for women's and 41 for relative's needs (excluding 29 duplicates). Based on the titles and abstracts, papers which focused on topics outside our domains of interest such as NonWestern cancer patients and relatives, women with benign breast tumours or children, articles considering cancer screening, described cancer patients' needs in general, evaluated professionals' needs, or on specific interventions, were excluded. In a secondary search process, guided by reference lists of the articles, three relevant 
studies which compromised more information on partners' needs and the interaction between the patients and their relatives were obtained. Hence 59 articles for women's and 29 for partners' needs were considered as important for this review. After retrieving and reading the full papers of these 88 studies, articles which were not directly related to the aim of this review or did not exactly meet the inclusion criteria were excluded. Thirteen studies were excluded after quality assessment. Quality screening was derived from determinants of validity, following Polit \& Hungler's (1999) guidelines for research critique. Finally, twenty articles, twelve for women's and eight for relatives' needs, were included and analysed. The data collection process and the subsequent data extraction were continuously evaluated and discussed in the research team (authors).

\section{Analysis}

The domains of psychosocial needs (Ferrell \& Hassey Dow 1997, Bonevski et al. 2000, Soothill et al. 2001) and the interaction between the women and their partners were the determining factors for data extraction.

\section{RESULTS}

\section{Study characteristics}

In total, twenty publications were included in this critical review, twelve for women's needs, five for the partners' needs and three studies which primarily focused on women's and partners' needs and the interaction between them. Seven studies were conducted in Australia, nine in the USA, three in the UK and one in Canada. Ten of the twelve studies which described the women's needs were cross-sectional, one longitudinal and one consisted of semi-structured interviews with focus groups. The great majority was based on convenience or consecutive samples, three on random samples and one surveyed a cohort. The number of women in the twelve studies ranged between 76 to 544 . Measurement took place between three to 30 months after diagnosis. One study compared rural and urban women and another investigated different groups of women with newly-diagnosed breast cancer, adjuvant therapy, with stable and recurrent disease. Three of the five studies which investigated partners of women with breast cancer were based on descriptive designs and involved between 72 to 141 partners. In one study, data was obtained from nine partners using two focus group interviews, while another gathered data from eleven partners in semi-structured interviews. The three studies that focused on the interaction of patients' and partners' needs were explorative in design and 
involved 74, 102 and 189 pairs of women with breast cancer and their partners. The main findings from our analysis are presented in Tables 1 - 3.

\section{Needs of women}

\section{Physical and treatment-related needs}

More than $60 \%$ of long-term survivors indicated that breast cancer had affected their overall health (Schultz et al. 2005). Several studies describe fatigue and lack of energy as relevant problems for women suffering from breast cancer both during active treatment and for long term-survivors (Hoskins 1997, Girgis et al. 2000, Hanson Frost et al. 2000, Schultz et al. 2005). Women were impaired by restricted arm/shoulder movements and lymphoedema and expressed a need for information about breast reconstruction and prosthesis (Raupach \& Hiller 2002, Schultz et al. 2005). Menopausal problems appeared as hot flashes, night sweats, diminished interest in sex and impaired sexual functioning, as sleep disturbance and impaired ability to concentrate, (McPhail \& Wilson 2000, Hunter et al. 2004, Schultz et al. 2005). Specific physical problems related to cancer and its treatment seemed to directly cause psychological problems. Patients reported body image problems, loss of sense of attractiveness, femininity and sexuality. Some women felt more selfconscious about their appearance than prior to their diagnosis and treatment, even if they were satisfied with the physical appearance of their breast after breastconserving surgery (McPhail \& Wilson 2000, Raupach \& Hiller 2002, Schultz et al. 2005).

\section{Psychological and social needs}

Emotional distress was one of the most persistent problems in the study by Hoskins (1997). Women suffered from anxiety and stress, felt down and depressed and feared the spread or recurrence of the cancer (Hoskins 1997, Girgis et al. 2000, Hodgkinson et al. 2007). Acknowledgment from relatives and friends of the exhausting experience of living with breast cancer was the unmet need most often reported by Marlow and colleagues (2003). Retaining a sense of control is an equally relevant need. The sense of successful control was experienced when women were encouraged to choose the level of involvement in decisions regarding treatment and felt able to explore their own expectations about the cause and course of breast cancer (Marlow et al. 2003). More than half of the long-term survivors indicated that they were unhappy with the way things had turned out for them (Schultz et al. 2005). Anxious women and women who felt depressed had significantly more unmet needs (Hodgkinson et al. 2007). Women with newly-diagnosed breast cancer and adjuvant therapy experienced greater role limitations and impairment in their social functioning than women with stable disease (Hanson Frost et al. 2000). Nearly $50 \%$ of the women in the study by Schultz and colleagues (2005) experienced im- 
provement in their family relationships and about $30 \%$ an impairment in their intimate relationship. Almost $20 \%$ indicated that their sexual relationship had undergone negative change (McPhail \& Wilson 2000). No differences were found in global psychosocial measures, sexual and marital relationship between newly-diagnosed patients and women with stable or recurrent disease (Hanson Frost et al. 2000).

\section{Informational and support needs}

The women have a continuous need for information. More than $80 \%$ of the breast cancer patients wanted as much information as possible, only $16 \%$ wanted limited information (Lobb et al. 2001). They wished to be informed about treatment and side effects, cancer remission, length of life, things they could do to help themselves and possible risks for family members to get cancer as well (Girgis et al. 2000, Raupach \& Hiller 2002). The way in which such information is communicated was important to the women. They wanted their cancer specialist to first check with them to ascertain whether they wanted to know these delicate issues (Lobb et al. 2001). The women desired information which enabled them to manage their illness and the side effects of treatment (Girgis et al. 2000, Hodgkinson et al. 2007) they wanted explanations and to know what to expect, what is physically and psychologically "normal" (Marlow et al. 2003). In the study by Lobb et al. (2001) 53\% wanted collaborative decision-making regarding their treatment, $23 \%$ preferred the doctor made the decision and $23 \%$ wanted to make the decision themselves. The family was the main source of support, (Raupach \& Hiller 2002, Marlow et al. 2003). There was a need for additional information about support groups and complementary therapies (Lobb et al. 2001, Raupach \& Hiller 2002, Davis et al. 2004, Hunter et al. 2004, Hodgkinson et al. 2007). Women who had to overcome barriers in obtaining health information perceived significantly lower emotional, social and familial well-being, and had a lower perception of their health competence (Arora et al. 2002).

\section{Needs of partners}

\section{Emotional needs}

Partners and husbands of women with breast cancer had needs to protect themselves from multiple threats and their wives from further distress. They wanted to do well for their wives and to read their wives' needs, but they felt overwhelmed (Samms 1999). They were focused on their wives' illness, wanted to be informed and contribute to decision-making (Hilton et al. 2000). They tried to focus on their family and to keep life going, to be positive, to subjugate their own feelings and needs to those of their wives (Hilton et al. 2000) and to return to "normal" life (Samms 1999). 


\section{Information needs}

The majority of partners in the study by Rees \& Bath (2000) received the information from their wives. More than $60 \%$ had additional information from health care professionals. Forty percent of the partners liked accompanying the patient so they could remember information that the patient forgot, $98 \%$ to support them and $70 \%$ to get information for themselves. Nikoltti et al. (2003) found that the partners were concerned about their wives' condition, the future outcome and the quality of care they received. The partners wanted to know what they could do to help their wives (Samms 1999). If the family had younger children, husbands required more information. If their wives were diagnosed with a more advanced stage of disease, the husbands had a greater need for information (Nikoletti et al. 2003).

\section{Interaction between women and their partners}

Rees \& Bath, (2000) found that partners who were asked by their wives whether they wanted information, partners who received information from patients concerning their fears and partners who thought that their information was similar to that of the patients were significantly more likely to discuss the cancer with their wives. A significant association existed between the informal coping styles of partners (seeking or not seeking information) and the flow of communication between partners and patients.

Weiss (2004) studied the phenomena of posttraumatic growth (PTG) in husbands of breast cancer survivors. Posttraumatic growth was sometimes found to occur after partners had experienced their wives' suffering and after coping with their own crisis. The data revealed a significant association between husbands' PTG and positive marital qualities, marital support and depth of commitment. No association was found between partners' PTG and conflict between patient and partner (Weiss 2004). The experience of distress, health problems of partners, feelings of hopelessness and social support were the most important predictors for the adjustment process and for quality of life of both the women and their families (Northouse et al. 1995, Northouse et al. 2002). The women's physical impairment increased the partner's support and the women's distress eroded their partners' support (Bolger et al. 1996). For the patient, support was important and more support decreased feelings of hopelessness and improved the quality of life and the adjustment process. There was a positive relationship between women's and partners' adjustment process which suggests that partners have a mutual influence on one another (Northouse et al. 2002). 


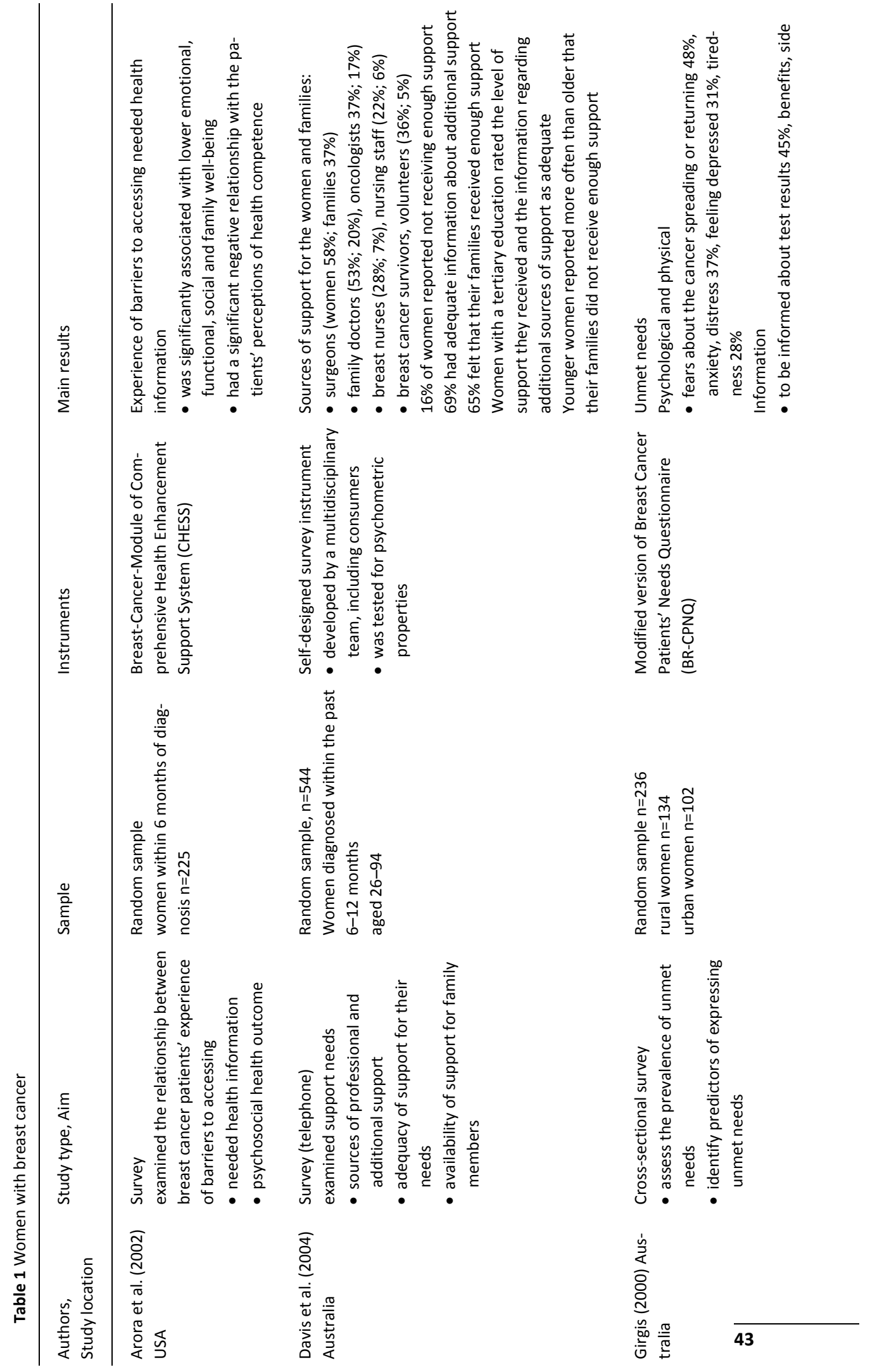




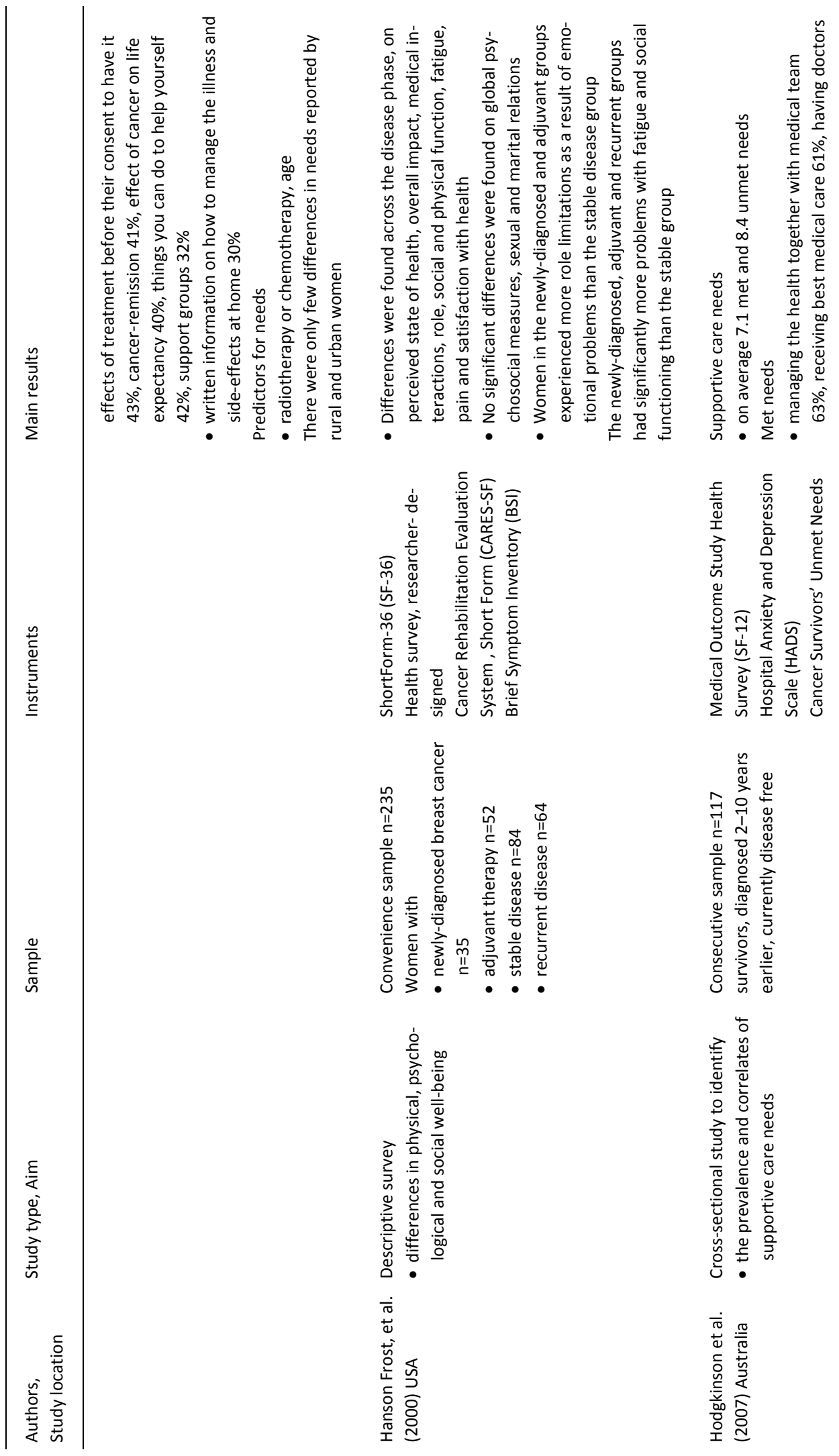




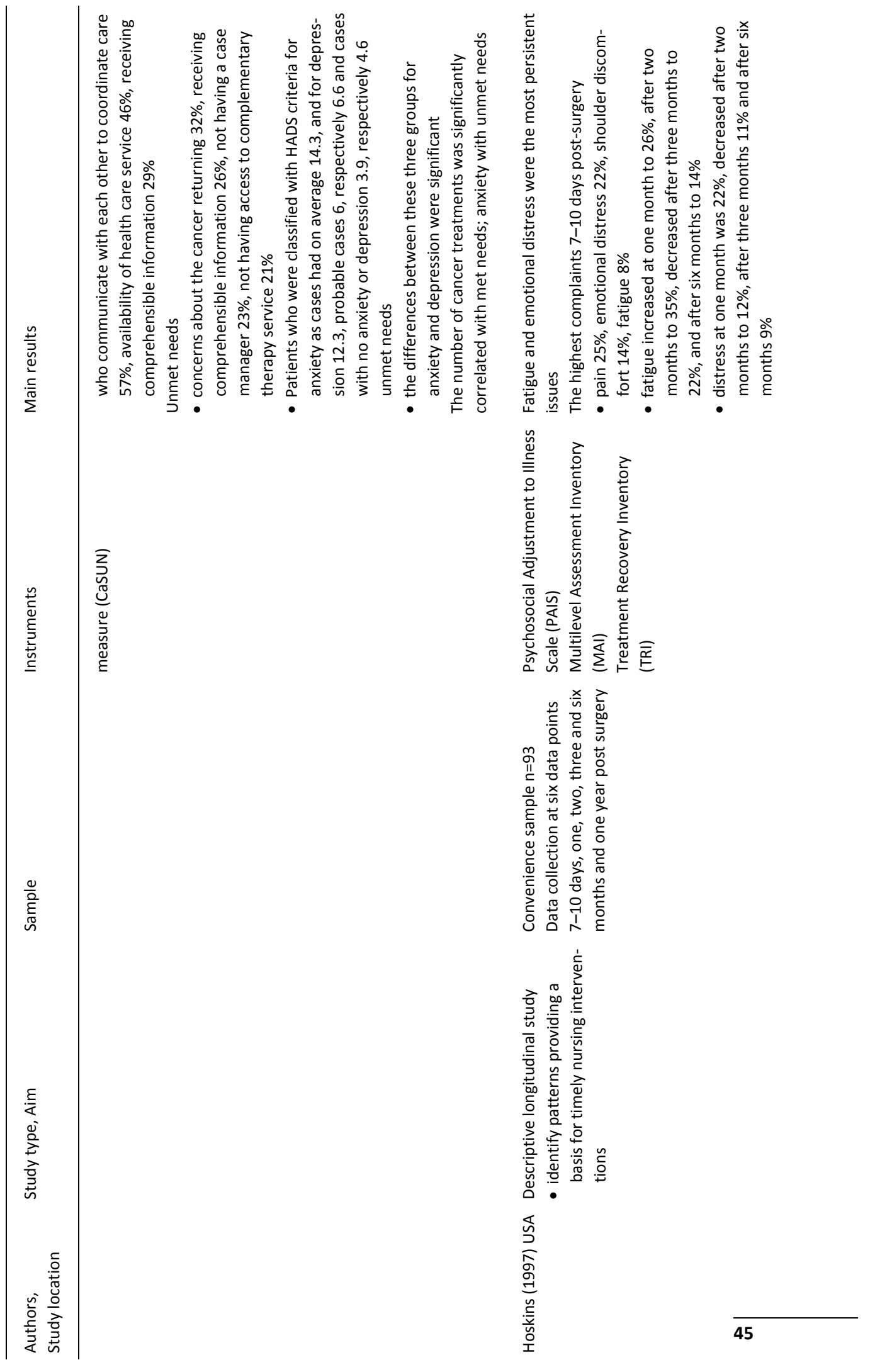




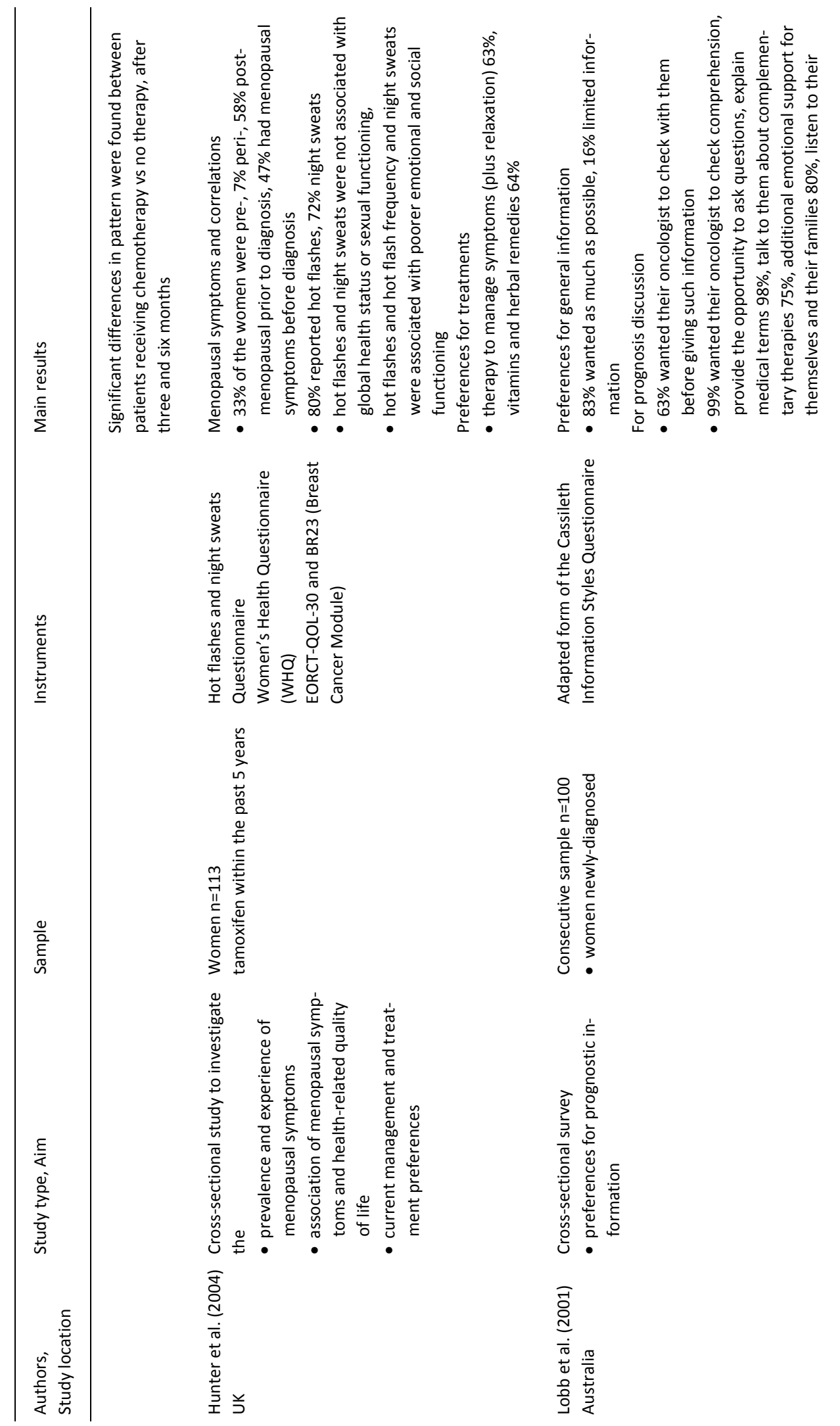




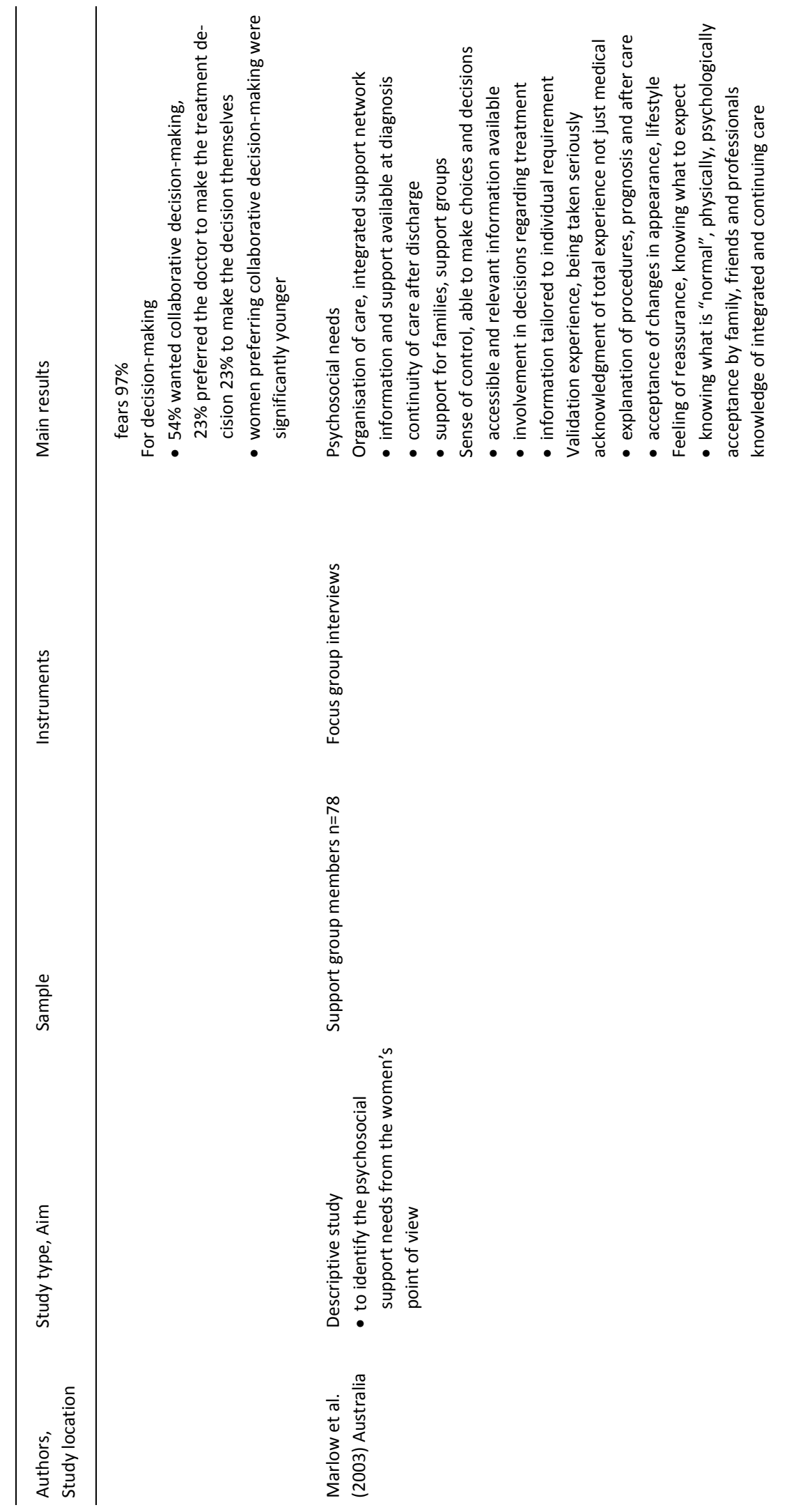




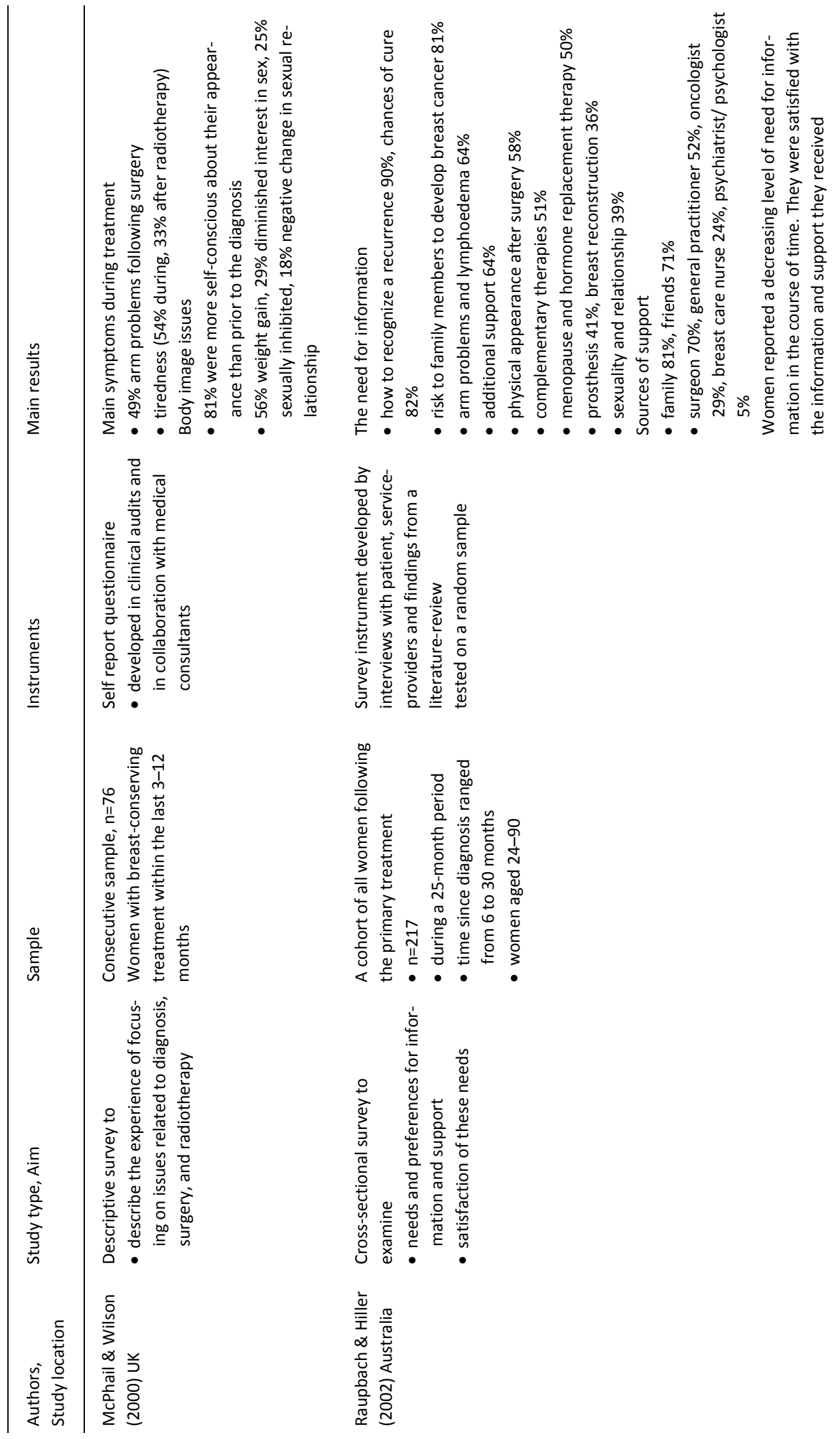




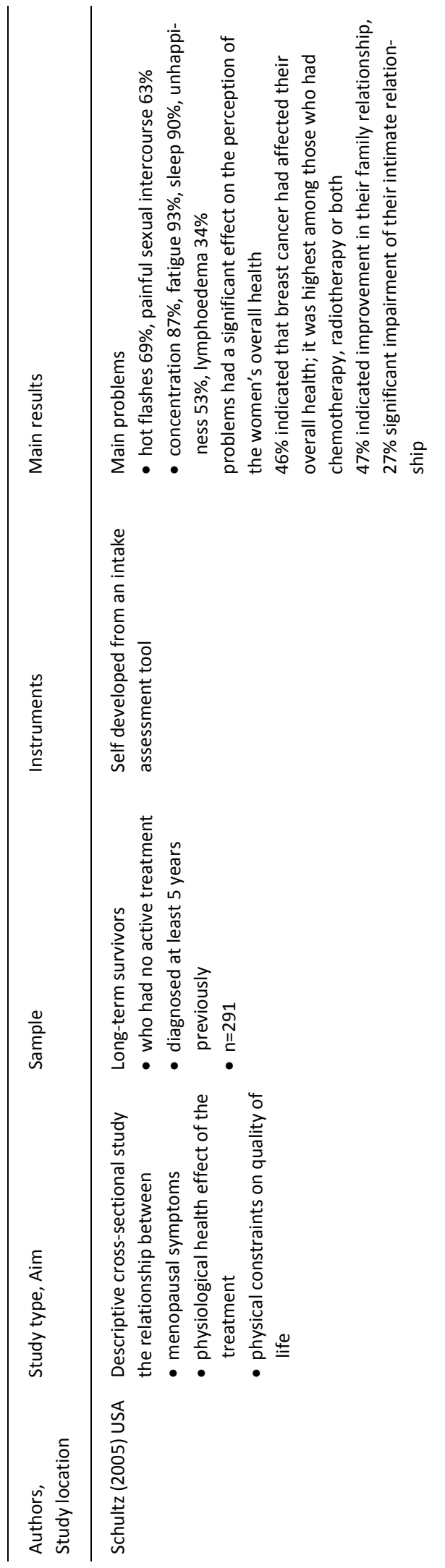




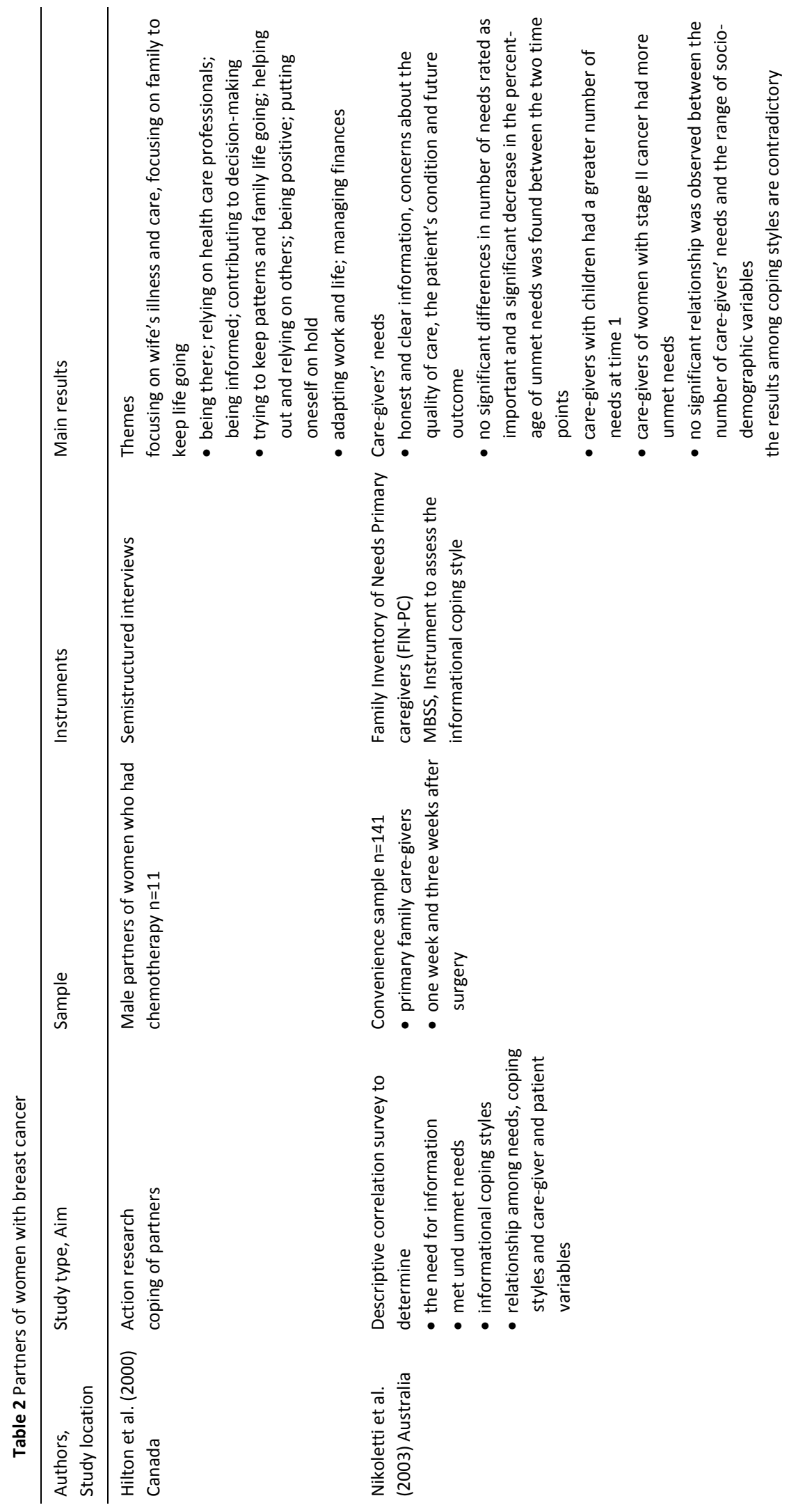




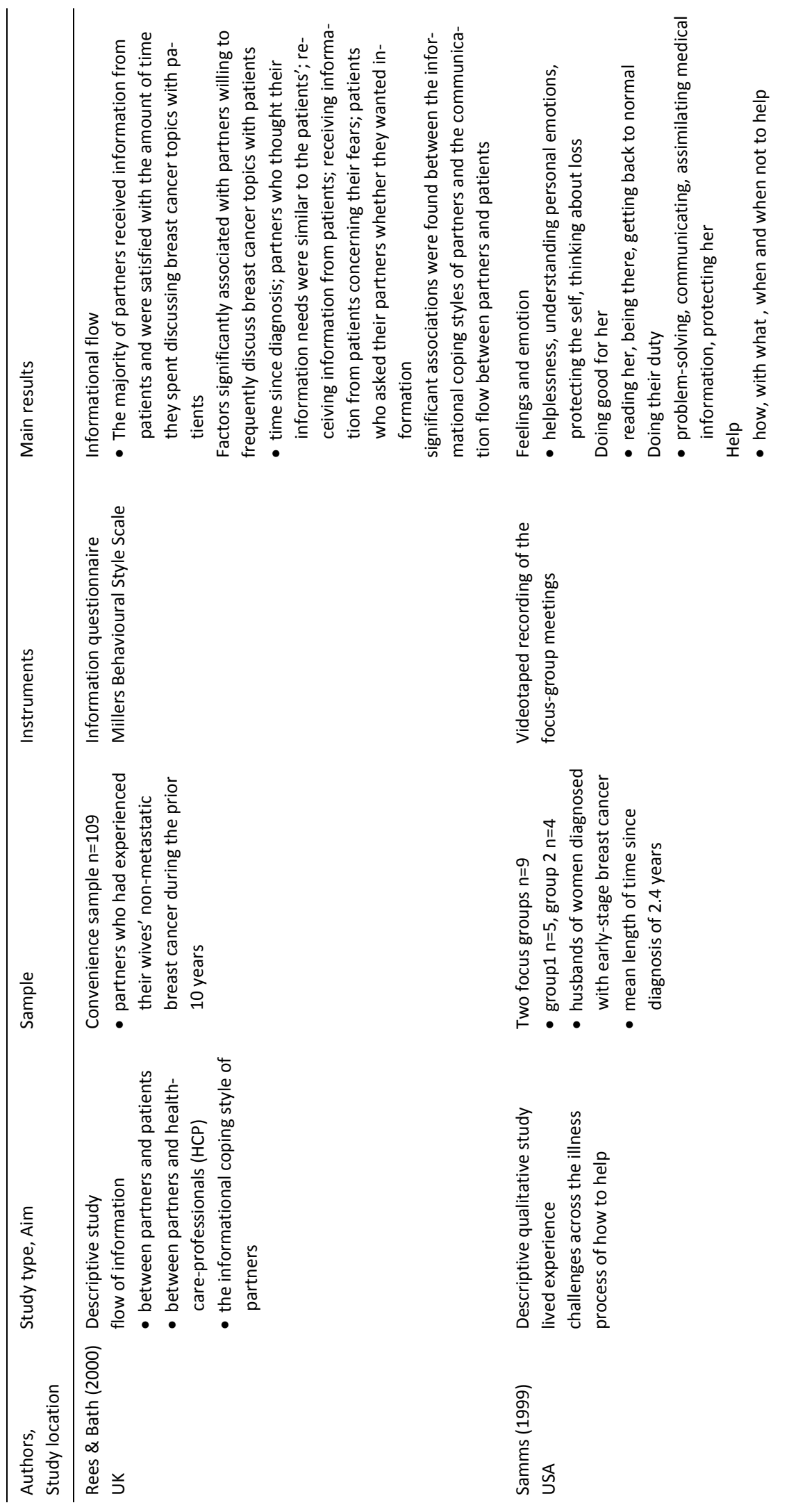




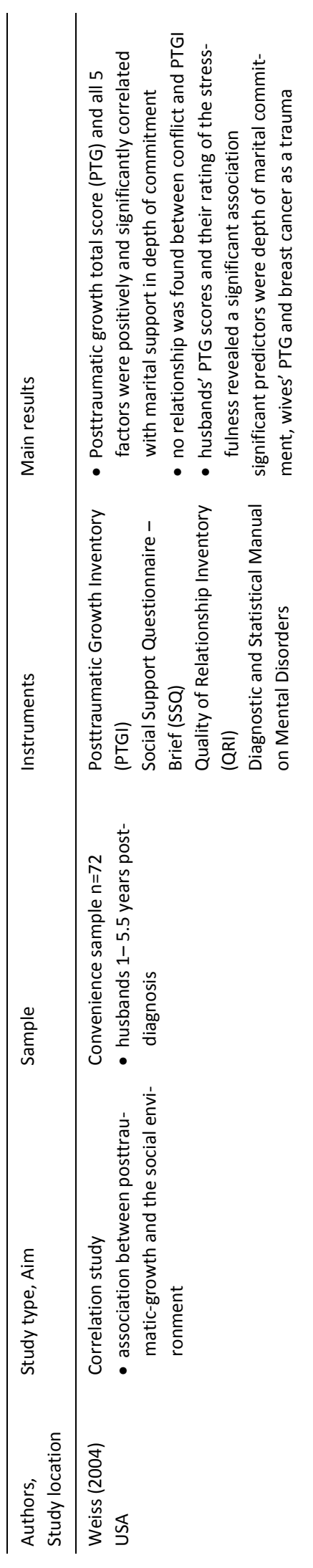




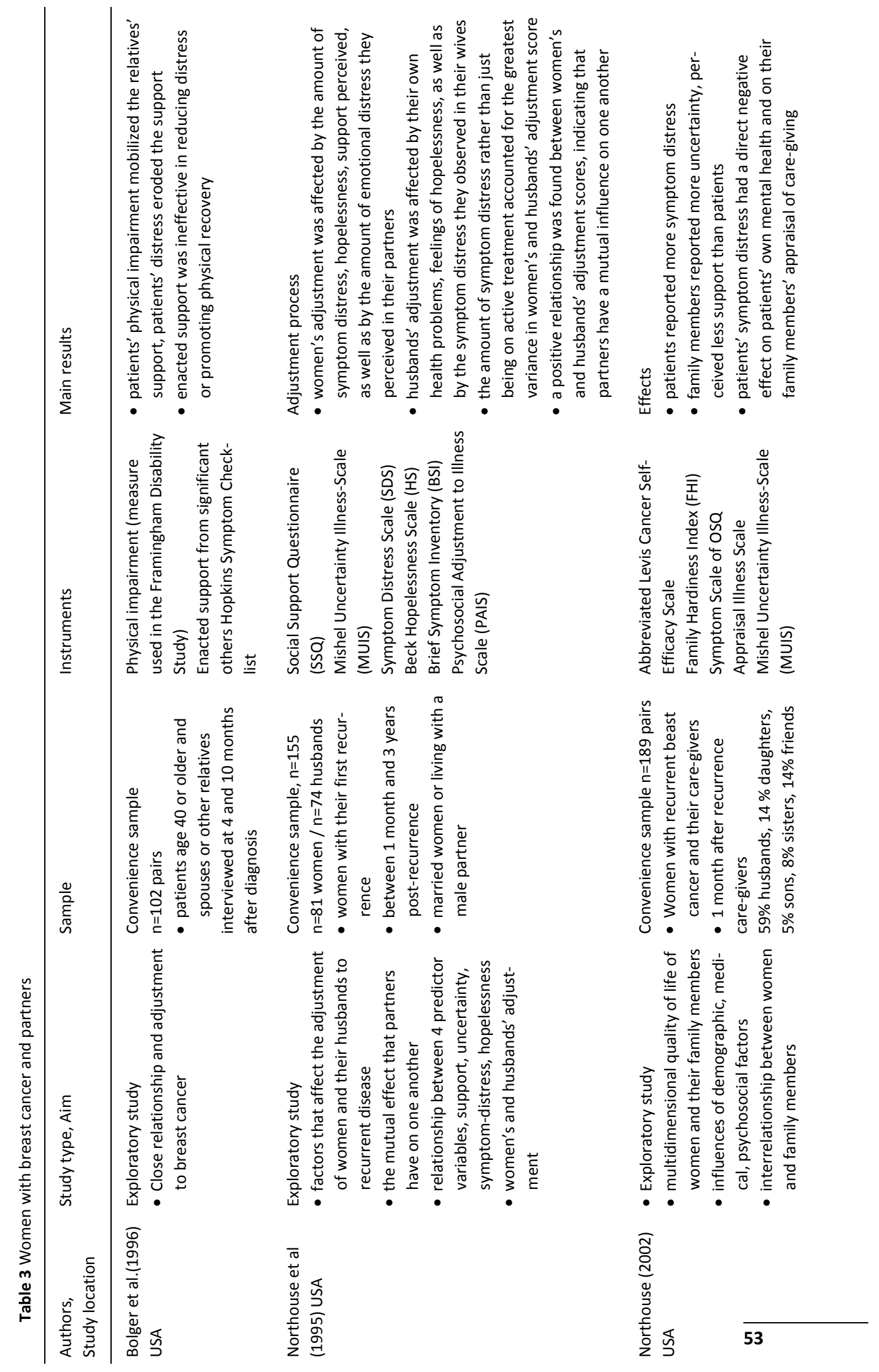




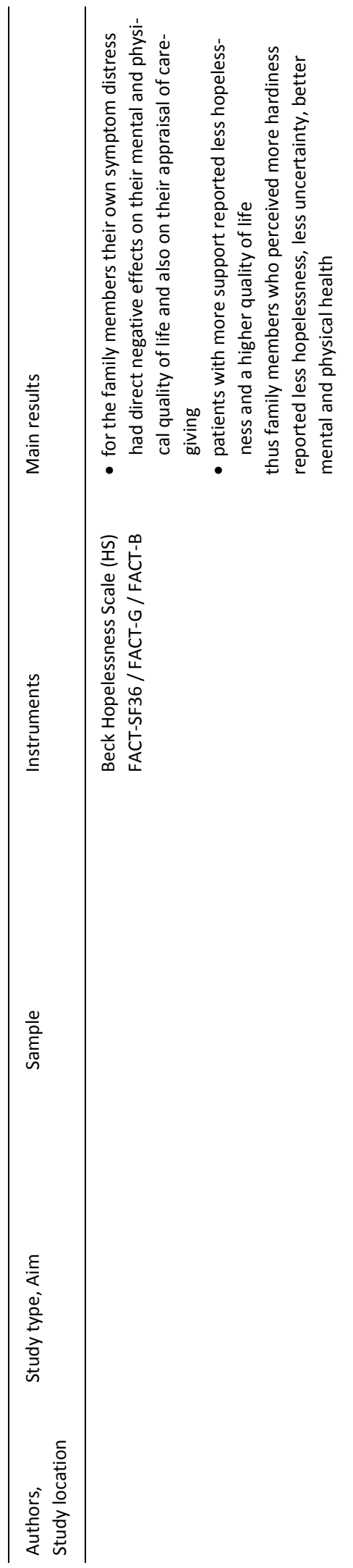




\section{Tentative model}

In a second step, we condensed the results of the review to provide a brief overview of the psychosocial needs of breast cancer patients and their relatives. This process resulted in the proposed tentative model (figure 1) as a potential conceptual framework for clinical practice and future research.

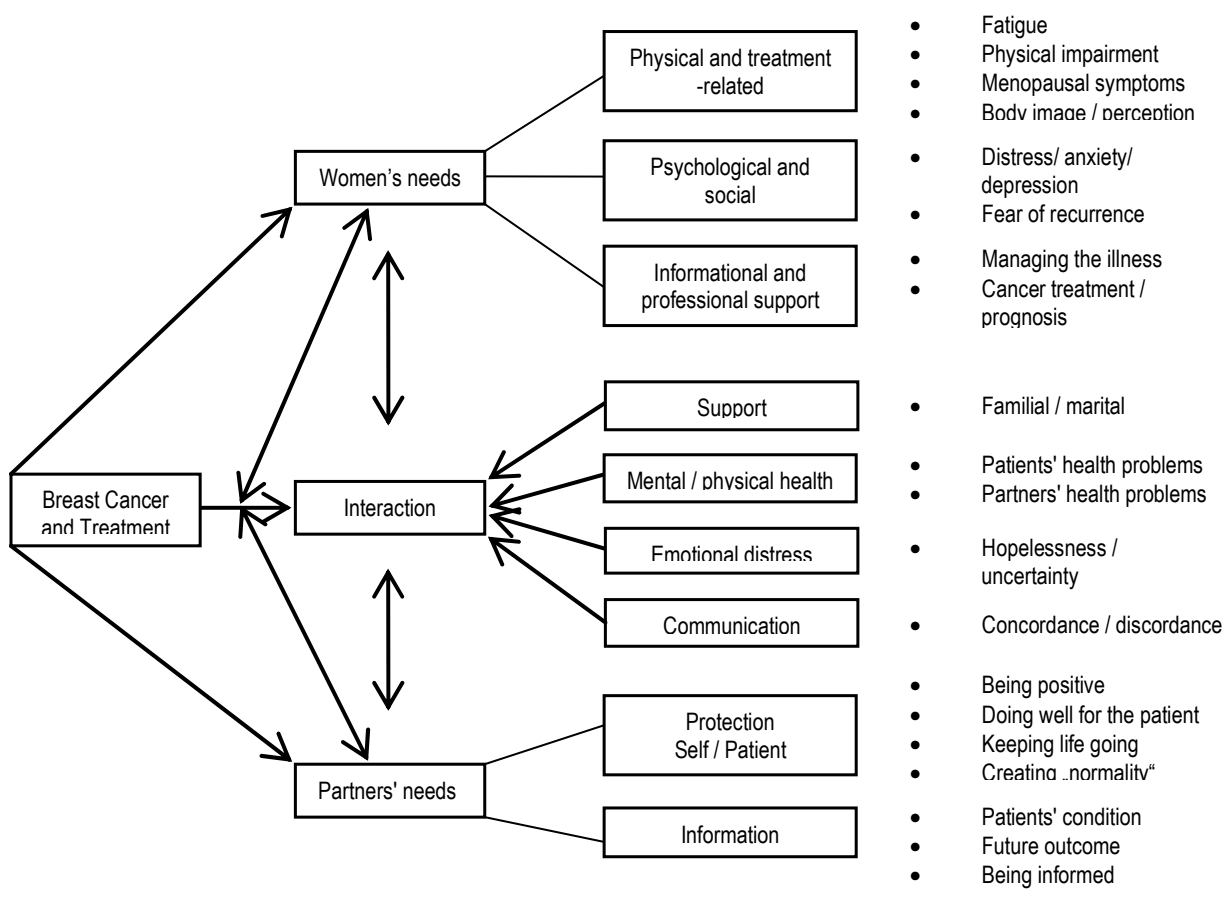

Figure 1: A model for breast cancer patients' and partners' needs during and after treatment

The model addresses four main dimensions: 1) breast cancer and its treatment, 2) the needs of women suffering from breast cancer, 3) the needs of the women's partners and 4) the interaction between the women and their partners. In our literature review, women's needs were influenced by cancer treatments and their longlasting side effects, and by resulting physical and social impairment. The lifethreatening condition of breast cancer may have an impact on psychological needs and challenges both the women and their partners. Women need to deal with distress such as anxiety and depression; partners may need help to protect themselves and the patients from threat and emotions. Women need information and professional support helping them to maintain control and to manage their illness. Partners want information concerning the patients' condition and both of them about prognosis and the future outcome. The model reflects the interrelationship between women's and their partner's needs. The breast cancer diagnosis per se may effect 
the interaction between the women and their partners. However factors, such as familial or marital support, the women's as well as the partners' mental or physical health and their emotional distress could affect the interaction between the women and their partners. Concordance or discordance in communication and satisfaction with the flow of information between the women and their partners might influence the mutual interaction.

\section{DISCUSSION}

This review shows that women and their partners experience substantial distress as a result of breast cancer and its treatment. The women's needs comprise mainly treatment-related physical and social impairments and emotional distress. Fatigue, menopausal symptoms, impaired sexuality and body-image were the most persistent problems and may have a long-lasting impact of the women's health and wellbeing. The women have a need for individualized information which enables them to manage their illness and side effects of treatment and helps them to control emotions about prognosis and future outcome. Partners are concerned about their wife's disease. They may feel overwhelmed and have a need to protect themselves from their own emotions. However, they try to keep life going, to fulfil their wife's needs and may subordinate their own difficulties. The partners need information concerning the patient's condition and perspectives and how to best help their wives. But what they really need to cope with their wives' breast cancer remained unclear. The women's and partner's health and emotional distress and the quality of their interpersonal relationship, like mutual familial support, depth of commitment and feelings of hope, could affect the interaction between the patients and their partners. Knowledge of partners' and other relatives' needs is insufficient.

\section{Limitation}

The studies in our review were inconsistent in design and had a considerable diversity of outcome variables, which limits comparability. The studies frequently measured similar constructs using different instruments. There is a lack of theoretical models for the measurement of needs. Only two studies had an underlying definition of the concept of needs, used a specific need assessment instrument and differentiated between met and unmet needs (Girgis et al. 2000, Hodgkinson et al. 2007). The majority of the studies described the women's needs in the first 2.5 years after diagnosis. The increasing numbers of long-term survivors necessitates exploration of the long-term effects of breast cancer and specific treatments for the women and their families. Only a few studies on the needs partners of breast-cancer patients 
were identified and these focused on a description of psychosocial concerns of partners rather than on specific needs.

\section{Conclusions}

Gaining an understanding of the full impact of breast cancer and correct appreciation of couples' and families' needs is very important for adequate clinical and nursing care and family support. This suggests attaching great importance to the systematic measurement of met and unmet needs and identification of factors which may influence the fulfilment or non-fulfilment of these needs. There remains a clear need for a family-based conceptual model to determine precisely which psychosocial variables are effective in promoting greater health for women with breast cancer and their families. Such a model may provide guidelines which are useful in both research and clinical practice. The proposed tentative model may be a beginning, while further research should develop a more sophisticated family model integrating the women's and families' needs, their burden of illness, and the interaction of their interpersonal relationship. Further research in this field needs to be theoretically and methodologically of high quality. The selection of appropriate need assessment instruments with well-established levels of reliability and validity and standardisation of their use is essential. Such research would provide appropriate knowledge for clinical practice, guide care planning for support, counselling and education of the women and their families to help them cope during the time of treatment, and facilitate their recovery and adjustment process. 


\section{REFERENCES}

Arman M, Rehnsfeldt A, Lindholm L \& Hamrin E (2002) The face of suffering among women with breast cancer-being in a field of forces. Cancer Nurs 25, 96-103.

Arora NK, Johnson P, Gustafson DH, McTavish F, Hawkins RP \& Pingree S (2002) Barriers to information access, perceived health competence, and psychosocial health outcomes: test of a mediation model in a breast cancer sample. Patient Educ Couns 47, 37-46.

Bolger N, Foster M, Vinokur AD \& Ng R (1996) Close relationships and adjustment to a life crisis: the case of breast cancer. J Pers Soc Psychol 70, 283-294.

Bonevski B, Sanson-Fisher R, Girgis A, Burton L, Cook P \& Boyes A (2000) Evaluation of an instrument to assess the needs of patients with cancer. Cancer 88, 217-225.

Davis C, Williams P, Parle M, Redman S \& Turner J (2004) Assessing the support needs of women with early breast cancer in Australia. Cancer Nurs 27, 169-174.

Endacott R (1997) Clarifying the concept of need: a comparison of two approaches to concept analysis. J Adv Nurs 25, 471-476.

Ferrell BR \& Hassey Dow K (1997) Quality of life among long-term cancer survivors. Oncology 11, 565576.

Girgis A, Boyes A, Sanson-Fisher RW \& Burrows S (2000) Perceived needs of women diagnosed with breast cancer: rural versus urban location. Aust N Z J Public Health 24, 166-173.

Hanson Frost M, Suman VJ, Rummans TA, Dose AM, Taylor M, Novotny P, Johnson R \& Evans RE (2000) Physical, psychological and social well-being of women with breast cancer: the influence of disease phase. Psychooncology 9, 221-231.

Hilton BA, Crawford JA \& Tarko MA (2000) Men's perspectives on individual and family coping with their wives' breast cancer and chemotherapy. West J Nurs Res 22, 438-459.

Hodgkinson K, Butow P, Hunt GE, Pendlebury S, Hobbs KM \& Wain G (2007) Breast cancer survivors' supportive care needs 2-10 years after diagnosis. Support Care Cancer 15, 515-523.

Holmes CA \& Warelow PJ (1997) Culture, needs and nursing: a critical theory approach. J Adv Nurs 25, 463-470.

Hoskins CN (1997) Breast cancer treatment-related patterns in side effects, psychological distress, and perceived health status. Oncol Nurs Forum 24, 1575-1583.

Hunter MS, Grunfeld EA, Mittal S, Sikka P, Ramirez AJ, Fentiman I \& Hamed H (2004) Menopausal symptoms in women with breast cancer: prevalence and treatment preferences. Psychooncology 13, 769778.

Lobb EA, Kenny DT, Butow PN \& Tattersall MH (2001) Women's preferences for discussion of prognosis in early breast cancer. Health Expect 4, 48-57.

Marlow B, Cartmill T, Cieplucha H \& Lowrie S (2003) An interactive process model of psychosocial support needs for women living with breast cancer. Psychooncology 12, 319-330.

Maslow AH (1968) Toward a Psychology of Being. D. Van Nostrand Company, New York, Cincinnati.

McPhail G \& Wilson S (2000) Women's experience of breast conserving treatment for breast cancer. Eur J Cancer Care 9, 144-150.

Nikoletti S, Kristjanson L, Tataryn D, McPhee I \& Burt L (2003) Information needs and coping styles of primary family caregivers of women following breast cancer surgery. Oncol Nurs Forum 30, 987-996.

Northouse LL, Dorris G \& Charron-Moore C (1995) Factors affecting couples' adjustment to recurrent breast cancer. Soc Sci Med 41, 69-76.

Northouse LL, Mood D, Kershaw T, Schafenacker A, Mellon S, Walker J, Galvin E, Decker V (2002) Quality of life of women with recurrent breast cancer and their family members. J Clin Oncol 20, 4050-4064.

Polit DF \& Hungler BP (1999) Nursing Research: Principles and Methods, Lippincott, Philadelphia, New York, Baltimore.

Raupach JC \& Hiller JE (2002) Information and support for women following the primary treatment of breast cancer. Health Expect 5, 289-301. 
Rees CE \& Bath PA (2000) Exploring the information flow: partners of women with breast cancer, patients, and healthcare professionals. Oncol Nurs Forum 27, 1267-1275.

Samms MC (1999) The husband's untold account of his wife's breast cancer: a chronologic analysis. Oncol Nurs Forum 26, 1351-1358.

Sanson-Fisher R, Girgis A, Boyes A, Bonevski B, Burton L \& Cook P (2000) The unmet supportive care needs of patients with cancer. Cancer 88, 226-237.

Schultz PN, Klein MJ, Beck ML, Stava C \& Sellin RV (2005) Breast cancer: relationship between menopausal symptoms, physiologic health effects of cancer treatment and physical constraints on quality of life in long-term survivors. J Clin Nurs 14, 204-211.

Soothill K, Morris SM, Harman J, Francis B, Thomas C \& Mclllmurray MB (2001) The significant unmet needs of cancer patients: probing psychosocial concerns. Support Care Cancer 9, 597-605.

Weiss T (2004) Correlates of posttraumatic growth in husbands of breast cancer survivors. Psychooncology 13, 260-268.

Wen K \& Gustafson D (2004) Need assessment for cancer patients and their families Health Qual. Life Outcomes 2, 2-12. 



\section{Chapter Four}

\section{Psychosocial problems and needs}

of post-treatment patients with breast cancer and their relatives

Manuscript in press as: Schmid-Büchi S, Halfens RJG, Dassen T, van den Borne B (2009) Psychosocial problems and needs of post-treatment patients with breast cancer and their relatives. European Journal of Oncology Nursing, doi:10.1016/j.ejon.2009.11.001. 


\section{ABSTRACT}

Purpose. The study assessed and compared the psychosocial needs of patients with breast cancer and of their relatives, the patients' and relatives' burden of illness, anxiety, depression and distress and assessed the patients' cancer treatmentrelated symptoms and identified relevant factors influencing patients' and relatives' needs.

Method. Seventy-two patients $(n=72)$ participated with a relative in a crosssectional mail-survey, 1-22 months after cancer treatment.

Results. The patients reported needing help with psychological and sexual issues. They suffered form treatment-related symptoms. More treatment-related symptoms and depression were related to the patients' needs for supportive care. Their relatives' needs primarily concerned access to information and communication with health care professionals. Relatives had higher levels of anxiety $(25.0 \%$ vs $22.2 \%)$, depression (12.5\% vs $8.3 \%$ ) and distress (40\% vs $34 \%$ ) than patients. Higher levels of depression, younger age and having a disease themselves were associated with relatives' need for help.

Conclusion. Patients' and relatives' substantial needs and psychological problems require professional support even after completion of the patients' treatment. Continued assessment of the patients' and their relatives' needs and of the patients' symptoms provide the basis for purposeful counselling and education. Rehabilitation programs for patients and their relatives should be developed and implemented in clinical practice. 


\section{INTRODUCTION}

Diagnosis and treatment of breast cancer are stressful events (Arman et al. 2002) and may result in a wide range of physical, psychological, and social effects that may influence the patient's needs (Boehmke \& Dickerson 2006, Kissane et al. 1998, McPhail \& Smith 2000, McPhail \& Wilson 2000, Schmid-Büchi et al, 2005, Shimozuma et al. 1999). Breast cancer not only causes substantial distress to the women themselves (Bleiker et al. 2000, Mclllmurray et al. 2001) but also to their relatives who experience problems that may influence their needs (Hilton et al. 2000, Samms 1999). However, little is known about how the relatives of breast cancer patients overcome cancer-related problems. What we know about their problems mainly comes from qualitative, descriptive research. These findings indicate that relatives experience fear, a sense of powerlessness, exhaustion, shock, disbelief and anger, sometimes resulting in depression. It is hard for them to see their partner suffering from cancer and cancer treatment (Hilton et al. 2000, Lethborg et al. 2003, Lindholm et al. 2002). They frequently place themselves in the role of "caregiver" and try to take control of the situation. But they often feel uninformed and unprepared to cope with this life crisis (Hilton et al. 2000, Kilpatrick et al. 1998, Lethborg et al. 2003, Samms 1999). Relatives may perceive an ongoing burden of managing their own emotions whilst supporting the patient and the family (Hodgkinson et al. 2007a, Hodgkinson et al. 2007c, Lewis et al. 2008). However, we do not know if they have the same needs for help as the patients.

Cancer survivorship is an ongoing challenge, both for patients and their relatives. After treatment, patients and their relatives do not return to a pre-cancer diagnosis state. They still have specific and unique needs (Hodgkinson et al. 2007c). Breast cancer patients $(n=1051)$ in the study of Hoybye et al. (2008) suffered from cancer or cancer treatment-related late effects before they started a rehabilitation program. Many of these patients suffered from fatigue (66\%), lack of concentration $(46 \%)$ and joint or muscle pains (49\%), less from digestive- (18\%) and urinary problems (11\%). Particularly endocrine symptoms may have a substantial impact on quality of life, mainly if the patients receive adjuvant systemic treatment for breast cancer (Ribi et al. 2007). Fear of the future and the threat of cancer recurrence resulting in a shortened life are stressful concerns for the patients even years after diagnosis (Lebel et al. 2007, McPhail \& Smith 2000, McPhail \& Wilson 2000).

Understanding the full impact of breast cancer on patients and their relatives is indispensable and clinically of prime importance in assessing the met and unmet needs of both groups. Need assessment is a direct measure of the divergence between the patients' or relatives' experiences and expectations (Soothill et al. 2001) and helps clinicians in focusing their care on those issues considered most relevant by patients and significant others (Rankin et al. 2000, Wen \& Gustafson 2004). Evaluation of the real demand for help and support even after the patients' cancer 
treatment may guide care planning, counselling and education of the women and their relatives (Bonevski et al. 2000, Sanson-Fisher et al, 2000, Sheppard 2007, Wen \& Gustafson 2004).

To summarize, there remains a lack of knowledge concerning the relatives' specific needs and whether they have the same needs for help as the patients. Breast cancer causes emotional problems in both the patients and their relatives. The patients' cancer treatment may impose a burden. However, we do not know enough about how these problems may influence the needs of the patients and their relatives.

\section{Aim of the study}

Therefore, the aim of this study was to assess and compare: (1) the met -and unmet psychosocial needs of patients and of their relatives; (2) the patients' and relatives' burden of illness, anxiety, depression and distress; (3) to assess the patients' cancer and cancer treatment-related symptoms after medical treatment and; (4) to identify relevant factors influencing patients' and relatives' needs.

\section{METHODS}

\section{Research strategy and context}

For this study, we approached all breast cancer patients in two hospitals in Switzerland, Zurich area who, following the diagnosis, underwent subsequent cancer treatments such as surgery, chemotherapy and/or radiotherapy, who were within 1-24 months after completion of these treatments and who were not undergoing another cancer treatment during this period (except endocrine treatment).

The potential study participants $(n=485)$ listed in the databases of the two hospitals were invited by mail to participate in the study, under the condition that they had no advanced cancer and cancer treatment. They were also requested to invite an adult relative to participate. They received the study documentation and the questionnaires for themselves and their relatives. A relative was defined as a close person (connected by blood or affinity), who was emotionally involved with the patient and identified by the patient as her primary source of emotional and physical support (adapted from Northouse et al. 2002 and Hilton et al. 2000). Relatives decided independent of the patient whether or not to participate. 


\section{Research design and recruitment strategy}

Patients and their relatives were recruited by mail for a cross-sectional survey. A cross-sectional design is appropriate to describe relationships among phenomena at a fixed point in time and when a theoretical framework is guiding the analysis (Polit \& Hungler 1999). This study was based on a prior qualitative study and a literature review which provided a tentative model (Schmid-Büchi et al. 2005, Schmid-Büchi et al. 2008)

Not all patients who received their cancer treatment in one of the two hospitals also returned there for their clinical follow-up medical cancer care. Many consulted their private oncologist for the follow-ups. As a result, a face-to-face recruitment would hardly have been possible, and therefore the necessary information was gained from the databases of the two hospitals. For this study, 485 questionnaires were mailed, of which 15 were returned to the sender and 22 patients had died in the meantime. After 3 weeks, a written reminder (including questionnaires) was sent to non-responders. Reasons for patients and relatives not to participate in the survey were language problems (not reading/speaking German) ( $n=11)$. Some patients or relatives sent back an incomplete $(n=10)$ or a blank questionnaire $(n=19)$ and eight patients had advanced cancer and cancer treatment and were therefore not eligible for the sample. The other potential participants did not respond, some of them because of advanced cancer. The final survey sample included 128 patients (overall response rate of $28.6 \% ; n=448$ ) and 78 relatives, 72 were pairs. The response rate for pairs was $56.25 \%$. For this paper we analyzed the data of the 72 pairs.

\section{Ethical considerations}

The study complies with the principles laid down in the Declaration of Helsinki (1964) and in the current version. Patients and relatives who participated in the study gave their informed consent. Ethics approval was obtained from the Institutional Review Board of the Canton of Zurich, Switzerland.

\section{Measures and instruments}

German versions of self-reported instruments were used in the Supportive Care Needs Survey (SCNS-SF34), Cancer and Cancer Treatment-related Symptom Scale (CTSS) for patients, the Psychosocial Need Inventory (PNI) for relatives, and the Hospital Anxiety and Depression Scale (HADS), the Distress-Thermometer (DT) and the Pictorial Representation of Illness and Self-Measure (PRISM) for patients and relatives. To confirm the accuracy of the German versions of the SCNS-SF34, CTSS and $\mathrm{PNI}$, factor analyses were conducted with data of the current study, and from a second study in which patients under treatment for breast cancer $(n=176)$ and their 
relatives ( $n=104)$ were measured with the same instruments as in this study (paper submitted).

Supportive Care Needs Survey (SCNS-SF34) (Bonevski et al.,2000). Patients' needs were measured with the German version of the SCNS (Holdener-Mascheroni 2003). The SCNS contains 34 items designed to measure patients' perceived needs in five core domains: psychological (10 items), health system and information (11 items), physical and daily living (five items), patient care and support (five items) and sexuality (three items) (Sanson-Fisher et al. 2000). The patients indicated their level of need for help in the last month on a five-point scale, scoring from no need, low, moderate, and high need; and a not applicable/satisfied category. For this investigation, a sixth domain was added with four items related to the need for specific information regarding the self-examination of the breasts, prevention of lymphoedema, impact on fertility and possible risks for female family members to get breast cancer as well. Our factor analysis confirmed the validity and reliability of the original instrument (Bonevski et al. 2000) for the German version, i.e. principal component analysis (PCA); with oblimin rotation; Kaiser-Meyer-Olkin measure of sampling adequacy (KMO=0.922; $n=304)$. Factor analysis explained $60 \%$ of the total variance. The Cronbach's alpha coefficients were between 0.83 and 0.90

The 51-item German version (Mathis-Jäggi 2003) of the Psychosocial Need Inventory (PNI) (Soothill et al. 2001) was used to measure the relatives' needs. The PNI measures the unmet psychosocial needs of cancer patients' caregivers. Each need item has two scales, assessing first the importance of the need item scored from no need (0), to very important (5). The second scale measures the level of satisfaction with the need having been met during the last weeks, scored from not at all satisfied (0) to very satisfied (5). Our factor analysis (PCA with oblimin rotation; KMO $=0.889$; $\mathrm{n}=182$ ) explained $56 \%$ of the total variance and extracted five main factors related to: (1) need for information (six items); (2) need for effective access to health care professionals (11 items); (3) need for spiritual support (five items); (4) need for emotional and social support (24 items); and (5) need for practical support (five items). Cronbach's alpha coefficients ranged from 0.73 to 0.95 .

The Cancer and Cancer Treatment-related Symptom Scale (CTSS), was used to assess the patients' cancer and treatment-related symptoms. Based on a literature review (Schmid-Büchi et al. 2008), a qualitative study (Schmid-Büchi et al. 2005), clinical experience and the topics being discussed in an internet-forum by a self-help group of women with breast cancer (Forum), a 27-item scale was developed to assess patients' symptoms, complaints and impairments. The respondents were asked how impaired they had felt in the past month by these symptoms. The symptoms were measured with a four-point scale ranging from not at all impaired (1) to very much 
impaired (4). A factor analysis (PCA, oblimin rotation; $\mathrm{KMO}=0.899 ; \mathrm{n}=304$ ) extracted four main factors: gastro-intestinal symptoms (six items), pain and well-being (six items), physical and social impairment (10 items) and body image (five items). Factor analysis explained $55 \%$ of the total variance. Cronbach's alpha coefficients ranged from 0.78 to 0.91 .

Hospital Anxiety and Depression Scale (HADS) (Herrmann 1997, Zigmond \& Snaith 1983). The established and well-tested HADS assessed the patients' and relatives' anxiety (seven items) and depression (seven items). Participants were asked to indicate which of the four options (scores 0-3) came closest to describing how they had felt in the past week. The range of both scales is $0-21$. According to the HADScriteria (Herrmann 1997, Zigmond \& Snaith 1983), scores of 8-10 on each subscale were taken to indicate a probable clinical anxiety or depression and scores $>10$ were taken to indicate clinical anxiety or depression.

Distress-Thermometer (DT). Distress was measured using the original version by Roth et al. (1998). The scale is a modified visual analogue scale that looks like a thermometer and ranges from no distress (0) to extreme distress (10). The patients and their relatives were asked to rate how distressed they had felt in the past week. In earlier studies, a score of 5 was identified in applying the DT to a group of prostate cancer patients as a threshold for differentiating distressed from non-distressed patients (Roth et al., 1998). Ambulatory cancer patients who completed the DT showed that a cut-off score of 4 had a good sensitivity of 0.77 and a specificity of 0.68 , using the HADS as a distress criterion. (Jacobsen et al. 2005, Roth et al. 1998).

The Pictorial Representation of Illness and Self-Measure (PRISM) (Buchi et al. 1998) was used to measure the burden of suffering by using the self-administered paperpencil version. The PRISM is scored using a rectangle of $10.2 \times 7 \mathrm{~cm}$ labelled "your life" and a circle of $2 \mathrm{~cm}$ in diameter in the bottom right corner labelled "self". Patients and relatives were asked to place a cross in the first rectangle, to express the place which the illness holds in their lives (self-assessment) and in the second rectangle, how they think their close person feels. The distance in millimetres between the "self" circle and the cross can range from 0 to $94 \mathrm{~mm}$. A cross close to "self " indicates that the illness takes a lot of space of the "self " and reflects greater suffering, further away from the "self " indicates that the illness takes less space, thus less suffering. The PRISM has recently been validated (Buchi et al. 2002, Buchi \& Sensky 1999, Buchi et al., 1998). 


\section{Patients' and relatives' characteristics}

Patients' and relatives' demographic characteristics such as age, education, marital status, kind of relationship to the close person, other diseases, patients' menopausal state before the cancer diagnosis and cancer treatment-related characteristics such as surgery and kind of treatment were assessed.

\section{Data analyses}

Statistical analysis was carried out using SPSS 15.00. Descriptive statistics for the data of patients and relatives were calculated and ratings of patients and relatives were compared using t-tests for paired samples. To analyze the impact on the patients' and relatives' needs, multiple regression models were calculated for each of the dependent variables (factors of the need-assessment instruments SCNS / PNI). For the patient's models, the mean scores of the factors of the CTSS, the scores of the HADS, Distress-thermometer and PRISM, the continuous variables age, and months since therapy, were included as covariables. Further covariables were previous treatment (radiotherapy vs. chemo-radiotherapy), hormonal therapy (no vs. yes), menopausal state before cancer diagnosis (menopause no vs. yes and no vs. postmenopausal state), other disease (no vs. yes), and education (primary vs. middle and primary vs. high).

The scores of the HADS, Distress-Thermometer, PRISM, the covariables age, own diseases, education and the women's previous therapy, hormonal therapy and months since therapy were included for the relatives' regression models. Variables were eliminated using a backwards selection. Skewed scores of the dependent SCNS-variables were transformed using the natural logarithm.

\section{RESULTS}

\section{Patients' and their relatives' characteristics}

Sixty-one of the relatives (84.7\%) were the patients' husbands or partners. Eleven (15.3\%) were neither husbands nor partners, of whom only two were men. The women were questioned within 1-24 months after completion of their cancer treatment. The results are summarized in Table 1. 
Table 1: Demographic characteristics of patients and their relatives', and patients' cancer-related characteristics

\begin{tabular}{|c|c|c|}
\hline Characteristics & $\begin{array}{l}\text { Patients } \\
(n=72)\end{array}$ & $\begin{array}{l}\text { Relatives } \\
(n=72)\end{array}$ \\
\hline \multicolumn{3}{|l|}{ Age } \\
\hline Mean & 57.5 & 57.6 \\
\hline Median & 60 & 60 \\
\hline SD & 11.8 & 12.3 \\
\hline Range & $28-77$ & $30-85$ \\
\hline Marital status patients & $\mathrm{n}(\%)$ & $\mathrm{n}(\%)$ \\
\hline Married / living with partner & $59(81.9)$ & \\
\hline Single / divorced / widowed & $13(18.1)$ & \\
\hline \multicolumn{3}{|l|}{ Relatives } \\
\hline Females & & $9(12.5)$ \\
\hline Males & & $63(87.5)$ \\
\hline Husbands / Partners & & $61(84.7)$ \\
\hline Daughters / Sons & & $3(4.2)$ \\
\hline Sisters / Brothers & & $3(4.2)$ \\
\hline Parent / Friends / Others & & $5(6.9)$ \\
\hline \multicolumn{3}{|l|}{ Education } \\
\hline Primary school & $3(4.2)$ & $5(7.0)$ \\
\hline Professional education & $48(66.7)$ & $39(55.0)$ \\
\hline Higher education & $14(19.4)$ & $14(19.7)$ \\
\hline University & $7(9.7)$ & $13(18.3)$ \\
\hline \multicolumn{3}{|l|}{ Surgery } \\
\hline Breast conserving & $58(80.6)$ & \\
\hline Mastectomy & $14(19.4)$ & \\
\hline \multicolumn{3}{|l|}{ Treatment } \\
\hline No additional treatment & $1(1.4)$ & \\
\hline Chemotherapy & $3(4.2)$ & \\
\hline Radiotherapy & $29(40.3)$ & \\
\hline Chemo- and Radiotherapy & $39(54.1)$ & \\
\hline Endocrine therapy & $51(70.8)$ & \\
\hline \multicolumn{3}{|l|}{ Months since treatment } \\
\hline Mean & 10.8 & \\
\hline Median & 10.5 & \\
\hline SD & 5.0 & \\
\hline Range & $1-22$ & \\
\hline
\end{tabular}




\section{Patients' needs and cancer and cancer treatment-related symptoms}

The 72 women still needed help in their post-treatment time, particularly with respect to psychological problems and sexual issues. Fear about the cancer spreading (31.9\%), uncertainty about the future $(25.0 \%)$, lack of energy $(23.6 \%)$, feelings of sadness $(21.4 \%)$, feeling down or depressed (18.3\%), anxiety (18.1\%), worries that the results of treatment are beyond their control (24.2\%) and learning to feel in control of the situation (21.7\%) were the most frequently reported unmet needs.

Furthermore, they had needs related to changes in their sexual relationships (22.2\%), sexual feelings (23.6\%) and to be given information about sexual relationships (22.5\%). They needed help in their concern about worries of the persons close to them (18.1\%). The breast cancer-specific items were the lowest ranked unmet needs (ratings between $2.9 \%$ and $5.9 \%$ ).

The majority of the patients reported cancer and cancer treatment-related symptoms. They felt impaired in their physical and social activities, body image and suffered from pain even months after these treatments. They were affected by hot flashes $(76.4 \%)$, fatigue $(73.2 \%)$, insomnia (66.6\%), joint pain $(59.7 \%)$, pain in hands and feet $(54.2 \%)$, muscle pain $(46.4 \%)$, pain $(49.4 \%)$ and restriction $(48.6 \%)$ of movement in arm and shoulder of the affected side. They felt less feminine and attractive $(39.0 \%)$, complained of weight gain $(62.5 \%)$, changes of body perception (51.4\%) and appearance (48.6\%), felt impaired in their leisure activities (42.9\%), at work and in their daily activities (43.1\%). They reported fewer problems with gastrointestinal symptoms such as nausea/vomiting (23.9\%) or changes in perception of taste when eating (25.4\%); diarrhea was the least common symptom (11.6\%).

\section{Relatives' needs}

The relatives' most significant unmet needs were primarily related to access to information and health care professionals. They felt dissatisfied and had needs for information regarding the patient's medication and side-effects (35.3\%), about what to expect $(33.3 \%)$, and treatment plans (27.9\%). Relatives needed the opportunity to participate in choices concerning treatment $(29.0 \%)$ and advice about the availability of services and help (32.3\%). They reported dissatisfaction and a need for honest information (31.3\%) and to develop confidence in the health care professionals (32.4\%). They needed easy and quick access to doctors (29.9\%), had a need for doctors $(39.7 \%)$ and nurses $(30.9 \%)$ who have time for discussion, and for nurses (29\%) and doctors (26.5\%) who would listen to them. The relatives needed help with finding a sense of purpose and meaning (29.9\%) and to develop hope for the future (39.1\%). Fewer had a need for more practical help and their needs for social and family support seemed to be satisfactorily fulfilled (ratings between $4.5 \%$ and $14.9 \%)$. 
The mean-scores of patients' and relatives' needs and the patients' cancer and cancer treatment-related symptoms for the domains of the instruments are summarized in Table 2.

Table 2: Patients' supportive care need domains, patients' cancer and cancer treatment-related symptom domains and relatives' psychosocial need domains

\begin{tabular}{|c|c|c|c|c|c|c|}
\hline Domains & $\mathrm{n}$ & Min. & Max. & Mean & SD & $\begin{array}{l}\text { Cronbach's } \\
\text { alpha Coef. }\end{array}$ \\
\hline \multicolumn{7}{|l|}{ Patient } \\
\hline \multicolumn{7}{|l|}{ SCNS domains (Range $1-5$ ) } \\
\hline Physical daily living & 72 & 1 & 4.40 & 1.77 & 0.82 & 0.85 \\
\hline Psychological & 72 & 1 & 4.70 & 1.89 & 0.83 & 0.93 \\
\hline Sexuality & 72 & 1 & 5.00 & 1.94 & 1.12 & 0.88 \\
\hline Patients' care and support & 72 & 1 & 4.60 & 1.75 & 0.76 & 0.83 \\
\hline Health care system and information & 72 & 1 & 4.82 & 1.92 & 0.68 & 0.90 \\
\hline Breast cancer & 71 & 1 & 3.25 & 1.69 & 0.47 & 0.75 \\
\hline \multicolumn{7}{|l|}{ CTSS domains (Range 1-4) } \\
\hline Gastrointestinal symptoms & 72 & 1 & 3.33 & 1.45 & 0.63 & 0.79 \\
\hline Pain and well-being & 72 & 1 & 3.50 & 1.88 & 0.73 & 0.78 \\
\hline Physical and social impairment & 72 & 1 & 3.50 & 1.74 & 0.67 & 0.91 \\
\hline Body image & 72 & 1 & 4.00 & 2.00 & 0.82 & 0.80 \\
\hline \multicolumn{7}{|l|}{ Relative } \\
\hline \multicolumn{7}{|l|}{ PNI domains (Range 0-25) } \\
\hline Need for information & 69 & 0 & 21.00 & 7.44 & 4.17 & 0.89 \\
\hline $\begin{array}{l}\text { Need for effective access to health care } \\
\text { professionals }\end{array}$ & 70 & 0 & 20.45 & 6.40 & 4.23 & 0.92 \\
\hline Need for spiritual support & 71 & 0 & 17.60 & 4.81 & 4.46 & 0.85 \\
\hline Need for emotional and social support & 70 & 0 & 18.83 & 4.48 & 3.99 & 0.95 \\
\hline Need for practical support & 70 & 0 & 20.00 & 2.91 & 3.41 & 0.73 \\
\hline
\end{tabular}

SCNS=Supportive Care Need Survey (patient); CTSS=Cancer and Cancer Treatment-related Symptom Scale (patient); PNI=Psychosocial Need Inventory (relative)

\section{Anxiety, depression, distress and the burden of suffering}

Twenty-two percent of the patients and $25.0 \%$ of the relatives scored $\geq 8$ points on the HADS anxiety subscale and $8.3 \%$ of the patients respectively $12.5 \%$ of the relatives on the depression subscale, which indicated a possible clinical anxiety or depression according to HADS-criteria. Forty percent of the relatives and $32.8 \%$ of the patients showed clinical evident distress (cut-off point $\geq 4$ ). The relatives' higher means on anxiety, depression and distress were statistically not significant (Table 3 ). 
On the PRISM scale, patients and relatives rated their own burden of suffering and how they thought it was for their relative. The patients' self-assessment for their own burden of suffering was significantly lower $(56.2 \mathrm{~mm}$, mean) than their assessment for their relatives $(50.6 \mathrm{~mm}, \mathrm{p}$-value $<0.01)$. The relatives' self-assessment of their burden $(35.2 \mathrm{~mm}$ ) was approximately as high as for the patients $(36.5 \mathrm{~mm})$ (Figure 1).

Table 3: Scores of the HADS-Scale (Anxiety and Depression) and the Distress-Thermometer

\begin{tabular}{lll}
\hline & $\begin{array}{l}\text { Patients } \\
\mathrm{n}=72\end{array}$ & $\begin{array}{l}\text { Relatives } \\
\mathrm{n}=72\end{array}$ \\
\hline $\begin{array}{ll}\text { Anxiety (Score) } \\
\text { No (0-7) }\end{array}$ & $77.8 \%$ & $75.0 \%$ \\
Probable (8-10) & $11.1 \%$ & $12.5 \%$ \\
Yes (11-21) & $11.1 \%$ & $12.5 \%$ \\
Mean (SD) & $4.67(3.82)$ & $5.19(4.31)$ \\
Depression (Score) & & \\
No (0-7) & $91.7 \%$ & $87.5 \%$ \\
Probable (8-10) & $5.6 \%$ & $4.2 \%$ \\
Yes (11-21) & $2.8 \%$ & $8.3 \%$ \\
Mean (SD) & $2.69(2.90)$ & $3.50(3.78)$ \\
Distress-Thermometer & & \\
Cut-off point $\geq 5$ & $21.4 \%$ & $34.3 \%$ \\
Cut-off point $\geq 4$ & $32.8 \%$ & $40.0 \%$ \\
Mean (SD) & $2.85(2.37)$ & $3.44(3.02)$ \\
\hline
\end{tabular}

\section{Factors affecting the patients' needs}

Five multiple linear regression models have been calculated for the women's supportive care needs (Table 4). Needs in the domain physical daily living, were positively related with higher body image problems. An existing other disease and a premenopause state before the cancer diagnosis indicated more care needs in the domain physical daily living. Higher psychological supportive care needs were associated with higher physical and social impairment. When sexuality was used as a dependent variable, lower burden of suffering, more problems with pain and wellbeing and body image and previous radiotherapy (radiotherapy vs chemo- radiotherapy) were significant predictors for greater needs. Pre-menopausal status before the cancer diagnosis had a borderline significant $p$-value when sexuality was used as a dependent variable. More care and support needs were associated with lower burden of suffering and more gastro-intestinal symptoms. When health system and information needs were used as dependent variables, more depressive feelings 
were a significant predictor for greater needs. The $\mathrm{R}^{2}$ of the five models varied between 0.15 and 0.47 (Table 4).

Figure 1. PRISM - Burden of suffering of illness (Pictorial Representation of Illness and Self-Measure)

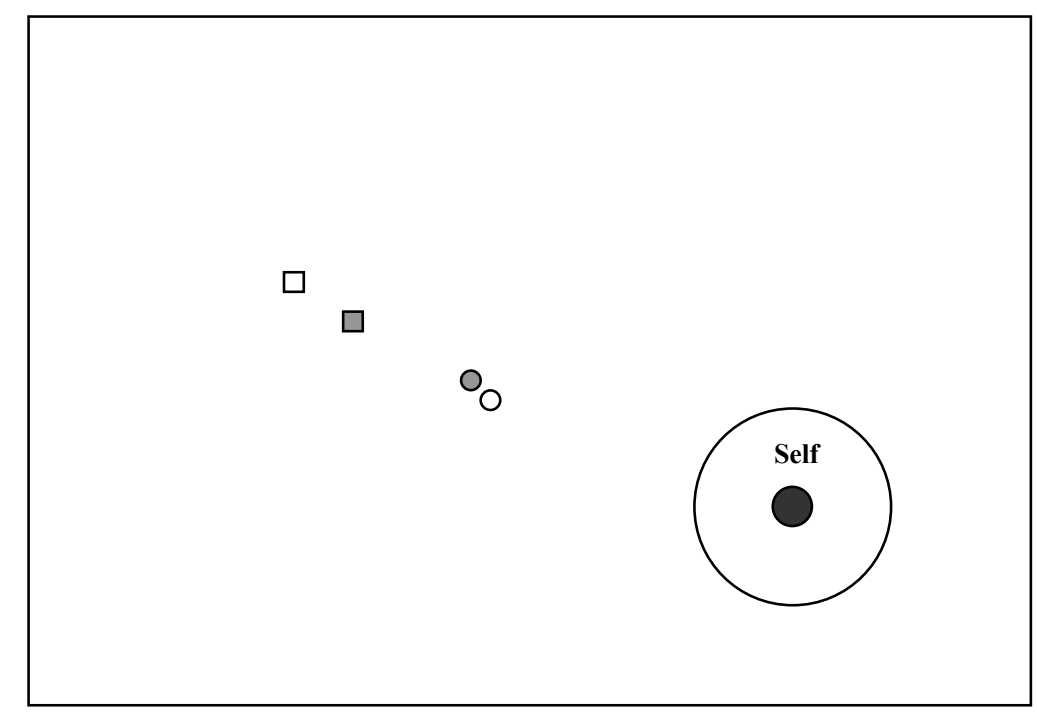

Patients' self-assessment (56.2 mm / SD 18.7)

$\square$ Patients' assessment for their relatives (50.6 mm / SD 21.3)

O Relatives' self-assessment (35.2 mm / SD 20.5)

O Relatives' assessment for the patients ( $36.5 \mathrm{~mm} / \mathrm{SD} 20.7)$

( shorter distance $=$ more burden)

\section{Factors affecting the relatives' needs}

Four models were calculated for the relatives' psychosocial needs (Table 5). The total variance $\left(R^{2}\right)$ explained in each of the four models varied between 0.19 and 0.30. For the two dependent variables, need for information and need for effective access to health care professionals, more depressive feelings of relatives and younger age were predictors for greater needs. Depressive feelings were also associated with a higher need for spiritual support. Relatives who were experiencing a health problem themselves had a greater need for support with emotional and social problems. Furthermore, younger age seems to raise emotional and social support needs. No association was found between the patients' previous medical treatments and the relatives' needs and between relatives' explanatory variables and the dependent variable need for practical support. 


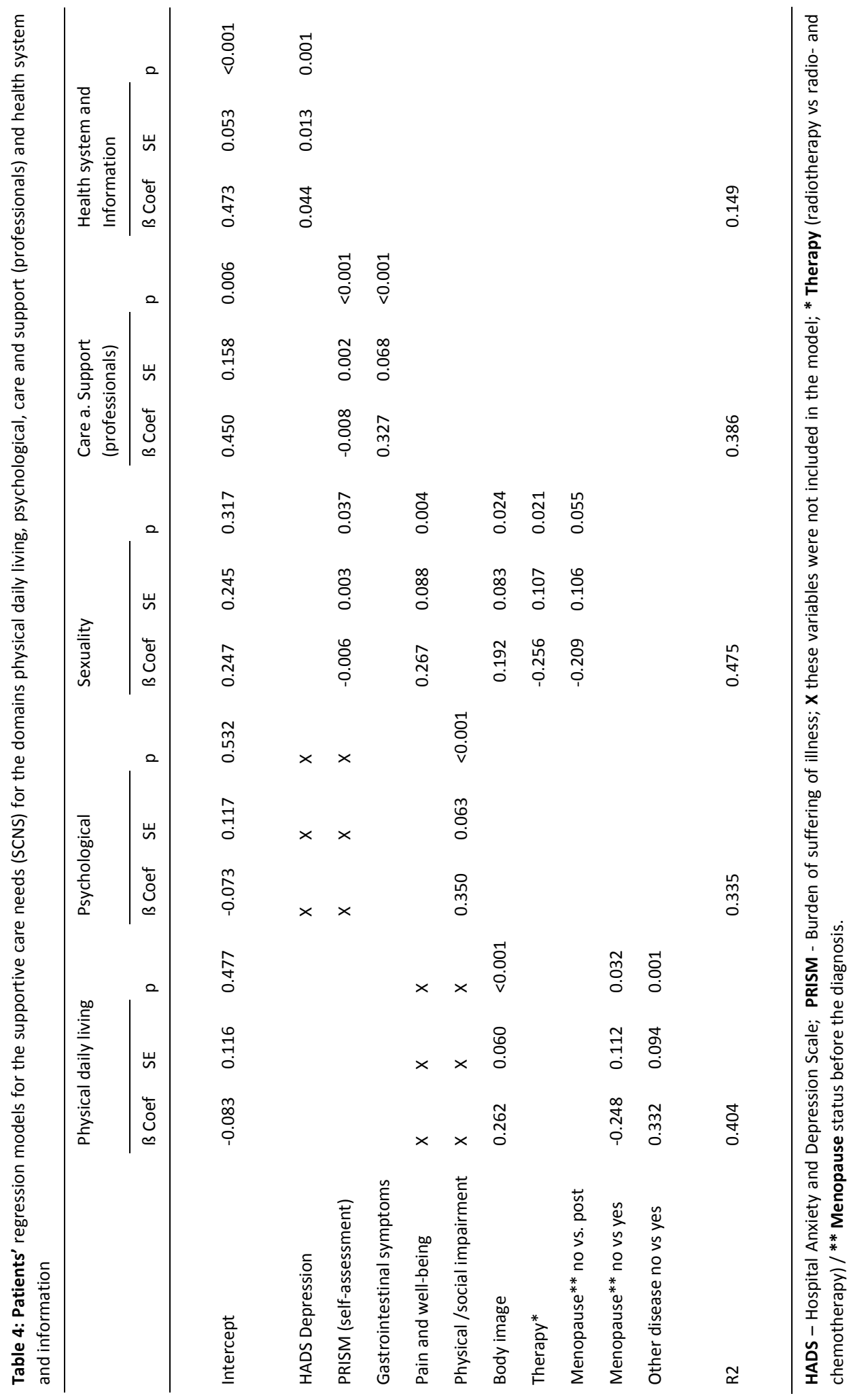




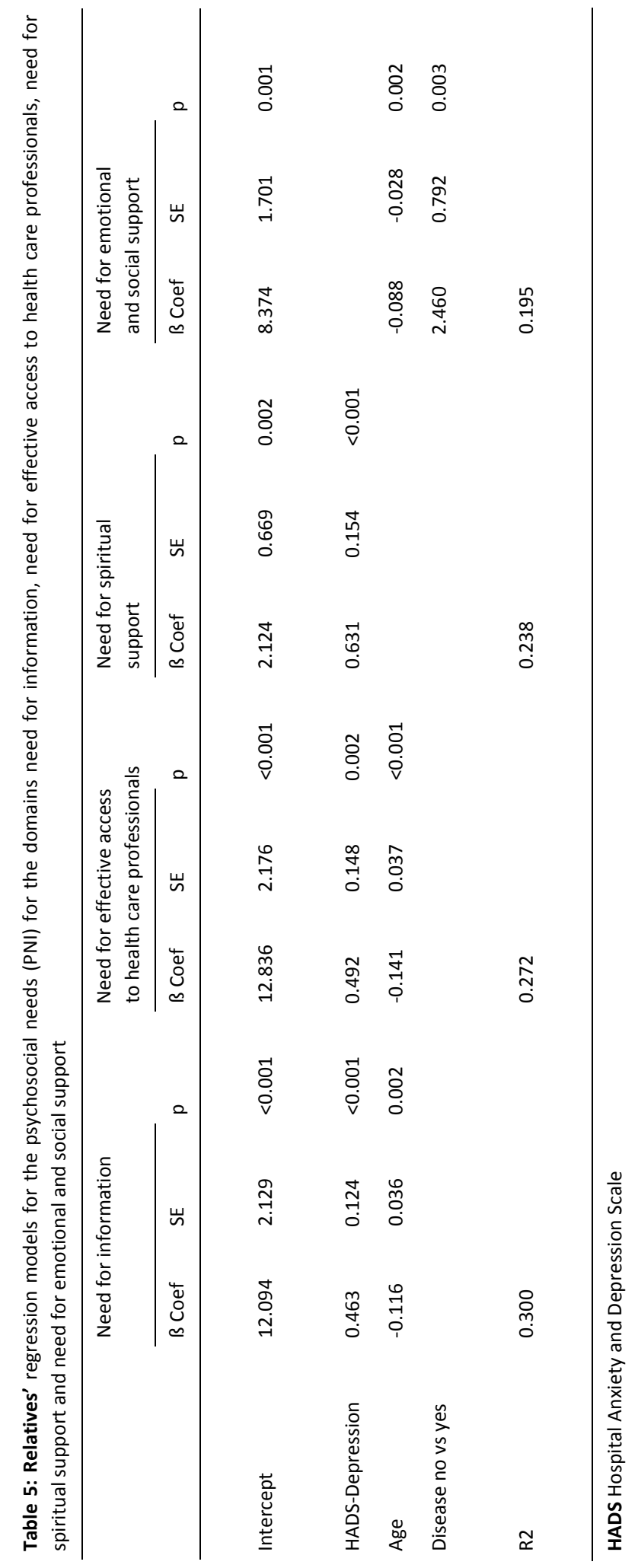




\section{DISCUSSION}

Approximately 1 year after finishing their medical treatment, patients with breast cancer still have a substantial need for help with specific problems related to the cancer and its treatment. Particular amongst these, psychological problems such as uncertainty, worry about the future and the course of the illness, fear of losing control, need to take care of relatives, and sexual problems indicate a need for help. The main problems for the patients are the cancer and cancer treatment-related symptoms such as fatigue and pain, whilst many feel impaired in their daily and social activities and have to deal with weight gain and a changed body image. These findings are confirmed by other studies (Hoybye et al. 2008, Northouse et al. 2002, Ribi et al. 2007). Patients have fewer needs related to access to the health care system and professionals and with information provided, probably because the treatment had already finished several months earlier.

In contrast to the patients, their relatives indicated in particular that they had high needs for information and they were not satisfied with the access to health care professionals or the support they received. Many wanted more information about the patient's disease and cancer treatment, and they had a need to participate more in choices concerning the treatment. They look to nurses and doctors who have time to listen to them for honest information, and they have a need to develop confidence in the clinical team. This is quite an alarming result exacerbated by their difficulties in finding a sense of purpose and meaning and developing hope for the future. Compared to the patients, relatives, mostly partners, have a significantly higher burden of suffering 1 year after treatment, identified both by patients and by relatives themselves. A possible explanation for the relatives' higher burden of suffering could be a divergence between their expectations that the patient would quickly return to normal post-treatment, making sense of breast cancer and moving back from the role of carer to partner (Lethborg et al. 2003). Other studies found that the feelings of being left out, not knowing how to provide effective support and feelings of guilt concerning their own needs were a great burden for relatives (Hilton et al. 2000, Hodgkinson et al. 2007a, Hodgkinson et al. 2007b, Lindholm et al. 2002, Samms 1999). Therefore, health care professionals must be aware that relatives have a need for specific types of information in order to be effective in their caregiving (Beaver \& Witham 2007).

Depression, the cancer and cancer treatment-related problems and burden of illness appear as the most relevant influencing factors identified by the patients' regression models. A higher level of depression in women is associated with greater need in respect of the health care system and information sources. Cancer and cancer treatment-related problems are associated with a higher demand for help in 
daily activities, psychological needs, sexuality and with needs regarding professional care and support.

One unexpected result was that lower burden of suffering in women is associated with greater needs concerning sexual issues, and the need for professional care and support. Furthermore, prior monotherapy with radiotherapy seems to increase needs regarding sexual issues and not the treatment with both radiotherapy and chemotherapy which is often considered more invasive. Sexuality is an important part of human life which can be altered by breast cancer and cancer treatment. On the other hand, staying sexually active can be an appropriate part of recovery from cancer and its treatment (Fobair \& Spiegel 2009; Herbenick et al. 2008). Therefore, as seen in our study, the decrease or increase in well-being, such as higher treatment-related symptoms, less invasive treatment or lower burden may improve the demand for help and appropriate counselling in sexual issues. It is important to counsel patients, when appropriate, to prevent or relieve problems with sexuality.

A substantial number of patients still have problems with anxiety, depression and high levels of distress. In other studies, depressive symptoms of women treated for breast cancer did not seem to be associated with objective cancer-related factors such as stage of disease and medical treatment (Bardwell et al. 2006), but fear for the future seems to predict reduced quality of life in breast cancer survivors (Lebel et al. 2007). Self-image, sense of control, and supportive relations may affect the course of long-term adjustment (Arman et al. 2002, Helgeson et al. 2004). There appears to be a substantial relationship between well-being, mood disturbance, level of depressive symptoms, subjective quality of life and social disruption shortly after treatment (Badger et al. 2004, Bardwell et al. 2006, Carver et al. 2005, Lebel et al. 2007). Early and appropriate psychosocial support and physical rehabilitation could enhance the cancer patients' quality of life, facilitate their adjustment process and possibly prevent them from developing chronic psychiatric disease (Dorval et al. 1998, Helgeson et al. 2004, Hodgkinson et al. 2007c, Kirshbaum 2007, Lebel et al. 2007).

Relatives' depression was found to be a relevant influencing factor for a higher need for information, more need for effective access to health care professionals and need for spiritual support. Younger age appeared to increase information needs for relatives as well as access to health care professionals and the need for emotional and social support. Relatives with health problems of their own had greater needs in respect of social support or in handling their emotions.

Our results confirm findings of qualitative studies showing that relatives of cancer patients perceive a specific existential trauma with feelings of helplessness, isolation, and the awareness that healthcare workers primarily focus on the patient, 
while they have to face their situation largely on their own (Hilton et al. 2000, Hodgkinson et al. 2007c, Samms 1999).

\section{Limitation}

This study has some limitations. The small sample of 72 pairs, a low response rate and the cross-sectional design limit the ability to generalize from the results. The regression models must be seen as preliminary models and the relationships between variables should be seen as association rather than as causal relationships. Collecting information from non-responders was not allowed. We do not know in what ways our sample was biased. The number of questions could have been overwhelming for some patients and relatives and may have contributed to the low response rate. Only 61 of the significant relatives lived in a relationship with the patient as a couple. Hence the relatives were not a homogenous sample and the group of the non-partnered relatives was too small to look for differences between them and the couples. The cross-sectional design of the study did not allow assessing changes over time. However, the results of the study suggest some issues pertinent to care and support for patients and relatives.

\section{Conclusion}

The study reveals opportunities for providing comprehensive breast cancer care both for cancer patients and their relatives. Patients' psychological problems, depression, burden of suffering and particularly high levels of treatment-related symptoms suggest substantial needs for ongoing supportive care and for well-directed and effective symptom management in clinical follow-up. Sexual problems should be an important issue in counselling. Clinicians should be aware of relatives' high needs for information and support. Therefore, continued assessment of psychological problems of the patients' and relatives' needs and of the patients' symptoms may provide a basis for purposeful counselling and education. Rehabilitation programmes should be developed for patients and their relatives and implemented in clinical practice, to support them in their long-term adjustment process.

\section{Conflict of interest}

The authors declare that there is no conflict of interest.

\section{Acknowledgement}

The authors thank the patients and their relatives who participated in this study for their valuable contributions. Thanks go to Dr. J. Eysell and A. Wolf for proofreading. Funding was provided in part by the Cancer League Zurich, Switzerland. 


\section{REFERENCES}

Arman M, Rehnsfeldt A, Lindholm L \& Hamrin E (2002) The face of suffering among women with breast cancer-being in a field of forces. Cancer Nurs 25, 96-103.

Badger TA, Braden CJ, Mishel MH \& Longman A (2004) Depression burden, psychological adjustment, and quality of life in women with breast cancer: patterns over time. Res Nurs Health 27, 19-28.

Bardwell WA, Natarajan L, Dimsdale JE, Rock CL, Mortimer JE, Hollenbach K \& Pierce JP (2006) Objective cancer-related variables are not associated with depressive symptoms in women treated for earlystage breast cancer. J Clin Oncol 24, 2420-2427.

Beaver K \& Witham G (2007) Information needs of the informal carers of women treated for breast cancer. Eur J Oncol Nurs 11, 16-25.

Bleiker EM, Pouwer F, van der Ploeg HM, Leer JW \& Ader HJ (2000) Psychological distress two years after diagnosis of breast cancer: frequency and prediction. Patient Educ Couns 40, 209-217.

Boehmke MM \& Dickerson SS (2006) The diagnosis of breast cancer: transition from health to illness. Oncol Nurs Forum 33, 1121-1127.

Bonevski B, Sanson-Fisher R, Girgis A, Burton L, Cook P \& Boyes A (2000) Evaluation of an instrument to assess the needs of patients with cancer. Cancer 88, 217-225.

Buchi S, Buddeberg C, Klaghofer R, Russi EW, Brandli O, Schlosser C, Stoll T, Villiger PM \& Sensky T (2002) Preliminary validation of PRISM (Pictorial Representation of Illness and Self Measure) - a brief method to assess suffering. Psychother Psychosom 71, 333-341.

Buchi S \& Sensky T (1999) PRISM Pictorial Representation of Illness and Self Measure. A brief nonverbal measure of illness impact and therapeutic aid in psychosomatic medicine. Psychosomatics 40, 314320.

Buchi S, Sensky T, Sharpe L \& Timberlake N (1998) Graphic representation of illness: a novel method of measuring patients' perceptions of the impact of illness. Psychother Psychosom 67, 222-225.

Carver CS, Smith RG, Antoni MH, Petronis VM, Weiss S \& Derhagopian RP (2005) Optimistic personality and psychosocial well-being during treatment predict psychosocial well-being among long-term survivors of breast cancer. Health Psychol 24, 508-516.

Dorval M, Maunsell E, Deschenes L, Brisson J \& Masse B (1998) Long-term quality of life after breast cancer: comparison of 8-year survivors with population controls. J Clin Oncol 16, 487-494.

Fobair P \& Spiegel D (2009) Concerns about sexuality after breast cancer. Cancer J 15, 19-26.

Forum Schweizerischer Verein für Frauen nach Brustkrebs "Leben wie zuvor", Forum, (2005) http://www.leben-wie-zuvor.ch/.

Helgeson VS, Snyder P \& Seltman H (2004) Psychological and physical adjustment to breast cancer over 4 years: identifying distinct trajectories of change. Health Psychol 23, 3-15.

Herbenick D, Reece M, Hollub A, Satinsky S \& Dodge B (2008) Young female breast cancer survivors: their sexual function and interest in sexual enhancement products and services. Cancer Nurs 31, 417-425.

Herrmann C (1997) International experiences with the Hospital Anxiety and Depression Scale--a review of validation data and clinical results. J Psychosom Res 42, 17-41.

Hilton BA, Crawford JA \& Tarko MA (2000) Men's perspectives on individual and family coping with their wives' breast cancer and chemotherapy. West J Nurs Res 22, 438-459.

Hodgkinson K, Butow P, Hobbs KM \& Wain G (2007a) After cancer: the unmet supportive care needs of survivors and their partners. J Psychosoc Oncol 25, 89-104.

Hodgkinson K, Butow P, Hunt GE, Pendlebury S, Hobbs KM \& Wain G (2007b) Breast cancer survivors' supportive care needs 2-10 years after diagnosis. Support Care Cancer 15, 515-523.

Hodgkinson K, Butow P, Hunt GE, Wyse R, Hobbs KM \& Wain G (2007c) Life after cancer: couples' and partners' psychological adjustment and supportive care needs. Support Care Cancer 15, 405-15.

Holdener-Mascheroni E (2003) The supportive care needs of cancer patients. Universiteit Maastricht, NL.

Hoybye MT, Dalton SO, Christensen J, Larsen LR, Kuhn KG, Jensen JN, Carlsen K \& Johansen C (2008) Research in Danish cancer rehabilitation: Social characteristics and late effects of cancer among participants in the FOCARE research project. Acta Oncol, 1-9. 
Jacobsen PB, Donovan KA, Trask PC, Fleishman SB, Zabora J, Baker F \& Holland JC (2005) Screening for psychologic distress in ambulatory cancer patients. Cancer 103, 1494-1502.

Kilpatrick MG, Kristjanson LJ, Tataryn DJ \& Fraser VH (1998) Information needs of husbands of women with breast cancer. Oncol Nurs Forum 25, 1595-1601.

Kirshbaum MN (2007) A review of the benefits of whole body exercise during and after treatment for breast cancer. J Clin Nurs 16, 104-121.

Kissane DW ,Clarke DM, Ikin J, Bloch S, Smith GC, Vitetta L \& McKenzie DP(1998) Psychological morbidity and quality of life in Australian women with early-stage breast cancer: a cross-sectional survey. Med J Aust 169, 192-196.

Lebel S, Rosberger Z, Edgar L \& Devins GM (2007) Comparison of four common stressors across the breast cancer trajectory. J Psychosom Res 63, 225-232.

Lethborg CE, Kissane D \& Burns WI (2003) 'It's not the easy part': the experience of significant others of women with early stage breast cancer, at treatment completion. Soc Work Health Care 37, 63-85.

Lewis FM, Fletcher KA, Cochrane BB \& Fann JR (2008) Predictors of depressed mood in spouses of women with breast cancer. J Clin Oncol 26, 1289-1295.

Lindholm L, Rehnsfeldt A, Arman M \& Hamrin E (2002) Significant others' experience of suffering when living with women with breast cancer. Scand J Caring Sci 16, 248-255.

Mathis-Jäggi $F$ (2003) Needs of relatives of patients with head and neck cancer Universiteit Maastricht, NL.

Mclllmurray MB, Thomas C, Francis B, Morris S, Soothill K \& Al-Hamad A (2001) The psychosocial needs of cancer patients: findings from an observational study. Eur J Cancer Care 10, 261-269.

McPhail G \& Smith LN (2000) Acute menopause symptoms during adjuvant systemic treatment for breast cancer: a case-control study. Cancer Nurs 23, 430-443.

McPhail G \& Wilson S (2000) Women's experience of breast conserving treatment for breast cancer. Eur J Cancer Care 9, 144-150.

Northouse LL, Mood D, Kershaw T,Schafenacker A, Mellon S, Walker J, Galvin E \& Decker V (2002) Quality of life of women with recurrent breast cancer and their family members. J Clin Oncol 20, 4050-4064.

Polit DF \& Hungler BP (1999) Nursing Research: Principles and Methods. Lippincott. Philadelphia, New York, Baltimore.

Rankin N, Newell S, Sanson-Fisher R \& Girgis A (2000) Consumer participation in the development of psychosocial clinical practice guidelines: opinions of women with breast cancer. Eur J Cancer Care (Engl) 9, 97-104.

Ribi K, Bernhard J, Rufibach K, Thurlimann B, von Moos R, Ruhstaller T, Glaus A \& Bohme C (2007) Endocrine symptom assessment in women with breast cancer: what a simple "yes" means. Support Care Cancer 15, 1349-1356.

Roth AJ, Kornblith AB, Batel-Copel L, Peabody E, Scher HI \& Holland JC (1998) Rapid screening for psychologic distress in men with prostate carcinoma: a pilot study. Cancer 82, 1904-1908.

Samms MC (1999) The husband's untold account of his wife's breast cancer: a chronologic analysis. Oncol Nurs Forum 26, 1351-1358.

Sanson-Fisher R, Girgis A, Boyes A, Bonevski B, Burton L \& Cook P (2000): The unmet supportive care needs of patients with cancer. Cancer 88, 226-237.

Schmid-Büchi S, Dassen T \& Halfens RJ (2005) Die Erfahrung an Brustkrebs zu erkranken, und wie die betroffenen Frauen ihr Leben wieder unter Kontrolle bringen. [Experiencing breast cancer and getting life under control again]. Pflege 18, 345-352.

Schmid-Büchi S, Halfens RJ, Dassen T \& van den Borne B (2008) A review of psychosocial needs of breastcancer patients and their relatives. Journal of Clinical Nursing 17, 2895-2909.

Sheppard C (2007) Breast cancer follow-up: literature review and discussion. Eur J Oncol Nurs 11, 340347.

Shimozuma K, Ganz PA, Petersen L \& Hirji K (1999) Quality of life in the first year after breast cancer surgery: rehabilitation needs and patterns of recovery. Breast Cancer Res Treat 56, 45-57. 
Soothill K, Morris SM, Harman J, Francis B, Thomas C \& Mclllmurray MB (2001) The significant unmet needs of cancer patients: probing psychosocial concerns. Support Care Cancer 9, 597-605.

Wen K \& Gustafson D (2004) Need assessment for cancer patients and their families Health Qual. Life Outcomes 2, 2-12.

Zigmond AS \& Snaith RP (1983) The hospital anxiety and depression scale. Acta Psychiatr Scand 67, 361370. 



\section{Chapter Five}

\section{Factors associated with}

\section{supportive care needs of patients under treatment for breast cancer}

Manuscript submitted as: Schmid-Büchi S, Halfens RJG, Müller M, Dassen T, van den Borne B. Factors associated with supportive care needs of patients under treatment for breast cancer. 


\section{ABSTRACT}

Aims. 1) To gain insight into the supportive care needs, cancer treatment-related symptoms, anxiety, depression and distress of patients under treatment for breast cancer, 2) to identify how the patients perceive their interpersonal relationship, and 3) to determine factors associated with supportive care needs.

Background. Breast cancer and its treatment cause emotional trauma and health complaints. For some patients these lead to supportive care needs while others are more able to cope with these consequences themselves. To be able to address these needs, it is important to identify patients' needs at the time they arise.

Design. Women with newly-diagnosed breast cancer, who are under treatment, participated in a cross-sectional survey.

Method. Data were collected from 175 patients in two Swiss breast cancer clinics. Standardized instruments were used: the Supportive Care Needs Survey (SCNSSF34), Cancer- and Cancer Treatment-related Symptom Scale (CTSS), the Hospital Anxiety and Depression Scale (HADS), the Distress-Thermometer (DT) and the Interpersonal Relationship Inventory (IPRI).

Results. The patients' highest needs for help were related to psychological issues. Many had treatment-related symptoms such as fatigue $(87.7 \%)$, hot flashes $(71.5 \%)$, and a changed body appearance (55.8\%). The majority suffered from distress (56.2\%), less from anxiety (24.1\%) and depression (12.1\%). Physical and social impairment, an impaired body image, distress, anxiety and depression, a lack of social support and conflicts in their personal relations were associated with supportive care needs.

Conclusions. The findings can help to identify more vulnerable patients with unsatisfied needs and a higher demand for support.

Relevance to clinical practice. Assessment of patients in need of help enables healthcare professionals to provide support and counselling. In these assessments, the patients' relationship to close relatives should also be addressed. Healthcare professionals should be skilled in handling relationship issues of breast cancer patients. 


\section{INTRODUCTION}

A diagnosis of breast cancer frequently causes an emotional trauma to patients which is reflected in increased feelings of vulnerability, loss of control and uncertainty (Arman et al. 2002, Schmid-Büchi et al. 2005). Patients experience stress and loss of energy. Cancer treatments such as surgery, chemo- / radio- and hormonal therapy may lead to a large number of health complaints and endocrine symptoms (Hoskins 1997, Hunter et al. 2004, Wengstrom et al. 2000). Patients need psychosocial support from close relatives and from healthcare professionals in order to manage the challenges of everyday life and complete an effective adjustment process (Landmark et al. 2008). To provide the best possible support, the experiences and needs of breast cancer patients must be understood. Equally important is to know more about factors that may influence the patients' needs. This knowledge may help to specify assessments and the real demand for support.

\section{Background}

Results from scientific research on the adjustment- and recovery process during and shortly after treatment for breast cancer are ambiguous. Schou et al. (2005) reported that women with breast cancer scored significantly lower on emotional-, cognitive- and social functioning than the general female population, even up to one year after surgery. On the other hand, DiSipio et al. (2008) found that the patients' quality of life was comparable to the general female population with the exception that younger patients perceived reduced emotional well-being. In a lot of research on the consequences and on the outcome of treatment of breast cancer, the patient's quality of life provides meaningful information, but used alone may not adequately assess persistent symptoms (Cleeland 2007, Ganz 2000, Ganz et al. 2004, Mols et al. 2005). The specific measurement of symptoms is more indicative and more important, because symptoms impose a significant burden upon the patient and frequently lead to specific care needs (Burkett \& Cleeland 2007, Henry et al. 2008). Fatigue, perceived cognitive impairment and mood problems were three symptom clusters identified by Bender et al. (2005) for breast cancer patients across different phases of the disease.

The patients' ability to successfully adapt to their diagnosis and treatment depends not only on their body's physical response but also on their emotional wellbeing (Bertero \& Chamberlain Wilmoth 2007). Patients may suffer from psychological distress, even if they have an early stage of breast cancer with a relatively good prognosis (Bleiker et al. 2000). Physical and psychological adjustment to breast cancer is not the same for all women. Some women steadily improved with time, whereas others show marked deteriorations in functioning (Helgeson et al. 2004). 
Due to considerable individual variability in the reaction of breast cancer patients to their illness and treatment, we do not know enough about why some patients have supportive care needs while others have no needs and why some women have unsatisfied needs. Identifying patients with unsatisfied needs in an early stage of their treatment provides the opportunity to address these needs and enhance the quality of care (Bonevski et al. 2000, Wen \& Gustafson 2004). Therefore, factors predicting patients' needs have to be identified. Unsatisfied needs and the patients' symptom burden has a significant impact on patients' well-being during treatment and also on their long-term adjustment (Holmes \& Warelow 1997, Janz et al. 2007, Wen \& Gustafson 2004). Generally it seems that the greatest change in adjustment occurs within a 4-13 month period after diagnosis (Helgeson et al. 2004). Emotional distress and problem-solving within 3-7 months following diagnosis significantly predict long-term emotional distress (Lebel et al. 2008). For that reason, professional support and counselling may be required and should begin as soon as possible. It is therefore clinically of prime importance to assess the patients' needs. Need assessment allows a direct measure of the discrepancy between the patients' experiences and expectations and their own perception of their need for help (Bonevski et al. 2000). If a need has been identified, action is recognised as desirable. Inaction may result in dissatisfaction and persistence of the need (Holmes \& Warelow 1997). Needs assessment helps clinicians in focusing their care very early on those issues considered most important by patients (Wen \& Gustafson 2004).

Close relatives are the most important source of support for patients with breast cancer (Marlow et al. 2003, Raupach \& Hiller 2002, Schmid-Büchi et al. 2005). Several studies demonstrate that the patients' perception of the close relatives' emotional involvement and supportive or unsupportive behaviour may influence their adjustment and recovery process (Figueiredo et al. 2004, Manne et al. 2005, Romero et al. 2008, Wimberly et al. 2005). Patients with more social support report better quality of life, while lack of social support is a risk factor for decreased psychological adjustment (Northouse et al. 2002, Pistrang \& Barker 1995). The perception of distress or the ability to discuss problems may affect the satisfaction with a relationship (Manne et al. 2006, Mesters et al. 1997). The experience with breast cancer may strengthen the patients' relationships, but research also showed that previously strong caring relationships suffered negative changes and can intensify pre-existing relationship problems (Holmberg et al. 2001). Tilden et al. (1994) found that existing measurements often only measure the network structures and perceived support. But in her opinion, reciprocity and conflict are part of human relationships, too (Tilden et al. 1994). Therefore, we should know more about the relationship issues of breast cancer patients and which aspects of relationship are important and how they are related to the patients' needs. 
There is a need to identify factors which may identify breast cancer patients early on who, while under treatment, are more vulnerable and have greater unsatisfied psychosocial needs, and therefore a higher demand for support and counselling.

\section{Aim}

The aim of this study was 1) to gain insight into supportive care needs, treatmentrelated symptoms, anxiety, depression and distress of breast cancer patients during their cancer treatment; 2) to identify how patients perceive their interpersonal relationships and 3 ) to determine factors associated with supportive care needs.

\section{METHODS}

\section{Research design}

Early breast cancer patients from two hospitals in the Zurich area of Switzerland were consecutively recruited for a cross-sectional survey in the breast cancer centre during the time they received cancer treatment.

\section{Sampling and research procedure}

For this study we consecutively approached all breast cancer patients of the two hospitals, who underwent cancer treatment such as chemotherapy and/or radiotherapy within 1-12 months after the breast cancer diagnosis. Nurses of the two hospitals contacted the patients and explained the study. Patients were eligible for participation if they signed the informed consent, were at least 18 years of age and were able to understand German. The study was explained to 279 potential participators. A total of 175 patients signed the informed consent and completed the questionnaire (response rate $62.7 \%$ ). Reasons not to participate in the survey were: some patients decided not to participate without giving any reasons, some had language problems and several had simply no time or were not interested and many were already engaged in medical studies and protocols. Ethics approval was obtained from the Institutional Review Board of the Canton of Zurich.

\section{Measures and instruments}

Supportive Care Needs Survey (SCNS-SF34) (Bonevski et al. 2000). Patients' care needs were measured with the validated German (Swiss) version of the SCNS (Holdener-Mascheroni 2003, Schmid-Buchi et al. 2009). The SCNS contains 34 items designed to measure patients' perceived care needs in five core domains: psycholo- 
gical needs (10 items, e.g. feelings about death and dying); health system and information needs (11 items, e.g. being given written information about the important aspects of your care); physical and daily living needs (5 items, e.g. not being able to do the things you used to do); patient care and support needs (5 items, e.g. staff attending promptly to your physical needs); and sexuality needs (3 items, e.g. information about changes in sexual relationships) (Sanson-Fisher et al. 2000). The patients indicated their need for help in the last month on a 5-point scale, scoring from no needs ( $1=$ no need for help or $2=$ satisfied / met needs), to some (unmet) needs ( $3=$ low need for help, $4=$ moderate and $5=$ high need for help).

The Cancer- and Cancer Treatment-related Symptom Scale (CTSS) was used to assess the patients' cancer- and cancer treatment-related symptoms (Schmid-Buchi et al. 2009). The validated 27 -item scale assesses the patients' cancer- and cancer treatment-related symptoms, complaints and impairments. The respondents were asked how impaired they had felt by these symptoms in the past month. The symptoms were measured on a 4-point scale ranging from not at all impaired (1) to very much impaired (4). The four main factors consist of gastrointestinal symptoms (6 items), pain and well-being (6 items), physical and social impairment (10 items) and body image (5 items).

The Interpersonal Relationship Inventory (IPRI) (Tilden et al. 1990a) consists of 39 items related to three domains of social support, reciprocity and conflict, each with 13 items. Twenty-two items are scored from strongly disagree (1) to strongly agree (5) and 17 from never (1) to very often (5). Respondents were asked whether they agree or disagree or how often something happened. The IPRI has been used in a wide variety of samples and is a valid and reliable instrument (Tilden et al. 1994, Tilden et al. 1990a, b). Douglass (1997) adapted the IPRI for married couples in the context of cancer. A German (Swiss) version of the Douglass instrument was used in our study to measure the patients' perceived quality of their interpersonal relationship. Our factor analysis with data of two studies confirmed the validity and reliability of the IPRI for the German (Swiss) version, i.e. principal component analysis (PCA); with oblimin rotation; with Kaiser- Meyer-Olkin measure of sampling adequacy ( $\mathrm{KMO}=0.938 ; \mathrm{n}=456$ ). Factor analysis with three factors explained $48 \%$ of the total variance. The Crohnbach's alpha coefficients were 0.91 for support, 0.79 for reciprocity and 0.86 for conflict.

Hospital Anxiety and Depression Scale (HADS) (Herrmann 1997, Zigmond \& Snaith 1983). The established and well-tested HADS assessed the patients' anxiety (7 items) and depression (7 items) (Herrmann 1997, Zigmond \& Snaith 1983). Participants were asked to indicate which of the four options (scores 0-3) came closest to describing how they had felt in the past week. The range of both scales is $0-21$. 
According to the HADS-criteria (Herrmann 1997, Zigmond \& Snaith 1983), scores of 8-10 on each subscale were taken to indicate a probable clinical anxiety or depression and scores $>10$ were taken to indicate clinical anxiety or depression.

Distress-Thermometer (DT). Distress was measured using the original version by Roth et al. (1998). The scale is a modified visual analog scale that looks like a thermometer and ranges from no distress (0) to extreme distress (10). The patients were asked to rate how distressed they had felt in the past week. Studies with cancer patients who completed the DT showed that a cut-off score of 4 had very good sensitivity and specificity (Jacobsen et al. 2005, Roth et al. 1998).

\section{Patients' characteristics}

Patients' demographic characteristics such as age, education, marital status and cancer treatment-related characteristics such as surgery and kind of treatment were assessed.

\section{Data analysis}

Statistical analysis was carried out using SPSS 15.0. Univariate statistics (means, scores, standard deviations, percentages) were used to describe the sample on several socio-demographic and clinical characteristics.

The main focus of our data analysis was to investigate 1) whether or not the patients needed help with a particular need as a result of having breast cancer and 2) whether or not a particular need was met. Therefore logistic regression analyses were conducted to compare patients 1 ) who had a need for help (response group) vs. patients with no needs (reference group) and also 2) to compare patients with unmet needs (response group) vs. patients with met needs (reference group). Outcome variables were the dichotomous variables of the five domains of the SCNS, 1) physical daily living, 2) psychological, 3) sexuality, 4) care and support and 5) health care and information. Predictor variables that may have an influence on the patients' supportive care needs were the scores of the HADS, Distress-Thermometer, the scores of the domains of the IPRI (support, reciprocity and conflict), the scores of the domains of the CTSS (gastrointestinal symptoms, pain and well-being, physical and social impairment and body image), the continuous variables age and months since diagnosis and the categorical variables like type of cancer treatment, education and the patients' marital status. Variables were eliminated using a backward selection method. The regression coefficients of the logistic regression models were transformed into odds ratios (OR) for easier interpretation. 


\section{RESULTS}

\section{Patients' characteristics}

One-hundred-seventy-five $(n=175)$ patients returned their questionnaires and contributed to this study. They were on average 57.5 years old (SD 11.4). The majority of the patients $(68.0 \%)$ were married or lived with a partner. More than eighty percent $(83.4 \%)$ had breast-conserving surgery and $16.6 \%$ a mastectomy. The patients were measured on average 4.2 months (SD, 2.6) after their cancer diagnosis during chemotherapy (14.3\%), most of them during radiotherapy (85.7\%). However, $38.4 \%$ of the radiotherapy patients had previous chemotherapy and $71.8 \%$ of the patients had additional endocrine therapy. More than sixty percent $(63.0 \%)$ had a primary or professional and $37.0 \%$ a higher or academic education.

\section{Patients' supportive care needs}

Table 1 shows that the patients had the highest need for help in the domains psychological, health care system and information and physical daily living during cancer treatment. Less important were the needs related to sexuality and to the care and support domain.

Examples of unmet psychological needs are: fear that the cancer will spread (31.8\%) and uncertainty about the future (31.0\%). Examples of unmet needs related to health care system and information are: being informed about things they could do to help themselves (24.1\%) and being given information about aspects of managing the illness and side effects at home (21.6\%).

\section{Patients' cancer- and treatment-related symptoms}

The most important cancer- and cancer treatment-related symptoms were physical and social impairments and body image problems (see table 1). Examples of problems with high ratings related to physical and social impairments were fatigue (87.7\%), body strains (83.0\%), impairments at work or daily activities (74.3\%) and problems with leisure activities (73.5\%). Examples of problems related to body image were changes in body appearance (55.8\%), body perception (55.5\%) and hot flashes (71.5\%). Less important were the domains pain and well-being and gastrointestinal symptoms. 
Table 1 Descriptive statistics for the supportive care need domains, patients'cancer- and cancer- treatment-related symptom domains and patients'perception of the interpersonal relationship with their close relative $(n=175)$

\begin{tabular}{lllll}
\hline & Min. & Max. & Mean & SD \\
\hline Patients' SCNS domains (Range 1-5) & & & & \\
Physical daily living & 1.00 & 5.00 & 1.97 & 0.87 \\
Psychological & 1.00 & 5.00 & 2.12 & 0.95 \\
Sexuality & 1.00 & 5.00 & 1.79 & 0.97 \\
Care and support & 1.00 & 4.60 & 1.75 & 0.63 \\
Health care system and information & 1.00 & 4.82 & 2.07 & 0.55 \\
Patients' CTSS domains (Range 1-4) & & & & \\
Gastrointestinal symptoms & 1.00 & 3.75 & 1.67 & 0.66 \\
Pain and well-being & 1.00 & 3.50 & 1.84 & 0.65 \\
Physical and social impairment & 1.00 & 3.70 & 2.11 & 0.68 \\
Body image & 1.00 & 3.80 & 1.98 & 0.76 \\
Patients' IPRI domains (Range 1-5) & & & & 0.53 \\
Social Support & 2.62 & 5.00 & 4.21 & 0.44 \\
Reciprocity & 2.62 & 4.92 & 3.88 & 0.55 \\
Conflict & 1.00 & 3.85 & 1.73 & \\
\hline
\end{tabular}

SCNS = Supportive Care Need Survey; CTSS = Cancer- and Cancer Treatment-related Symptom Scale; IPRI $=$ Interpersonal Relationship Inventory

\section{Interpersonal relationship}

The patients perceived a lot of social support and a high level of reciprocity in their interpersonal relationship but there were also conflicts (see table 1). Examples of the patients' perceived social support in their interpersonal relationship are: $m y$ close relative stands by me through good and bad times (97.0\%) and if I need my close relative's help, all I have to do is ask (96.4\%). Examples of lack of social support are: it is not safe for me to reveal my weakness to my close relative (34.7\%), and $22.6 \%$ of the patients answered the question I have enjoyable times with my close relative with no or, rather no. An example of the patients' perceived reciprocity is: I am available for my close relative when he/she needs to talk (95.2\%) and examples for the patients' problems with reciprocity are: my close relative comes to me for a boost of his/her spirit (37.2\%) and I put more effort into my close relative than he/she puts into me (36.7\%). Examples of low level of conflicts with their close relative were: my close relative is a burden for me (6.6\%) and I can't count on my close relative when I need to (7.1\%). Items which indicate some conflicts were: I wish my close relative would be more sensitive to my needs (40.7), further my close relative gets angry if we have different opinions (34.7\%) and I spend time doing things for my close relative when I'd really rather not (34.1\%). 


\section{Anxiety, depression and distress}

Nearly one-fourth $(24.1 \%)$ of the patients had a probable or clinical anxiety and 12.1\% a probable or clinical depression (scores 8-21 at the HADS- subscales). More than half $(56.2 \%)$ suffered from clinically-evident distress (scores of 4 or more on the DT) (see table 2).

Table 2 Scores of the HADS-Scale (anxiety and depression) and the Distress-Thermometer for breast cancer patients during medical treatment

\begin{tabular}{ll}
\hline & $\begin{array}{l}\text { Patients } \\
\mathrm{n}=175\end{array}$ \\
\hline Anxiety (Score) & $75.9 \%$ \\
no (0-7) & $13.2 \%$ \\
probable (8-10) & $10.9 \%$ \\
yes (11-21) & $5.13(4.07)$ \\
Mean (SD) & \\
Depression (Score) & $87.9 \%$ \\
no (0-7) & $8.1 \%$ \\
possible (8-10) & $4.0 \%$ \\
yes (11-21) & $3.29(3.40)$ \\
Mean (SD) & \\
Distress-Thermometer & $56.2 \%$ \\
Cut-off point $\geq 4$ & $4.38(2.72)$ \\
Mean (SD) & \\
\hline
\end{tabular}

\section{Predictors of patients' supportive care needs}

Table 3 gives the results of 5 logistic regression models with each of the supportive care needs of the SCNS (needs vs. no needs) as the dependent variable and sociodemographic and patient cancer- and cancer treatment-related symptoms (CTSS), HADS scores (anxiety and depression), distress (DT) score and the interpersonal relationship (IPRI) scores (social support, reciprocity, conflict) as predictor variables. Odds ratio (OR) for the predictor variables such as CTSS, HADS, DT and IPRI represent a 1-point increase in scores.

The most important variables which significantly predicted the supportive care needs were the treatment-related symptoms, such as impaired body image, physical and social impairment and gastrointestinal symptoms.

Needs for help in physical daily living were 3.78 (OR) times as likely, psychological needs were 2.79 (OR) times as likely and needs for help with sexual issues were 2.29 (OR) times as likely when the patients expressed higher body image impair- 
ments. Needs regarding sexuality were 1.95 (OR) times as likely when the patients had more gastrointestinal symptoms.

Table 3 Logistic regression analyses predicting presently-existing needs for care (yes vs. no) in 5 supportive care needs domains (SCNS) with psychosocial, cancer- treatment-related and socio-demographic and interpersonal relationship predictors in breast cancer patients during cancer treatment

\begin{tabular}{|c|c|c|c|c|c|c|c|}
\hline $\begin{array}{l}\text { Supportive care needs } \\
\text { (needs yes vs. no) }\end{array}$ & $\beta$ & SE $\beta$ & $\begin{array}{l}\text { Wald's } \\
\mathrm{X}^{2}\end{array}$ & df & $\begin{array}{l}\text { P- } \\
\text { value }\end{array}$ & $\begin{array}{l}\text { Odds } \\
\text { ratio }\end{array}$ & $95 \% \mathrm{Cl}$ \\
\hline \multicolumn{8}{|l|}{ 1. Physical daily living * $(n=163)$} \\
\hline Constant & 0.919 & 1.641 & 0.314 & 1 & 0.575 & & \\
\hline Distress & 0.243 & 0.079 & 9.553 & 1 & 0.002 & 1.27 & $1.09-1.49$ \\
\hline Impaired body image & 1.329 & 0.347 & 14.658 & 1 & $<0.001$ & 3.78 & $1.91-7.46$ \\
\hline IPRI Support & 0.918 & 0.389 & 5.580 & 1 & 0.018 & 0.40 & $0.19-0.85$ \\
\hline \multicolumn{8}{|l|}{ 2. Psychological ** ( $n=172)$} \\
\hline Constant & -3.926 & 0.772 & 25.87 & 1 & $<0.001$ & & \\
\hline Physical and social impairment & 0.978 & 0.321 & 9.286 & 1 & 0.002 & 2.66 & $1.42-4.99$ \\
\hline Impaired body image & 1.025 & 0320 & 10.252 & 1 & 0.001 & 2.79 & $1.49-5.22$ \\
\hline Education & 0.810 & 0.380 & 4.549 & 1 & 0.033 & 2.25 & $1.07-4.73$ \\
\hline \multicolumn{8}{|l|}{ 3. Sexuality $(n=169)$} \\
\hline Constant & -0.643 & 1.386 & 0.215 & 1 & 0.643 & & \\
\hline Gastrointestinal Symptoms & 0.669 & 0.276 & 5.850 & 1 & 0.016 & 1.95 & $1.13-3.54$ \\
\hline Impaired body image & 0.827 & 0.271 & 9.342 & 1 & 0.002 & 2.29 & $1.35-3.89$ \\
\hline $\begin{array}{l}\text { Marital status (married/close } \\
\text { relationship) }\end{array}$ & 1.228 & 0.437 & 7.901 & 1 & 0.005 & 3.41 & $1.45-8.04$ \\
\hline Age & -0.061 & 0.019 & 10.625 & 1 & 0.002 & 0.94 & $0.90-0.98$ \\
\hline \multicolumn{8}{|c|}{ 4. Care and support (professionals) $(n=172)$} \\
\hline Constant & -2.007 & 0.573 & 12.260 & 1 & $<0.001$ & & \\
\hline Physical and social impairment & 1.231 & 0.278 & 19.586 & 1 & $<0.001$ & 3.42 & $1.99-5.91$ \\
\hline \multicolumn{8}{|c|}{ 5. Health care system and information $(n=174)$} \\
\hline Constant & -0.612 & 0.918 & 0.445 & 1 & 0.505 & & \\
\hline Physical and social impairment & 1.613 & 0.540 & 8.936 & 1 & 0.003 & 5.02 & $1.74-14.50$ \\
\hline
\end{tabular}

1. Physical daily living: $\quad$ Model $X^{2} 52.134(d f=3) p<0.001, H-L X^{2} 12.005(d f=8) p=0.151$

2. Psychological: $\quad$ Model $X^{2} 46.744(d f=3) p<0.001, H-L X^{2} 13.442(d f=8) p=0.098$

3. Sexuality: $\quad$ Model $X^{2} 53.683(d f=4) p<0.001, H-L X^{2} 13.371(d f=8) p=0.100$

4. Care and support: $\quad$ Model $X^{2} 23.215(d f=1) p<0.001, H-L X^{2} 8.097(d f=8) p=0.424$

5. Health care system and information: Model $X^{2} 11.736(d f=1) p 0.001, H-L X^{2} 3.427(d f=8) p=0.098$ $\mathrm{H}-\mathrm{L}=$ Hosmer \& Lemeshow test; * Only the CTSS domain body image was included because of potential interdependence (multicollinearity) of items; ** The HADS scores (anxiety, depression) and the score of the Distress-thermometer were not ; included because of potential interdependence (multicollinearity) of items 
Psychological needs were 2.66 (OR), care and support needs were 3.42 (OR) times as likely and needs related to health care and information were 5.02 (OR) times as likely when physical and social impairments increased. Needs for help in physical daily living were $1.27(\mathrm{OR})$ times as likely when distress increased and less likely $(O R=0.40)$ when support increased. Needs with sexual issues seemed to be more likely for married or partnered patients than for patients who did not live in an intimate relationship. Younger patients seemed to more often have needs regarding sexual issues, and more highly-educated patients seemed to more often have psychological needs. The overall prediction rates of the models were between $70.3 \%$ and $91.4 \%$.

\section{Predictors of patients' need satisfaction}

Table 4 gives the results of 5 logistic regression models with each of the supportive care needs domains of the SCNS (unmet needs vs. met needs) as the dependent variable and demographic and patient cancer- and cancer treatment-related symptoms (CTSS), HADS sores (anxiety and depression), distress (DT) score, and the interpersonal relationship (IPRI) scores (social support, reciprocity, conflict) as predictor variables. Odds ratio (OR) for the predictor variables such as CTSS, HADS, DT and IPRI represent a 1-point increase in scores.

Distress, anxiety and depression and the interpersonal relationship in the five models were the most important significant variables which predicted the patients' unmet needs.

Unmet needs for help in physical and daily living were 1.25 (OR) times as likely and unmet needs regarding sexuality were 1.30 (OR) times as likely when distress increased. Unmet needs related to health care system and information were 1.24 (OR) times as likely when anxiety increased and unmet care and support needs 1.44 (OR) times as likely when depression increased. Unmet psychological needs were 3.34 (OR) times as likely when the patients felt more physical and social impairments. Unmet care and support needs were 3.13 (OR) times as likely and unmet needs related to health care system and information were 2.13 (OR) times as likely when the patients perceived higher conflict in the interpersonal relationship. Unmet needs related to sexuality were less likely $(O R=0.20)$ when the patients perceived more support in their relationship. Patients who were treated with chemo- and radiotherapy seemed more likely to have unmet care and support needs than patients who were treated solely with radiotherapy. Patient with less elapsed time since the cancer diagnosis seemed to have a higher likelihood for unmet psychological needs. The overall prediction rates of the models were between $65.2 \%$ and $74.5 \%$. 
The correct prediction rate of the models was moderate to good. Together with the significant overall tests of the parameters of the models and insignificant Hosmer \& Lemeshow $(\mathrm{H}-\mathrm{L})$ tests, they indicate an acceptable goodness of fit of the models (see tables 3 and 4).

Table 4 Logistic regression analyses predicting existing needs for care (unmet vs. met needs) in 5 supportive care needs domains (SCNS) with psychosocial, cancer- treatment-related,socio-demographic and interpersonal relationship predictors in breast cancer patients during cancer treatment

\begin{tabular}{|c|c|c|c|c|c|c|c|}
\hline $\begin{array}{l}\text { Supportive care needs } \\
\text { (unmet vs. met needs) }\end{array}$ & $\beta$ & SE $\beta$ & $\begin{array}{l}\text { Wald's } \\
x^{2}\end{array}$ & df & $\begin{array}{l}\mathrm{P}- \\
\text { value }\end{array}$ & $\begin{array}{l}\text { Odds } \\
\text { ratio }\end{array}$ & $95 \% \mathrm{Cl}$ \\
\hline \multicolumn{8}{|l|}{ 1. Physical daily living * $(n=141)$} \\
\hline Constant & -0.757 & 0.368 & 4.224 & 1 & 0.040 & & \\
\hline Distress & 0.226 & 0.071 & 10.146 & 1 & 0.001 & 1.25 & $1.09-1.46$ \\
\hline \multicolumn{8}{|l|}{ 2. Psychological ** $(n=150)$} \\
\hline Constant & -1.637 & 0.673 & 5.911 & 1 & 0.015 & & \\
\hline Physical and social impairment & 1.207 & 0.305 & 15.716 & 1 & $<0.001$ & 3.34 & $1.84-6.07$ \\
\hline Month since diagnosis & -0.219 & 0.072 & 9.287 & 1 & 0.002 & 0.80 & $0.70-0.92$ \\
\hline \multicolumn{8}{|l|}{ 3. Sexuality $(n=93)$} \\
\hline Constant & 5.896 & 2.368 & 6.200 & 1 & 0.013 & & \\
\hline Distress & 0.263 & 0.088 & 8.851 & 1 & 0.003 & 1.30 & $1.09-1.55$ \\
\hline IPRI Support & -1.579 & 0.552 & 8.171 & 1 & 0.004 & 0.20 & $0.07-0.61$ \\
\hline \multicolumn{8}{|c|}{ 4. Care and support (professionals) ( $n=137)$} \\
\hline Constant & -5.047 & 1.028 & 24.116 & 1 & $<0.001$ & & \\
\hline HADS Depression & 0.366 & 0.076 & 23.065 & 1 & $<0.001$ & 1.44 & $1.24-1.71$ \\
\hline IPRI Conflict & 1.140 & 0.411 & 7.675 & 1 & 0.006 & 3.13 & $1.41-7.00$ \\
\hline Chemo- and radiotherapy & 1.368 & 0.486 & 7.928 & 1 & 0.005 & 3.93 & $1.52-10.18$ \\
\hline \multicolumn{8}{|c|}{ 5. Health care system and information $(n=164)$} \\
\hline Constant & -3.319 & 0.709 & 21.896 & 1 & $<0.001$ & & \\
\hline HADS Anxiety & 0.218 & 0.48 & 20.429 & 1 & $<0.001$ & 1.24 & $1.13-1.37$ \\
\hline IPRI Conflict & 0.756 & 0.325 & 5.402 & 1 & 0.020 & 2.13 & $1.13-4.02$ \\
\hline
\end{tabular}

1. Physical daily living: $\quad$ Model $X^{2} 11.060(d f=1) p 0.001, H-L X^{2} 4.407(d f=7) p=0.732$

2. Psychological: $\quad$ Model $X^{2} 25.635(d f=2) p<0.001, H-L X^{2} 2.526(d f=8) p=0.961$

3. Sexuality: $\quad$ Model $X^{2} 19.334(d f=2) p<0.001, H-L X^{2} 11.012(d f=8) p=0.201$

4. Care and support: $\quad$ Model $X^{2} 37.956(d f=3) p<0.001, H-L X^{2} 6.655(d f=8) p=0.574$

5. Health care system and information: Model $X^{2} 29.969(d f=2) p<0.001, H-L X^{2} 3.349(d f=8) p=0.911$

$\mathrm{H}-\mathrm{L}=$ Hosmer \& Lemeshow test; * Only the CTSS domain body image was included because of potential interdependence (multicollinearity) of items; ** The HADS scores (anxiety, depression) and the score of the Distress-thermometer were not included because of potential interdependence (multicollinearity) of items 


\section{DISCUSSION}

This study evaluated the supportive care needs of breast cancer patients under treatment, the cancer- and cancer treatment-related symptoms and psychological problems and the perception of the patients' interpersonal relationship with their close relatives. The findings of our study demonstrated that the patients supportive care needs were predominantly related to the domains physical daily living, health care system and information, and to psychological needs. The findings indicate that many patients suffered from cancer and treatment-related symptoms and more than half suffered from clinically significant distress. The patients perceived support and reciprocity in their interpersonal relationship with their relatives but also conflicts.

Cancer- and cancer treatment-related symptoms such as physical and social impairment and impaired body image, psychological problems such as distress, anxiety and depression, and problems in the patient's relationships, such as a lack of support and conflicts, were the factors which were associated with patients' supportive care needs.

Patients with higher physical and social impairment and an impaired body image were found in five regression models to have more supportive care needs. Younger patients and patients living in a close relationship more likely had needs regarding sexuality. The results of our study demonstrate that cancer- treatment-related symptoms, primarily physical and social impairment and impaired body image, are the most important predictive factors which may identify patients who are more vulnerable and in need of help.

Although breast cancer patients often judge their general health as good (Hoybye et al. 2007), our study revealed a high prevalence of treatment-related side effects (e.g. fatigue, hot flashes, sleep disturbance and pain) while under treatment. Similar findings were found in other recent studies (Cappiello et al. 2007, Henry et al. 2008, Janz et al. 2007, Landmark et al. 2008, Ribi et al. 2007). These symptoms impose a significant burden on the patients and can have a profound impact on daily, social and work activities (Burkett \& Cleeland 2007, Henry et al. 2008, Holmberg et al. 2001, Knobf 2007) and may lead to specific needs. Hence, with regard to the predictive factors, particularly to physical and social impairment and impaired body image, early identification of women at risk of supportive care needs must be a key principle during their medical treatment (Helgeson et al. 2004, Knobf 2007). Also systematic and accurate assessment of cancer- and cancer treatment-related symptoms and well-directed symptom management is important to improve the patients' well-being and reduce the risk that treatment-related symptoms will persist. 
Important factors which distinguished patients with unmet needs from patients with met needs were emotional problems like distress, depression and anxiety. Also physical and social impairments were related to unmet needs regarding psychologi$c a l$ issues. In other recent studies, the emotional condition and the ability to maintain a daily routine played an important part in the improvement of the quality of life, whereas a higher symptom burden may decrease well-being (Budischewski et al. 2008, Gwede et al. 2008, Knobf 2007). Women with breast cancer who perceived an increased level of anxiety and intrusive thoughts and a large number of health complaints shortly after surgery were at risk of long-term psychological problems (Bleiker et al. 2000). Therefore, the assessment of distress, anxiety and depression may help identify patients with unmet needs early on. Psychological support and individual counselling could help them to satisfy their needs and improve the adjustment process.

Conflict in interpersonal relations was a factor associated with the patients' unmet needs, while perceived support was associated with fewer unmet needs. These predictive factors reached high odds ratios. The quality of social support in interpersonal relationships seems particularly important. Previous research also showed that a lack of confiding relationships was associated with longer episodes of depression, anxiety and impaired quality of life (Burgess et al. 2005, Ganz et al. 2002). Women who see their partner as remaining emotionally connected to them adjust better in marital, emotional and sexual areas (Wimberly et al. 2005).

Mutual and open communication between close relatives seems an important factor for better psychosocial and more positive rehabilitation outcomes and for more satisfaction in the relationship (Lewis 2006, Manne et al. 2006, Mesters et al. 1997). However, findings of studies which investigated close relatives of cancer patients (mostly spouses) showed that they sometimes felt left out and did not know how to provide effective support, whereas healthcare professionals primarily focused on the patient (Hilton et al. 2000, Hodgkinson et al. 2007a, Hodgkinson et al. 2007b, Lindholm et al. 2002, Samms 1999). Clinicians working with breast cancer patients should be aware of the relatives' problems and try to promote good communication patterns between the patient and their relatives and motivate the patient to involve their relatives in the illness- and treatment process. This may contribute to satisfying the patients' needs and promote the adjustment process of patients as well as of their relatives.

Breast cancer is a challenge but also an individual experience for each patient. Some patients are more, others less vulnerable. Not all patients need help in their adjustment process, but as seen in our study, many patients have supportive care needs and unsatisfied needs. It is important to identify patients with such needs early in their illness and treatment process. The factors developed in our research may help 
to identify patients with a higher need for help and to conduct targeted support to those who actually need it.

\section{Limitations}

Limitations of this study were that the patients had early-stage breast cancer with a relatively good prognosis and therefore the results cannot be generalized to other populations (e.g. patients with advanced or recurrent breast cancer). Bias may have occurred during the recruitment process. Nurses may not have contacted women they perceived as psychologically or physically too fragile. Furthermore, the crosssectional design of the study did not allow assessing changes in needs, problems, and processes taking place over time. Logistic regression models suggest causality, but these data are cross-sectional so that relationships between variables should be seen as associations. However, the results of the study suggest some issues pertinent to care and support for patients with breast cancer.

\section{Conclusion and clinical implications}

This study has identified factors which were significantly associated with supportive care needs of breast cancer patients. The results demonstrate that mainly distressed, anxious or depressed breast cancer patients with treatment-related symptoms or with a lack of support and conflicts in their interpersonal relationship during their initial cancer treatment may have needs for supportive care and a higher demand for help.

The results suggest a critical need for specific assessments and screenings in clinical routine, which may help to identify patients at risk of psychosocial problems and with unmet needs. Early detection of more vulnerable patients at risk and with unmet needs, resulting in timely and appropriate information, support and counselling, may help them to satisfy their needs. Health-care professionals must be knowledgeable about relationship issues with breast cancer patients. The patients' perception of their interpersonal relationship with their close relatives should be addressed. Specific assessment and care programs, including purposeful symptommanagement, counselling and education, should be developed to better support breast cancer patients particularly for the Swiss health care system,. Future research is needed to refine the models to determine more precisely which psychosocial variables are effective in promoting greater well-being and better adjustment to breast cancer and treatment. 
Conflict of interest

The authors declare that there is no conflict of interest

Acknowledgement

The authors thank the patients who participated in this study for their valuable contributions. Funding was provided in part by the Cancer League Zurich, Switzerland. 


\section{REFERENCES}

Arman M, Rehnsfeldt A, Lindholm L \& Hamrin E (2002) The face of suffering among women with breast cancer-being in a field of forces. Cancer Nurs 25, 96-103.

Bender CM, Ergyn FS, Rosenzweig MQ, Cohen SM \& Sereika SM (2005) Symptom clusters in breast cancer across 3 phases of the disease. Cancer Nurs 28, 219-225.

Bertero C \& Chamberlain Wilmoth M (2007) Breast cancer diagnosis and its treatment affecting the self: a meta-synthesis. Cancer Nurs 30, 194-202; quiz 203-194.

Bleiker EM, Pouwer F, van der Ploeg HM, Leer JW \& Ader HJ (2000) Psychological distress two years after diagnosis of breast cancer: frequency and prediction. Patient Educ Couns 40, 209-217.

Bonevski B, Sanson-Fisher R, Girgis A, Burton L, Cook P \& Boyes A (2000) Evaluation of an instrument to assess the needs of patients with cancer. Cancer 88, 217-225.

Budischewski K, Fischbeck S \& Mose S (2008) Quality of life of breast cancer patients in the course of adjuvant radiotherapy. Support Care Cancer 16, 299-304.

Burgess C, Cornelius V, Love S, Graham J, Richards M \& Ramirez A (2005) Depression and anxiety in women with early breast cancer: five year observational cohort study. Bmj 330, 702.

Burkett VS \& Cleeland CS (2007) Symptom burden in cancer survivorship. J Cancer Surviv 1, 167-175.

Cappiello M, Cunningham RS, Knobf MT \& Erdos D (2007) Breast cancer survivors: information and support after treatment. Clin Nurs Res 16, 278-293.

Cleeland CS (2007) Symptom burden: multiple symptoms and their impact as patient-reported outcomes. J Natl Cancer Inst Monogr, 16-21.

DiSipio T, Hayes S, Newman B \& Janda M (2008) Health-related quality of life 18 months after breast cancer: comparison with the general population of Queensland, Australia. Support Care Cancer 16, 1141-1150.

Douglass LG (1997) Reciprocal support in the context of cancer: perspectives of the patient and spouse. Oncol Nurs Forum 24, 1529-1536.

Figueiredo MI, Fries E \& Ingram KM (2004) The role of disclosure patterns and unsupportive social interactions in the well-being of breast cancer patients. Psychooncology 13, 96-105.

Ganz PA (2000) Quality of life across the continuum of breast cancer care. Breast J 6, 324-330.

Ganz PA, Desmond KA, Leedham B, Rowland JH, Meyerowitz BE \& Belin TR (2002) Quality of life in longterm, disease-free survivors of breast cancer: a follow-up study. J Nat/ Cancer Inst 94, 39-49.

Ganz PA, Kwan L, Stanton AL, Krupnick JL, Rowland JH, Meyerowitz BE, Bower JE \& Belin TR (2004) Quality of life at the end of primary treatment of breast cancer: first results from the moving beyond cancer randomized trial. J Natl Cancer Inst 96, 376-387.

Gwede CK, Small BJ, Munster PN, Andrykowski MA \& Jacobsen PB (2008) Exploring the differential experience of breast cancer treatment-related symptoms: a cluster analytic approach. Support Care Cancer 16, 925-933.

Helgeson VS, Snyder P \& Seltman H (2004) Psychological and physical adjustment to breast cancer over 4 years: identifying distinct trajectories of change. Health Psychol 23, 3-15.

Henry DH, Viswanathan HN, Elkin EP, Traina S, Wade S \& Cella D (2008) Symptoms and treatment burden associated with cancer treatment: results from a cross-sectional national survey in the U.S. Support Care Cancer 16, 791-801.

Herrmann C (1997) International experiences with the Hospital Anxiety and Depression Scale--a review of validation data and clinical results. J Psychosom Res 42, 17-41.

Hilton BA, Crawford JA \& Tarko MA (2000) Men's perspectives on individual and family coping with their wives' breast cancer and chemotherapy. West J Nurs Res 22, 438-459.

Hodgkinson K, Butow P, Hobbs KM \& Wain G (2007a) After cancer: the unmet supportive care needs of survivors and their partners. J Psychosoc Oncol 25, 89-104.

Hodgkinson K, Butow P, Hunt GE, Pendlebury S, Hobbs KM \& Wain G (2007b) Breast cancer survivors' supportive care needs 2-10 years after diagnosis. Support Care Cancer 15, 515-523.

Holdener-Mascheroni E (2003) The supportive care needs of cancer patients. Universiteit Maastricht, NL. 
Holmberg SK, Scott LL, Alexy W \& Fife BL (2001) Relationship issues of women with breast cancer. Cancer Nurs 24, 53-60.

Holmes CA \& Warelow PJ (1997) Culture, needs and nursing: a critical theory approach. J Adv Nurs 25, $463-470$.

Hoskins CN (1997) Breast cancer treatment-related patterns in side effects, psychological distress, and perceived health status. Oncol Nurs Forum 24, 1575-1583.

Hoybye MT, Dalton SO, Christensen J, Larsen LR, Kuhn KG, Jensen JN, Carlsen K \& Johansen C (2007) Research in Danish cancer rehabilitation: social characteristics and late effects of cancer among participants in the FOCARE research project. Acta Oncol, 1-9.

Hunter MS, Grunfeld EA, Mittal S, Sikka P, Ramirez AJ, Fentiman I \& Hamed H (2004) Menopausal symptoms in women with breast cancer: prevalence and treatment preferences. Psychooncology 13, 769778.

Jacobsen PB, Donovan KA, Trask PC, Fleishman SB, Zabora J, Baker F \& Holland JC (2005) Screening for psychologic distress in ambulatory cancer patients. Cancer 103, 1494-1502.

Janz NK, Mujahid M, Chung LK, Lantz PM, Hawley ST, Morrow M, Schwartz K \& Katz SJ (2007) Symptom experience and quality of life of women following breast cancer treatment. $J$ Womens Health (Larchmt) 16, 1348-1361.

Knobf MT (2007) Psychosocial responses in breast cancer survivors. Semin Oncol Nurs 23, 71-83.

Landmark BT, Bohler A, Loberg K \& Wahl AK (2008) Women with newly diagnosed breast cancer and their perceptions of needs in a health-care context. J Clin Nurs 17, 192-200.

Lebel S, Rosberger Z, Edgar L \& Devins GM (2008) Predicting stress-related problems in long-term breast cancer survivors. J Psychosom Res 65, 513-523.

Lewis FM (2006) The effects of cancer survivorship on families and caregivers. More research is needed on long-term survivors. Am J Nurs 106, 20-25.

Lindholm L, Rehnsfeldt A, Arman M \& Hamrin E (2002) Significant others' experience of suffering when living with women with breast cancer. Scand J Caring Sci 16, 248-255.

Manne SL, Ostroff J, Winkel G, Grana G \& Fox K (2005) Partner unsupportive responses, avoidant coping, and distress among women with early stage breast cancer: patient and partner perspectives. Health Psychol 24, 635-641.

Manne SL, Ostroff JS, Norton TR, Fox K, Goldstein L \& Grana G (2006) Cancer-related relationship communication in couples coping with early stage breast cancer. Psychooncology 15, 234-247.

Marlow B, Cartmill T, Cieplucha H \& Lowrie S (2003) An interactive process model of psychosocial support needs for women living with breast cancer. Psychooncology 12, 319-330.

Mesters I, van den Borne H, McCormick L, Pruyn J, de Boer M \& Imbos T (1997) Openness to discuss cancer in the nuclear family: scale, development, and validation. Psychosom Med 59, 269-279.

Mols F, Vingerhoets AJ, Coebergh JW \& van de Poll-Franse LV (2005) Quality of life among long-term breast cancer survivors: a systematic review. Eur J Cancer 41, 2613-2619.

Northouse LL, Mood D, Kershaw T, Schafenacker A, Mellon S, Walker J, Galvin E \& Decker V (2002) Quality of life of women with recurrent breast cancer and their family members. J Clin Oncol 20, 40504064.

Pistrang N \& Barker C (1995) The partner relationship in psychological response to breast cancer. Soc Sci Med 40, 789-797.

Raupach JC \& Hiller JE (2002) Information and support for women following the primary treatment of breast cancer. Health Expect 5, 289-301.

Ribi K, Bernhard J, Rufibach K, Thurlimann B, von Moos R, Ruhstaller T, Glaus A \& Bohme C (2007) Endocrine symptom assessment in women with breast cancer: what a simple "yes" means. Support Care Cancer 15, 1349-1356.

Romero C, Lindsay JE, Dalton WT, Nelson DV \& Friedman LC (2008) Husbands' perceptions of wives' adjustment to breast cancer: the impact on wives' mood. Psychooncology 17, 237-243.

Roth AJ, Kornblith AB, Batel-Copel L, Peabody E, Scher HI \& Holland JC (1998) Rapid screening for psychologic distress in men with prostate carcinoma: a pilot study. Cancer 82, 1904-1908. 
Samms MC (1999) The husband's untold account of his wife's breast cancer: a chronologic analysis. Oncol Nurs Forum 26, 1351-1358.

Sanson-Fisher R, Girgis A, Boyes A, Bonevski B, Burton L \& Cook P (2000) The unmet supportive care needs of patients with cancer. Cancer 88, 226-237.

Schmid-Büchi S, Dassen T \& Halfens RJ (2005) Die Erfahrung an Brustkrebs zu erkranken, und wie die betroffenen Frauen ihr Leben wieder unter Kontrolle bringen. [Experiencing breast cancer and getting life under control again]. Pflege 18, 345-352.

Schmid-Buchi S, Halfens RJ, Dassen T \& van den Borne B (2009) Psychosocial problems and needs of posttreatment patients with breast cancer and their relatives. Eur $J$ Oncol Nurs, 10.1016/j.ejon.2009.11.001.

Schou I, Ekeberg O, Sandvik L, Hjermstad MJ \& Ruland CM (2005) Multiple predictors of health-related quality of life in early stage breast cancer. Data from a year follow-up study compared with the general population. Qual Life Res 14, 1813-1823.

Tilden VP, Hirsch AM \& Nelson CA (1994) The Interpersonal Relationship Inventory: continued psychometric evaluation. J Nurs Meas 2, 63-78.

Tilden VP, Nelson CA \& May BA (1990a) The IPR inventory: development and psychometric characteristics. Nurs Res 39, 337-343.

Tilden VP, Nelson CA \& May BA (1990b) Use of qualitative methods to enhance content validity. Nurs Res 39, 172-175.

Wen K \& Gustafson D (2004) Need assessment for cancer patients and their families Health Qual. Life Outcomes 2, 2-12.

Wengstrom Y, Haggmark C, Strander H \& Forsberg C (2000) Perceived symptoms and quality of life in women with breast cancer receiving radiation therapy. Eur J Oncol Nurs 4, 78-88; discussion 89-90.

Wimberly SR, Carver CS, Laurenceau JP, Harris SD \& Antoni MH (2005) Perceived partner reactions to diagnosis and treatment of breast cancer: impact on psychosocial and psychosexual adjustment. $J$ Consult Clin Psychol 73, 300-311.

Zigmond AS \& Snaith RP (1983) The hospital anxiety and depression scale. Acta Psychiatr Scand 67, 361370. 


\section{Chapter Six}

\section{Factors associated with}

psychosocial needs of close

relatives of women under

treatment for breast cancer

Manuscript in press as: Schmid-Büchi S, van den Borne B, Dassen T, Halfens RJG (2010). Factors associated with psychosocial needs of close relatives of women under treatment for breast cancer. Journal of Clinical Nursing. 


\section{ABSTRACT}

Aims. 1) To gain insight into the psychosocial needs and distress of close relatives of women under treatment for breast cancer and identify how they perceive the interpersonal relationship with the patient and 2) to determine factors associated with the relatives' psychosocial needs.

Background. Breast cancer affects patients but also close relatives. Relatives need support themselves but there is still a lack of knowledge about their specific needs.

Design. Relatives of women newly-diagnosed with breast cancer participated in a cross-sectional survey.

Method. Relatives were approached by patients, who were contacted by nurses in two Swiss breast cancer clinics. The patients received the questionnaire for their closest relative, who decided independently of the patient about participation. Standardised questionnaires were completed by 107 relatives.

Results. The relatives needed help with access to information and health care professionals. They needed information about the patients' treatment (50.9\%), honest information (41.6\%) and had difficulties with confidence in healthcare professionals (39.2\%). The majority (61.0\%) suffered from distress, less (26.1\%) from anxiety and depression (10.9\%). Distress, anxiety and conflict in their interpersonal relationship were associated with the relatives' unmet psychosocial needs.

Conclusions. The findings increase the knowledge of the psychosocial needs of relatives of breast cancer patients and provide the basis for purposeful support. Distress, anxiety and conflicts in the relationship are important factors which may identify more vulnerable relatives with unmet needs or a higher demand for support.

Relevance to clinical practice. Assessment of the relatives' specific needs, distress and anxiety is important and the relatives' perception of their relationship should be addressed. Healthcare professionals are key persons in contact with relatives and should motivate the patients to involve their relatives in the illness and treatment process. Support programs for relatives of breast cancer patients should be developed in Swiss cancer clinics. 


\section{INTRODUCTION}

A diagnosis of breast cancer frequently causes an emotional trauma to patients which is reflected in increased feelings of vulnerability, loss of control and uncertainty (Arman et al. 2002, Schmid-Büchi et al. 2005). Patients experience a large number of health complaints caused by the illness and the demands of treatment (Hoskins 1997, Hunter et al. 2004, Landmark et al. 2008, Wengstrom et al. 2000). Patients need psychosocial support to manage the challenges of everyday life (Landmark et al. 2008). However, breast cancer also affects close relatives. There is a need to know more about how they overcome cancer-related problems (Dalton et al. 2007) .

For women with breast cancer, close relatives are the most important source of support (Marlow et al. 2003, Raupach \& Hiller 2002, Schmid-Büchi et al. 2005). Close relatives' positive support can improve the patients' adjustment process and quality of life (Foy \& Rose 2001, Northouse et al. 2002), while relatives' unsupportive reactions are related to emotional and social problems (Figueiredo et al. 2004). However, the relatives are not merely providers of support, they are affected by their partners' illness and in need of support themselves (Hodgkinson et al. 2007b).

\section{Close relatives of breast cancer patients}

The life-threatening nature of breast cancer and the side effects of the patient's treatment also place great strains on relatives. They often feel unprepared to cope with this life crisis (Lethborg et al. 2003). Lindholm et al. (2002) found that close relatives often experience unrelieved suffering and they live in an area of conflict between the women's and their own suffering. Many have no confidence in being able to support their partner/ the patient (Lethborg et al. 2003).

The patient's cancer changes the relative's life and they place themselves in a new role of caregiver. They perceive their responsibility, focus on the patient's health and care and deal with care providers (Hilton et al. 2000, Wagner et al. 2006). Further they are challenged and conflicted, balancing work and home and have fears affecting their job performance (Hilton et al. 2000, Lethborg et al. 2003, Lewis et al. 2008, Lindholm et al. 2002, Samms 1999, Wagner et al. 2006). Husbands of patients with breast cancer experience worse psychological well-being, poorer health and feel more tired or worn out, compared to spouses of healthy women who do not suffer from breast cancer (Wagner et al. 2006).

Supporting a spouse, relative or friend though cancer can be a traumatic experience which may influence the interpersonal relationship with the patient (Lethborg et al. 2003). Relationship satisfaction is an important predictor for close relatives' and patients' well-being and adjustment-process (Northouse et al. 1995, Yang $\&$ Schuler 2009). On the other hand, research on the effectiveness of close relati- 
onships reveals limits in times of severe crisis (Bolger et al. 1996). Hence, Tilden et al. (1994) found that existing measurements often only measure the network structures and perceived support. But in their opinion, reciprocity as well as conflict is part of human relationships. To increase the understanding of the psychosocial needs and strengths of close relatives, an assessment of their perceived relationship with the patient is needed to support these relatives better.

Close relatives' perceptions, psychological problems and relationship in general when faced with breast cancer require more attention (Budischewski et al. 2008, Dalton et al. 2007, Hodgkinson et al. 2007b, Wagner et al. 2006). There is still a lack of knowledge about this specific population (Hodgkinson et al. 2007b, Wagner et al. 2006). Close relatives' adjustment to the patients' breast cancer may be compared to the adjustment and well-being of the patients (Wagner et al. 2006). Close relatives have needs they share with the patients but also have their own and unique needs (Hodgkinson et al. 2007b). There are few studies assessing their specific needs. It is important to assess the close relatives' needs, allowing a direct measure of the discrepancy between the close relatives' experiences and expectations and their own perception of their need for help (Bonevski et al. 2000). Need assessment may help clinicians to focus their care on those issues considered very important by relatives (Wen \& Gustafson 2004).

Furthermore, little is known about what predicts which relatives will be more vulnerable or will need more psychosocial support (Dalton et al. 2007, Lewis et al. 2008). Close relatives with significant unmet needs should be identified, since these relatives can be seen as an at-risk group who require extra attention (Wagner et al. 2006).

\section{Aims}

Therefore the aim of this study was 1) to gain insight into the psychosocial needs, anxiety, depression and distress of close relatives of women under treatment for breast cancer, 2) to identify the close relative's perception of his or her interpersonal relationship with the patient and 3) to determine factors associated with close relatives' psychosocial needs.

\section{METHODS}

\section{Research design}

Close relatives were approached for a cross-sectional survey through patients ( $n=175$ ) with newly-diagnosed breast cancer who participated in a survey. Data were collected during the time when patients of two hospitals in the Zurich, Swit- 
zerland, area (University Hospital Zurich, Cantonal Hospital Winterthur) received their cancer treatment.

\section{Sampling and research procedure}

Between October 2005 - February 2007, nurses of the two hospitals contacted the patients, explained the study and asked the patients to invite their close relative for participation. A relative was defined as a close person who was emotionally involved with the patient and identified by the patient as her primary source of emotional and physical support (adapted from Hilton et al. 2000, Northouse et al. 2002). Relatives were eligible for participation if they signed the informed consent, were at least 18 years of age and were able to understand German. One hundred-fifty-nine $(n=159)$ patients agreed to hand-over the written study information and the questionnaire to their closest relative. The close relative decided independently of the patient about his or her participation. A total of 107 relatives $(67.9 \%)$ signed the informed consent and completed the questionnaire. Reasons for the patients' relatives not to participate in the survey were: some relatives decided not to participate without giving any reasons, others considered the questions as too personal, had language problems or just had no time. Ethics approval was obtained from the Institutional Review Board of the Canton of Zurich.

\section{Measures and instruments}

The 51-item German version (Mathis-Jäggi 2003) of the Psychosocial Need Inventory (PNI) (Soothill et al. 2001) was used to measure the relatives' needs. The PNI measures the unmet psychosocial needs of cancer patients' caregivers. Each need item has two scales, assessing first the importance of the need item scored from no need (0), not at all important (1), to very important (5). The second scale measures the level of satisfaction with the need having been met during the last weeks, scored from very satisfied (1) to not at all satisfied (5). Subsequently, the importance of each need-item of the scale was multiplied by the level of satisfaction with the need-item having been met. Factor analysis using Principal Component Analysis (PCA) with oblimin rotation revealed five domains of relatives needs, namely: 1 ) need for information (6 items, e.g. information about treatment plans); 2 ) need for effective access to health care professionals (11 items e.g. nurses or doctors who have time to discuss issues with me); 3 ) need for spiritual support (5 items e.g. support from people of my faith); 4) need for emotional and social support (24 items e.g. help in maintaining a sense of control in my life or e.g. support from the family); and 5) need for practical support (5 items e.g. help with child care). The total variance explained was 56\% and Cronbach's alpha coefficients ranged from 0.73-0.95. 
Hospital Anxiety and Depression Scale (HADS) (Herrmann 1997, Zigmond \& Snaith 1983). The established and well-tested HADS assessed the relatives' anxiety (seven items) and depression (seven items) (Herrmann 1997, Zigmond \& Snaith 1983). Participants were asked to indicate which of the four options (scores $0-3$ ) came closest to describing how they had felt in the past week. The range of both scales is 0-21. According to the HADS-criteria (Herrmann 1997, Zigmond \& Snaith 1983), scores of 8-10 on each subscale were taken to indicate a probable clinical anxiety or depression and scores $>10$ were taken to indicate clinical depression or anxiety.

Distress-Thermometer (DT). Distress was measured using the original version of Roth et al. (1998). The scale is a modified visual analog scale that looks like a thermometer and ranges from no distress (0) to extreme distress (10). The relatives were asked to rate how distressed they had felt in the past week. Studies with cancer patients who completed the DT showed that a cut-off score of 4 had an optimal sensitivity and specificity (Jacobsen et al. 2005, Roth et al. 1998).

The Interpersonal Relationship Inventory (IPRI) (Tilden et al. 1990a) consists of 39 items related to three domains namely, social support, reciprocity and conflict, each with 13 items. Twenty-two items are scored from strongly disagree (1) to strongly agree (5) and 17 from never (1) to very often (5). Respondents were asked whether they agree or disagree or how often something happened. The IPRI has been used in a wide variety of samples and is a valid and reliable instrument (Tilden et al. 1994, Tilden et al. 1990a, b). Douglass (1997) adapted the IPRI for married couples in the context of cancer. A German version of the Douglass instrument was used in our study to measure the relatives' perceived quality of the interpersonal relationship. We could confirm the validity and reliability of the instrument for the German version. The factor analysis (PCA oblimin rotation) with three factors explained $47.9 \%$ of the total variance. The Crohnbach's alpha coefficients were 0.91 for support, 0.79 for reciprocity and 0.86 for conflict.

Further, the relatives' demographic characteristics such as age, education, kind of relationship to the patient and months since the patients' diagnosis were assessed.

\section{Data analysis}

Statistical analysis was carried out using SPSS 15.0. Univariate statistics (means, scores, standard deviations, percentages) were used to describe the sample on several socio-demographic and clinical characteristics. To analyse factors associated with the relatives' needs, correlation coefficients and multiple regression models were calculated for each of the outcome variables (mean-scores) of the PNI domains, namely for 1 ) information, 2) access to health care professionals, 3) spiritual 
support, 4) emotional and social support and 5) practical help). The mean scores of the three domains of the IPRI (support, reciprocity, conflict), the scores of the two HADS-Scales (anxiety and depression), the value of the Distress-Thermometer, the continuous variables age, months since the patients' diagnosis and the categorical variable education (primary $=0$ vs. high $=1$ ) were included in each model as 'predictors' or covariables. Variables were eliminated using a backward selection method. The adequacy of the models was assessed with residual plots.

\section{RESULTS}

\section{Close relatives' characteristics}

One-hundred-seven close relatives returned their questionnaires and contributed to this study on average 4.2 months (SD 2.6) after the patients' cancer diagnosis. The majority of the close relatives were members of the nuclear family, such as the patient's husband or partner (64.1\%), daughter or son (17.5\%), sister, brother or a parent $(8.7 \%)$ only $9.7 \%$ were not family members. Two-thirds of the close relatives were males (66.7\%). They were on average 54.1 years old (SD 15.2), half of them had a primary or professional education (52.4\%), the others a higher or academic education (47.6\%).

\section{Relatives' needs}

Table 1 shows that relatives had a fairly high level of unmet needs regarding access to information and healthcare professionals. Standard deviations for these two need domains are high, indicating that some relatives have very high needs in these areas. Examples of significant unmet information needs are: 'need for information about patient's medication and side effects' (50.9\%), 'information about what to expect' (49.5\%), 'a need for honest information' (41.6\%) and 'difficulties with confidence in the health professionals such as doctors and nurses' (39.2\%). Examples of unmet needs regarding access to health care professionals are: 'healthcare professionals who treat me with respect' (doctors, 35.2\%, nurses $25.0 \%$ ) and 'have time to discuss problems with me' (doctors, $34.3 \%$, nurses $21.2 \%$ ), 'to get advice on what services and help are available' (34.0\%) and 'opportunities to participate in choices concerning treatment' (31.7\%).

Needs related to spirituality, emotion and support network and needs for practical help received lower ratings (Table 1 ). The highest-rated unmet need regarding spirituality is: 'help to develop hope for the future' $(40.4 \%)$ The two highest-rated unmet needs regarding emotion and support network are: 'to have time for myself' 
(32.9\%) and 'help in dealing with the unpredictability' (32.3\%). The highest-rated need regarding practical help is: 'help with housework' (15.5\%).

Table 1 Descriptive statistics of close relatives' psychosocial need domains and relatives' perceived interpersonal relationship with the patients $(n=107)$

\begin{tabular}{llll}
\hline & Max. & Mean & \\
\hline & & & \\
Relative PNI domains (Range 0-25) & 23.00 & 8.56 & 4.34 \\
Information & 16.82 & 6.13 & 3.68 \\
Access to healthcare professionals & 12.92 & 4.02 & 4.29 \\
Spirituality & 11.00 & 3.86 & 3.04 \\
Emotions and support network & 11.00 & 2.57 & 3.08 \\
Practical help & & & \\
Relative IPRI domains (Range 1-5) & 5.00 & 4.18 & 0.50 \\
Social Support & 4.92 & 4.03 & 0.46 \\
Reciprocity & 3.69 & 1.83 & 0.56 \\
Conflict & & & \\
\hline
\end{tabular}

PNI=Psychosocial Need Inventory / IPRI=Interpersonal Relationship Inventory

\section{Interpersonal relationship}

In general, the close relatives perceived a high level of social support and reciprocity in their interpersonal relationship with the partner/ patient. However they also perceived conflicts (see Table 1). Examples of the close relatives' perceived social support in their interpersonal relationship are: 'my close person (patient) stands by me through good and bad times' (96.7\%) and 'I can talk openly about anything with my close person' (91.5\%). Examples of lack of social support are: 'it's not safe for me to reveal my weakness to her' $(49.5 \%)$ and $37.4 \%$ answers to the question 'she (the patient) makes me feel confident in myself' with no or rather no. An example of the relatives' perceived reciprocity is: 'I am available for my close person when she needs to talk' (94.4\%); and an example of problems with reciprocity is: 'I put more effort into her than she puts into me' (43.0\%). Examples of conflicts with the patient are: 'she gets angry if we have different opinions' (51.9\%), 'I spend time doing things for her when I'd really rather not' (40.6\%) and 'I wish she would be more sensitive to my needs' (39.0\%). Statements suggesting less conflict are: 'I can't count on my relative when I need to' $(5.7 \%)$ and 'my relative is a burden for me' (9.5\%). 


\section{Anxiety, depression and distress}

More than one-fourth of the close relatives (26.1\%) had a probable or clinical anxiety and $10.3 \%$ of the relatives were found to have symptoms of probable or clinical depression (scores 8-21 on the HADS- subscales). More than sixty percent of the relatives $(61.0 \%)$ suffered from clinically-evident distress (score of 4 or more on the DT) (Table 2).

Table 2 Scores of the HADS-Scale (anxiety and depression) and of the Distress-Thermometer for close relatives of breast cancer patients under treatment

Relatives

$\mathrm{n}=107$

$\begin{array}{ll}\text { Anxiety (Score) } & \\ \text { no (0-7) } & 73.9 \% \\ \text { probable (8-10) } & 14.0 \% \\ \text { yes (11-21) } & 12.1 \% \\ \text { Mean (SD) } & 5.66(3.62) \\ \text { Depression (Score) } & \\ \text { no (0-7) } & 89.7 \% \\ \text { probable (8-10) } & 8.4 \% \\ \text { yes (11-21) } & 1.9 \% \\ \text { Mean (SD) } & 3.37(3.09) \\ \text { Distress-Thermometer } & \\ \text { Cut-off point } \geq 4 & 61.0 \% \\ \text { Mean (SD) } & 4.55(2.61)\end{array}$

\section{Factors associated with breast cancer patients' relatives' psychosocial needs}

Correlation coefficients were calculated for each of the five domains of psychosocial needs (outcome variables) and between distress, anxiety, depression, social support, reciprocity, conflict, the relatives' age and months since the patients' breast cancer diagnosis (independent variables). The psychological variables such as distress, anxiety and depression were significantly and positively correlated with all five outcome variables. Conflict in the interpersonal relationship was significantly and positively correlated with four of the five psychosocial need domains. The relatives' age was significantly and negatively correlated with the domains 'need for information' and 'need for emotional and social support' (Table 3). 
Table 3 Correlations between 5 psychosocial need domains (PNI) and psychological variables, interpersonal relationship variables and relatives' age and months since the patients' breast cancer diagnosis

\begin{tabular}{|c|c|c|c|c|c|}
\hline & $\begin{array}{l}\text { 1. Need for } \\
\text { information } \\
\text { Correlations }\end{array}$ & $\begin{array}{l}\text { 2. Need for } \\
\text { effective } \\
\text { access to } \\
\text { health care } \\
\text { professionals } \\
\text { Correlations }\end{array}$ & $\begin{array}{l}\text { 3. Need for } \\
\text { spiritual } \\
\text { support }\end{array}$ & $\begin{array}{l}\text { 4. Need for } \\
\text { emotional } \\
\text { and social } \\
\text { support } \\
\text { Correlations }\end{array}$ & $\begin{array}{l}\text { 5. Need for } \\
\text { practical help }\end{array}$ \\
\hline Distress (DT) & $0.262 * *$ & $0.281 * *$ & $0.220 *$ & $0.362^{* *}$ & $0.278 * *$ \\
\hline HADS Anxiety & $0.275^{* *}$ & $0.217^{*}$ & $0.391^{* *}$ & $0.580 * *$ & $0.332 * *$ \\
\hline HADS Depression & $0.254^{*}$ & $0.242^{*}$ & $0.276 * *$ & $0.482 * *$ & $0.338^{* *}$ \\
\hline IPRI Support & -0.052 & 0.017 & $-0.201^{*}$ & -0.074 & -0.119 \\
\hline IPRI Reciprocity & -0.53 & 0.074 & -0.174 & 0.097 & -0.144 \\
\hline IPRI Conflict & 0.052 & $0.223^{*}$ & $0.316 * *$ & $0.377^{* *}$ & $0.369 * *$ \\
\hline Age & $-0.268 * *$ & -0.169 & 0.027 & $-0.201^{*}$ & -0.72 \\
\hline Months since Diagnosis & 0.033 & -0.062 & -0.117 & 0.033 & -0.051 \\
\hline
\end{tabular}

* Pearson Correlation is significant at the 0.05 level (2-tailed); **Pearson Correlation is significant at the 0.01 level (2-tailed)

A regression model was calculated for each of the five domains of psychosocial needs. Predictors in these models were: social support, reciprocity, conflict, anxiety, depression, distress, relatives' age, level of education, kind of relationship to the patient and months since the patients' diagnosis. Table 4 shows that the dependent variable 'need for information' was positively associated with distress. When need for 'effective access to health care professionals' was used as a dependent variable, higher distress, more conflicts in the interpersonal relationship and more reciprocity in the relatives' contact with the patient were associated with higher needs in this area.

Needs for 'spiritual support', needs for 'emotional and social support' and needs for 'practical help' were positively related with anxiety and conflict in the personal relationship. A lower educational level seems to increase needs for 'spiritual support'. No other co-variables were related to the relatives' psychosocial needs. The total variance $\left(R^{2}\right)$ explained in each of four models varied between $20 \%$ and $41 \%$. In the model 'needs for information', the explained variance was only $7 \%$.

\section{DISCUSSION}

This study evaluated the psychosocial needs of relatives of women under treatment for breast cancer, their psychological problems and their perception of their interpersonal relationship with the patient. The results of this study demonstrate that 
the relatives' significant unmet psychosocial needs were primarily related to the domains 'information' and 'effective access to health care professionals'.

More than sixty percent of the close relatives suffered from clinically significant distress, more than one-fourth had a serious problem with anxiety and a bit more than ten percent had depressive symptoms (cut off point $\geq 8$ ). They had comparable values for anxiety but less depressive symptoms than described for breast cancer patients by Knobf (2007). His review showed that previous research had documented between $20-30 \%$ of breast cancer patients reporting psychological symptoms after finishing primary treatment. Compared to standardised values for the HADS assessed by Hinz and Schwarz (2001) ( $n=2037)$ for the general German population (which is comparable with the Swiss population), the relatives in our study had much higher anxiety $(12.1 \%$ relatives vs. $5.9 \%$ German population; cut off point $\geq 11$ ) but interestingly fewer depressive symptoms (10.3\% relatives vs. $15.8 \%$ German population cut off point $\geq 8$ ) than the general German population (Table 2) (Hinz \& Schwarz 2001).

This means that close relatives were at least as highly burdened as the patients. An explanation for the relatives' higher anxiety compared to the general (German) population could be that relatives of breast cancer patients are confronted with a real and existential threat that their partner/ patient will die of cancer and may therefore rate the HADS-anxiety items compared with the general population higher than the depression items. The general population might rather suffer from diffuse unpleasantness or depressive mood than from a real threat. Another reason could be that the close relatives expressed their psychological problems rather as distress than as depressive feelings. The term distress may be more acceptable and sounds more 'normal', particularly for male relatives, like the items in the HADSDepression Scale, which ask about emotional issues. However most important is to identify more vulnerable relatives who suffer from clinically-relevant anxiety, distress or depression.

Close relatives perceived not only social support and reciprocity in the relationship with the patient but also conflicts. Whereas social support and reciprocity can be seen as resources, conflict should be seen more as a risk factor for emotional problems (Lewis et al. 2008, Makabe \& Nomizu 2006, 2007). Distress, anxiety and conflict in the interpersonal relationship were the three most important factors in the regression models which were associated with the close relatives' unmet psychosocial needs and which may identify more vulnerable relatives at-risk, who need more support and attention. 


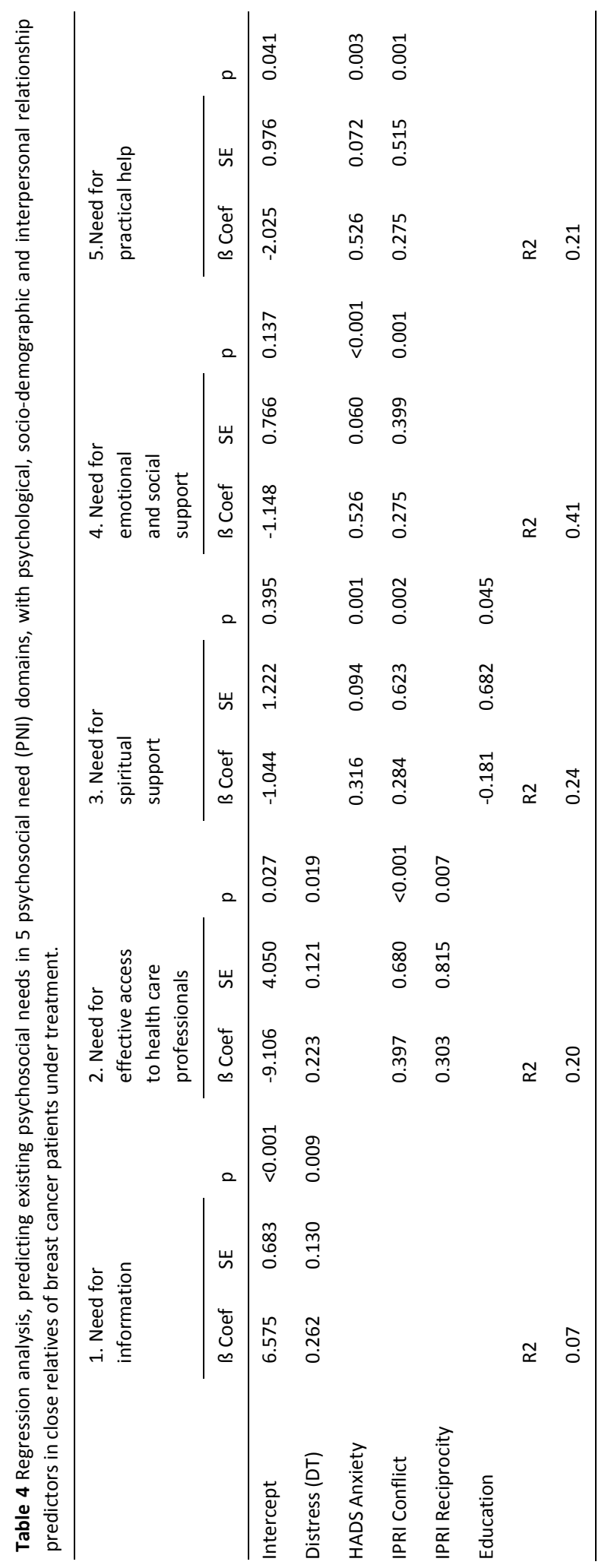


Distress was a factor for unmet needs in the dimensions access to 'health care professionals' and access to 'information'. The relatives' need for information and the wish for personal contact with medical staff were also significant in other studies (Kilpatrick et al. 1998, Lindholm et al. 2007, Rees \& Bath 2000). Hodgkinson et al. (2007b) found a positive relationship between psychological distress and supportive care needs in partners of long-term cancer survivors. Due to their knowledge and practical support, health care professionals may contribute to satisfying the relatives' needs in these dimensions which may also relieve the relatives' distress. As Nikoletti et al. (2003) also reported, relatives who received information from health care professionals (e.g. a breast care nurse counsellor) had lower unmet needs. Reasons for unmet needs and distress could be that not all close relatives filled a natural definite role, they often felt more as a witness or observer of professional care. Furthermore, many of them did not know if the patient wanted them to have a place in care (Lindholm et al. 2007). Communication flow among relatives, patients and health care professionals depended on the amount of communication desired by the patient (Rees \& Bath 2000). Sometimes patients avoid giving information to their relatives to protect them from worry. The majority of close relatives got information from patients or from health care professionals if they accompanied the patient to consultations in the health institutions (Rees \& Bath 2000). Therefore, together with the professionals, the patient seems to be a key person in close relatives receiving information and having access to health care professionals. However, the patients must always have the right to control the flow of information and the relatives' contact with the health care professionals.

Anxiety was positively associated with the needs for 'emotional social' and 'spiritual' support and with needs for 'practical help'. Lindholm et al. (2007) reported that relatives needed personal outside contact with a third party (e.g. healthcare professionals) and wished to receive the chance to acknowledge their fears, worries and concerns. Partners reported high levels of anxiety and high levels of supportive care needs (Hodgkinson et al. 2007b). The anxiety felt by women undergoing treatment was significantly associated with the anxiety felt by their partners (Segrin et al. 2007). Anxiety has often been investigated in a broader context of psychological problems. Lewis et al. (2008) investigated predictors of depressive mood in spouses of patients with recently-diagnosed breast cancer. Spouses were more likely to be depressed if they reported greater concerns over their wife's well-being, were more uncertain about their own future, had greater job-related problems, were less educated and in shorter-term or less adjusted marriages.

Conflict was related to four of the five dimensions namely access to 'health care professionals', to 'emotional and social support', 'spiritual support 'and 'practical help' but not to the dimension information. Hence, the perceived conflict in the 
relationship of close relatives was the most important factor associated with the psychosocial needs. In the study of Ozono et al. (2005) conflict was a key manifestation of family functioning that indicated dysfunction. In a study by Hodgkinson et al. (2007a), the partners of breast cancer survivors reported an increased closeness and stronger relationship, but some reported also that cancer had triggered ongoing relationship difficulties. Furthermore, the patients' and relatives' distress and relationship satisfaction were associated with their perceptions of the way they communicated about cancer-related stressors (Manne et al. 2005, Manne et al. 2006, Mesters et al. 1997). Identifying close relatives who perceive conflicts in their relationship is therefore important, because such conflicts also impact on the patient.

The finding that more reciprocity in the interpersonal relationship with the patient, which can be seen as a positive aspect in a relationship, was associated with more needs of relatives for 'effective access to health care professionals' was unexpected. Reasons for this result could be that relatives feel their responsibility for the patients' health and well-being (Hilton et al. 2000, Wagner et al. 2006). They try to focus on the positive and maintain normality. Therefore they consider personal needs as secondary to the patients' needs, control their emotions and hide their distress and suffering from the patient (Dalton et al. 2007, Hilton et al. 2000, Lethborg et al. 2003). Further, reciprocity and mutual corresponding in the relationship may help both the patient and the relative to control their emotions and to protect one another from the threat attached to the cancer (Manne et al. 2007, Mesters et al. 1997, Schmid-Büchi et al. 2005). However, this behaviour may constrain communication between them (Manne et al. 2006, Northouse 2005). The supposed lack of communication in the relationship and the relative's unrelieved suffering could be a possible explanation of our result (Lindholm et al. 2002). Further research is required to clarify such associations.

\section{Limitations}

Limitations of this study are that the patients in our study had early-stage breast cancer with a relatively good prognosis and therefore the results cannot be generalised to other populations (e.g. relatives of patients with advanced or recurrent breast cancer). These data are cross-sectional so that relationships between variables should be seen as associations rather than causal relationships. Furthermore, the cross-sectional design of the study did not allow assessing changes over time. The recruitment of close relatives through patients may have contributed to a biased sample with data more likely obtained from relatives in well-functioning relationships. Despite these limitations, the data add to our understanding of the problems and needs of close relatives of breast cancer patients - a group that frequently is not attended to. 


\section{Conclusion and Relevance to clinical practice}

The findings of this study enhance the knowledge of the psychosocial needs of close relatives of breast cancer patients and provide a basis for purposeful support and counselling. Close relatives of breast cancer patients need more attention from professional healthcare workers. Many of them suffer from distress, anxiety and have a lack of information and a need for access to healthcare professionals.

Distress, anxiety and perceived conflicts in the interpersonal relationship were the most important factors associated with the relatives' psychosocial needs. These factors may identify more vulnerable relatives with unmet needs. Healthcare professionals can help relieve the relatives' distress and anxiety, assist them to manage the threat of the patients' cancer and prepare them for a supporting role.

Healthcare professionals are key persons in contact with close relatives. They can promote a good communication pattern between the patient and their relatives and motivate the patients to involve their relatives in the illness and treatment process. Assessing the close relatives' specific needs is important and healthcare professionals should in particular be aware of the relatives' information needs. Systematic assessment should help to identify distressed and anxious relatives. Furthermore, the close relatives' and the patients' perception of their relationship should be addressed. It may lead to insight into family functioning. Addressing this functioning in a situation of high distress may improve the relatives' and the patients' well-being and the adjustment-process.

Guidelines and programs should be developed for relatives of breast cancer patients to better support them. However clinicians must be aware that it is the patient who determines the amount of their relatives' involvement in the treatment and care process. Further research is needed to refine the models, including and testing additional variables that were not included in this current study, most notably issues related to the interpersonal relationship between breast cancer patients and their relatives.

\section{Conflict of interest}

The authors declare that there is no conflict of interest.

\section{Acknowledgement}

The authors thank the patients who motivated their relatives to participate in this study and the close relatives for their valuable contribution. Thanks go to Dr. J. Eysell for proofreading. Funding was provided in part by the Cancer League Zurich, Switzerland. 


\section{REFERENCES}

Arman M, Rehnsfeldt A, Lindholm L \& Hamrin E (2002) The face of suffering among women with breast cancer-being in a field of forces. Cancer Nurs 25, 96-103.

Bolger N, Foster M, Vinokur AD \& Ng R (1996) Close relationships and adjustment to a life crisis: the case of breast cancer. J Pers Socl Psychol 70, 283-294.

Bonevski B, Sanson-Fisher R, Girgis A, Burton L, Cook P \& Boyes A (2000) Evaluation of an instrument to assess the needs of patients with cancer. Cancer 88, 217-225.

Budischewski K, Fischbeck S \& Mose S (2008) Quality of life of breast cancer patients in the course of adjuvant radiotherapy. Support Care Cancer 16, 299-304.

Dalton WT, 3rd, Nelson DV, Brobst JB, Lindsay JE \& Friedman LC (2007) Psychosocial variables associated with husbands' adjustment three months following wives' diagnosis of breast cancer. $J$ Cancer Edu 22, 245-249.

Douglass LG (1997) Reciprocal support in the context of cancer: perspectives of the patient and spouse. Oncol Nurs Forum 24, 1529-1536.

Figueiredo MI, Fries E \& Ingram KM (2004) The role of disclosure patterns and unsupportive social interactions in the well-being of breast cancer patients. Psychooncology 13, 96-105.

Foy S \& Rose K (2001) Men's experiences of their partner's primary and recurrent breast cancer. Eur J Oncol Nurs 5, 42-48.

Herrmann C (1997) International experiences with the Hospital Anxiety and Depression Scale-a review of validation data and clinical results. J Psychosom Res 42, 17-41.

Hilton BA, Crawford JA \& Tarko MA (2000) Men's perspectives on individual and family coping with their wives' breast cancer and chemotherapy. West J Nurs Res 22, 438-459.

Hinz A \& Schwarz R (2001) Angst und Depression in der Allgemeinbevölkerung: eine Normierungsstudie zur Hospital Anxiety and Depression Scale. [Anxiety and depression in the general population: normal values in the Hospital Anxiety and Depression Scale]. Psychother Psychosom Med Psychol 51, 193-200.

Hodgkinson K, Butow P, Hunt GE, Pendlebury S, Hobbs KM \& Wain G (2007a) Breast cancer survivors' supportive care needs 2-10 years after diagnosis. Support Care Cancer 15, 515-523.

Hodgkinson K, Butow P, Hunt GE, Wyse R, Hobbs KM \& Wain G (2007b) Life after cancer: couples' and partners' psychological adjustment and supportive care needs. Support Care Cancer 15, 405-415.

Hoskins CN (1997) Breast cancer treatment-related patterns in side effects, psychological distress and perceived health status. Oncol Nurs Forum 24, 1575-1583.

Hunter MS, Grunfeld EA, Mittal S, Sikka P, Ramirez AJ, Fentiman I \& Hamed H (2004) Menopausal symptoms in women with breast cancer: prevalence and treatment preferences. Psychooncology 13, 769778.

Jacobsen PB, Donovan KA, Trask PC, Fleishman SB, Zabora J, Baker F \& Holland JC (2005) Screening for psychologic distress in ambulatory cancer patients. Cancer 103, 1494-1502.

Kilpatrick MG, Kristjanson L, Tataryn DJ \& Fraser VH (1998) Information needs of husbands of women with breast cancer. Oncol Nurs Forum 25, 1595-1601.

Knobf MT (2007) Psychosocial responses in breast cancer survivors. Semin Oncol Nurs 23, 71-83.

Landmark BT, Bohler A, Loberg K \& Wahl AK (2008) Women with newly diagnosed breast cancer and their perceptions of needs in a health-care context. J Clin Nurs 17, 192-200.

Lethborg CE, Kissane D \& Burns WI (2003) 'It's not the easy part': the experience of significant others of women with early stage breast cancer, at treatment completion. Soc Work Health Care 37, 63-85.

Lewis FM, Fletcher KA, Cochrane BB \& Fann JR (2008) Predictors of depressed mood in spouses of women with breast cancer. J Clin Oncol 26, 1289-1295.

Lindholm L, Makela C, Rantanen-Siljamaki S \& Nieminen AL (2007) The role of significant others in the care of women with breast cancer. Int J Nurs Pract 13, 173-181.

Lindholm L, Rehnsfeldt A, Arman M \& Hamrin E (2002) Significant others' experience of suffering when living with women with breast cancer. Scand J Caring Sci 16, 248-255. 
Makabe R \& Nomizu T (2006) Social support and psychological and physical states among Japanese patients with breast cancer and their spouses prior to surgery. Oncol Nurs Forum 33, 651-655.

Makabe R \& Nomizu T (2007) Social support and psychological and physical states among Japanese women with breast cancer before and after breast surgery. Oncol Nurs Forum 34, 883-889.

Manne SL, Norton TR, Ostroff JS, Winkel G, Fox K \& Grana G (2007) Protective buffering and psychological distress among couples coping with breast cancer: The moderating role of relationship satisfaction. $J$ Fam Psychol 21, 380-388.

Manne SL, Ostroff J, Winkel G, Grana G \& Fox K (2005) Partner unsupportive responses, avoidant coping and distress among women with early stage breast cancer: patient and partner perspectives. Health Psychol 24, 635-641.

Manne SL, Ostroff JS, Norton TR, Fox K, Goldstein L \& Grana G (2006) Cancer-related relationship communication in couples coping with early stage breast cancer. Psychooncology 15, 234-247.

Marlow B, Cartmill T, Cieplucha H \& Lowrie S (2003) An interactive process model of psychosocial support needs for women living with breast cancer. Psychooncology 12, 319-330.

Mathis-Jäggi $F$ (2003) Needs of relatives of patients with head and neck cancer. Unpublished Master Thesis, Universiteit Maastricht, NL.

Mesters I, van den Borne H, McCormick L, Pruyn J, de Boer M \& Imbos T (1997) Openness to discuss cancer in the nuclear family: scale, development and validation. Psychosom Med 59, 269-279.

Nikoletti S, Kristjanson LJ, Tataryn D, McPhee I \& Burt L (2003) Information needs and coping styles of primary family caregivers of women following breast cancer surgery. Oncol Nurs Forum 30, 987-996.

Northouse L (2005) Helping families of patients with cancer. Oncol Nurs Forum 32, 743-750.

Northouse LL, Laten D \& Reddy P (1995) Adjustment of women and their husbands to recurrent breast cancer. Res Nurs Health 18, 515-524.

Northouse LL, Mood D, Kershaw T, Schafenacker A, Mellon S, Walker J, Galvin E \& Decker V (2002) Quality of life of women with recurrent breast cancer and their family members. $J$ Clin Oncol 20, 40504064.

Ozono S, Saeki T, Inoue S, Mantani T, Okamura H \& Yamawaki S (2005) Family functioning and psychological distress among Japanese breast cancer patients and families. Support Care Cancer 13, 10441050.

Raupach JC \& Hiller JE (2002) Information and support for women following the primary treatment of breast cancer. Health Expect 5, 289-301.

Rees CE \& Bath PA (2000) Exploring the information flow: partners of women with breast cancer, patients and healthcare professionals. Oncol Nurs Forum 27, 1267-1275.

Roth AJ, Kornblith AB, Batel-Copel L, Peabody E, Scher HI \& Holland JC (1998) Rapid screening for psychologic distress in men with prostate carcinoma: a pilot study. Cancer 82, 1904-1908.

Samms MC (1999) The husband's untold account of his wife's breast cancer: a chronologic analysis. Oncol Nurs Forum 26, 1351-1358.

Schmid-Büchi S, Dassen T \& Halfens RJ (2005) Die Erfahrung an Brustkrebs zu erkranken, und wie die betroffenen Frauen ihr Leben wieder unter Kontrolle bringen. [Experiencing the disease of breast cancer and getting life under control again]. Pflege 18, 345-352.

Schmid-Büchi S, Halfens RJ, Dassen T \& van den Borne B (2008) A review of psychosocial needs of breastcancer patients and their relatives. J Clin Nurs 17, 2895-2909.

Segrin C, Badger T, Dorros SM, Meek P \& Lopez AM (2007) Interdependent anxiety and psychological distress in women with breast cancer and their partners. Psychooncology 16, 634-643.

Soothill K, Morris SM, Harman J, Francis B, Thomas C \& Mclllmurray MB (2001) The significant unmet needs of cancer patients: probing psychosocial concerns. Support Care Cancer 9, 597-605.

Tilden VP, Hirsch AM \& Nelson CA (1994) The Interpersonal Relationship Inventory: continued psychometric evaluation. J Nurs Meas 2, 63-78.

Tilden VP, Nelson CA, \& May BA (1990a) The IPR inventory: development and psychometric characteristics. Nurs Res 39, 337-343. 
Tilden VP, Nelson CA \& May BA (1990b) Use of qualitative methods to enhance content validity. Nurs Res 39, 172-175.

Wagner CD, Bigatti SM \& Storniolo AM (2006) Quality of life of husbands of women with breast cancer. Psychooncology 15, 109-120.

Wen K \& Gustafson D (2004) Need assessment for cancer patients and their families Health Qual Life Outcomes 2, 2-12.

Wengstrom Y Haggmark C, Strander H, \& Forsberg C (2000) Perceived symptoms and quality of life in women with breast cancer receiving radiation therapy. European J Oncol Nurs 4, 78-88; discussion 89-90.

Yang HC \& Schuler TA (2009) Marital quality and survivorship: slowed recovery for breast cancer patients in distressed relationships. Cancer 115, 217-228.

Zigmond AS \& Snaith RP (1983) The Hospital Anxiety and Depression Scale. Acta Psychiatr Scand 67, 361370. 
Chapter Seven

Discussion 


\section{INTRODUCTION}

This dissertation investigated the experience and supportive care needs of breast cancer patients, their cancer and cancer treatment-related symptoms and the patients' relatives' psychosocial needs. Furthermore, we studied the psychological problems of the patients and their relatives and how they perceived their interpersonal relationship. Factors were identified which were associated with patients' supportive care needs and their relatives' psychosocial needs.

In this chapter we briefly summarise the main findings, discuss some of these findings, reflect on some methodological aspects, and present implications for practice and future research.

\section{MAIN RESULTS}

\section{The needs of patients and their relatives}

The most important needs of patients with breast cancer were related to the cancer and cancer treatment-related symptoms during the treatment period and also, but somewhat less, in their post-treatment period (1-22 months after treatment). Between $65 \%$ and $75 \%$ of the patients suffered from fatigue, insomnia, body strains and endocrine symptoms and more than $45 \%$ still had muscle-skeletal pain (posttreatment). More than $70 \%$ of the patients under treatment and over $40 \%$ in posttreatment felt impaired in their work, social and leisure activities. Between $40 \%$ and $60 \%$ reported body image problems caused by cancer treatments. In posttreatment, $22 \%$ had needs related to changes in their sexual relationships and needed information concerning such issues (chapters 4, 5).

The relatives had high needs (30-40\%) for access to healthcare professionals and information, and needs for honest information, and information about the patients' disease, treatment and expectations for the future. They wanted nurses and doctors to make time available and listen to them and they needed help to develop confidence in the health care professionals (chapters 4, 6).

The patients with breast cancer and the relatives still suffered from anxiety (22$26 \%$, HADS $>7$ ) in the period in which the patients' were under cancer treatment and also in the patients' post-treatment period. Fewer patients and relatives suffered from depression. More than half of the patients under treatment (56\%), and $61 \%$ of the relatives were distressed (chapters 5,6 ) and $33 \%$ of the patients and $40 \%$ of the relatives suffered from distress in post-treatment (chapter 4). Between $21 \%$ and $32 \%$ of the patients had unsatisfied needs such as fears regarding the unpredictable future because of their breast cancer, the course of the cancer and the effect of the 
cancer treatment (chapters 4, 5). Relatives needed help to develop confidence for the future (40\%) and a sense of meaning (30\%) (chapters 4,6$)$.

The patients and the relatives perceived a lot of support and reciprocity in their interpersonal relationships, but there were also conflicts (chapters 5, 6). The patients were concerned about the worries of their relatives and rated the relatives' burden of suffering (post-treatment) higher than their own (chapters 2, 4), which is in line with ratings of the relatives who rated their burden of suffering as being much higher than that of the patients. However the relatives perceived the patients' burden as high as their own (see figure 1 chapter 4 ). The relatives' social and familial needs seemed to be fulfilled (post-treatment, chapter 4).

\section{Factors associated with the patients' and the relatives' needs}

The evaluated factors demonstrate that the cancer and cancer treatment-related symptoms such as physical and social impairments and an impaired body image may identify patients who are more vulnerable and in need of help. Distress, depression and anxiety distinguished patients with unmet needs form patients with met needs. Conflict in the interpersonal relationship was associated with patients' unmet needs, while patients who perceived support in the relationship had fewer unmet needs (chapter 5).

Distress, anxiety and perceived conflicts in the interpersonal relationship with the patient were the factors which were associated with the relatives' unmet needs, which may identify more vulnerable relatives with a need for help (chapter 6).

\section{THEORETICAL REFLECTIONS}

This thesis reports findings of a more innovative approach by studying cancer patients' specific needs instead of focusing on the more general dimensions of quality of life (Bonevski et al. 2000, Hodgkinson et al. 2007b, Hodgkinson et al. 2007c, Soothill et al. 2001, Wen \& Gustafson 2004). Research describing the relationship between breast cancer and overall quality of life does not really identify the issues in which the patients and their relatives recognize their need for help. (Bonevski et al. 2000). We not only investigated the breast cancer patients' specific needs but also the psychosocial needs of their relatives'. The research of patients' and relatives' needs is important in nursing because such knowledge may guide the need assessment in clinical practice and may form the basis for providing specific nursing interventions to satisfy the patients' and their relatives' needs. Further, the factors evaluated in our studies may identify more vulnerable patients and relatives with higher and unsatisfied needs in order to give the required support and counselling to those who need them most. 
Maslow's model (1968) of a hierarchy of needs provides a framework in which to reflect the findings of our research and facilitates a more comprehensive understanding of the needs of breast cancer patients and their relatives.

\section{The patients' care needs}

The patients' most frequently reported unmet needs were mainly related to the psychological dimension of needs (chapters 4, 5). Patients are vulnerable to anxiety, distress and depression under treatment but also in the post-treatment period (chapters 2, 4, 5). Distress, anxiety and depression were also factors which characterized patients with unmet supportive care needs (chapter 5 ). Breast cancer is a psychological challenge. Patients undergo basic changes and have to deal with a new life situation. The overwhelming nature of treatments, the impact and discomfort of treatments and their side effects may be difficult to manage (Lethborg et al. 2000). In a recent study, one-third of cancer patients under treatment reported five or more unmet needs, and for $60 \%$ of these patients this situation did not improve after a six-month period. The most frequently reported unmet needs concerned psychological needs (Armes et al. 2009). As in our study (chapter 4), distress, anxiety, depressed mood and fear of the spreading or recurrence of cancer are problems often discussed in research by breast cancer patients (Girgis et al. 2000, Hodgkinson et al. 2007c, Hoskins 1997). To live in constant fear and uncertainty may influence the patients' psychological well-being (Lee-Jones et al. 1997, Lethborg et al. 2000). Breast cancer patients therefore have, according to Maslow (1968), high needs for safety and security, needs to find safe circumstances, stability, protection and to regain a more predictable life.

\section{The patients' cancer and cancer treatment-related symptoms}

A very important finding was that many patients under treatment suffered from cancer and cancer treatment-related symptoms and still suffered from these symptoms in their post-treatment period (chapters 4, 5). The patients' symptoms in our study were mainly focused on two dimensions, 1) physical and social impairments and 2) body image. These two were also factors identifying patients with a need for help and with unmet supportive care needs (chapter 5). In our research, fatigue, pain, sleep disturbances, arm problems and hot flushes were the symptoms most frequently reported by the patients (chapter 4). These symptoms are also often reported in other studies, as well as lack of concentration, anxiety, depression and mood problems, whereas fatigue is often the predominate symptom (Arndt et al. 2006, Bender et al. 2005, Bower 2008, De Jong et al. 2004, Hoybye et al. 2008, Nail 2001, Ribi et al. 2007, So et al. 2009, Yoon et al. 2008). 
Such symptoms, in the context of Maslow's hierarchy of human needs (1968), are the main cause of the patients' basic biological and physiological needs. These symptoms indicate a change in normal functioning or sensation due to disease or treatment. Such existential needs can restrain patients in their activities, and if unrelieved, delay the patients' recovery process (Cleeland 2000, 2007). In a recent study, almost half of all breast cancer patients reported at least one symptom severe enough to affect their daily functioning or mood (Yoon et al. 2008). In another recent study on average 4 years post-diagnosis, breast cancer survivors reported greater work limitations than a non-cancer comparison group (Hansen et al. 2008). Fatigue and the presence of hot flushes had negative effects on the work productivity of breast cancer survivors even three years post-treatment (Lavigne et al. 2008). Therefore the impact of cancer and cancer treatment-related symptoms on the ability of the patients' functioning and the severity of multiple untreated or unrelieved symptoms may cause distress and impose a burden on patients (Burkett \& Cleeland 2007). This burden may also affect higher hierarchical needs such as needs for safety, security and belonging.

Patients with body image problems complained about weight gain, perceived changes in their body appearance and felt less feminine and attractive while under treatment and also in post-treatment (chapters 4,5 ). Body image problems identified patients with a higher need for help (chapter 5). Cancer-treatment, such as surgical treatment of the breast, chemotherapy, radiotherapy and frequent endocrine treatments have an impact on physical appearance as well as on how patients experience their body (Little 2004, Rasmussen et al. 2009). Aesthetic changes, disturbance in the menstrual cycle and sexuality or premature menopause (chapters 2 , $4,5)$, not only affect the patients' body image but often also how they view themselves as women (Boehmke \& Dickerson 2006, Helms et al. 2008). Such selfperceptions may cause uncertainty, distress and compromise the patients' stability, their needs for safety and security and may negatively affect their self-esteem and belonging needs.

Research on symptoms is often focused on single symptoms, but often patients suffer from concurrent symptoms. In our study, we could build four sets or dimensions of symptoms (by factor analysis, chapter 4). The factors found in our research may help to better identify patients who have specific care needs. This, in turn, may help in providing more targeted symptom management and in the development of interventions to improve the patients' health outcomes and satisfy their needs.

\section{Relatives' psychosocial needs}

Relatives of cancer patients require substantial support and care. With our research, we improved the knowledge of the psychosocial needs of relatives, mainly husbands 
and partners, of breast cancer patients. The relatives' most important unsatisfied needs were in getting access to information and contact or communication with health care professionals (chapters 4,6 ). Further, relatives were at least as highly burdened as the patients, also in the patients' post-treatment period (chapter 4). Distress and anxiety were two of the three factors which were related to the relatives' unsatisfied needs (chapter 6). As in our study, distress was, a predictor in a recent study for unmet needs of partners' of breast cancer survivors (Hodgkinson et al. 2007d). Unmet psychosocial needs of relatives seem to be related to poor mental health of these relatives (Kim et al. 2009). Job concerns, spouses' concern over their wives' well-being, illness-related uncertainty, feelings of exclusion by the medical team and adjustment in their marriage were predictors for depressed mood of spouses of women with breast cancer (Lewis et al. 2008). The relatives' psychological problems and their high needs are signs that they are deeply affected by the patients' breast cancer (chapters 4, 6). Many feel unprepared and do not know how to provide effective support for the patients. In this period of uncertainty and ambiguity, they feel often dependent on others such as health care professionals, in obtaining guidance and instructions (Harrow et al. 2008, Lethborg et al. 2003). Therefore, the relatives' problems not only affect their needs for safety and security but also their esteem needs. Information and contact with health care professionals may help them to reduce distress, anxiety and uncertainty, to regain stability and selfconfidence and to develop competence for the new, more supportive role. But many relatives rate their needs as secondary to the patients' needs. Therefore, they often need an invitation from the patient and health care professionals to establish contact (Morris \& Thomas 2001, 2002). Further, relatives of cancer patients had a variety of needs which they shared with the patients but had also unique needs, which surfaced not only during the time of diagnosis and treatment but were still present years after (Kim et al. 2009). There are only a few studies which measured the relatives' needs and these studies mainly focused of the patients' spouses or partners. Particularly female family members may have specific needs because they may also belong to a risk-group for breast cancer, e.g. need to know about a genetic disposition for breast cancer or mammography screening (Chalmers et al. 2003). More differentiated knowledge allows purposeful interventions to satisfy the relatives' specific needs.

\section{The interpersonal relationship}

Having cancer or being confronted with cancer as a relative can change an interpersonal relationship. The patients and the relatives in our studies perceived a lot of support in their interpersonal relationships but also conflicts (chapters 5, 6). Associations between the cancer patients' or their relatives' supportive or psychosocial needs and their perception of their interpersonal relationship, particularly conflict, 
was not often an object for research. A considerable finding was therefore, that our research identified conflict in the interpersonal relationship as one of the factors which were related to the breast cancer patients' and the relatives' unmet needs, whereas support was only related to the patients' but not to the relatives' met needs (chapters 5, 6). A greater relationship satisfaction of the partners predicted fewer needs in one recent study of the needs of cancer survivors and their partners. The patients' relationship satisfaction was not associated with their needs (Hodgkinson et al. 2007d). Other studies did not focus on patients' or relatives' needs but on the quality of the patients' or relatives' relationship, patients' adaptation to cancer or the patients' well-being. Relationship quality was associated with distress, anxiety and with the perception of the way patients and partners communicated about cancer stressors (Manne et al. 2006, Segrin et al. 2007). Adaptation to breast cancer was related to the patients' supportive family structures, characterized by high cohesiveness and low conflict and the patients' state of health (Holland \& Mastrovito 1980, Ozono et al. 2005). The satisfaction with the partner relationship was positively associated with the patients' psychological well-being (Pistrang \& Barker 1995).

In our study, patients often perceived that they became closer to relatives and friends through the cancer experience, but they were also concerned about their relatives. The perceived support in the patients' relationship with the relative had a positive influence on the satisfaction of their needs, whereas conflict was related to unmet needs (chapters 2, 4, 5). Rosedale (2009) described that some breast cancer patients felt isolated and invalidated in the experience of ongoing symptom-burden and had a changed sense of identity. Some patients described that life and attachment to others were fragile, because others could not really understand their breast cancer experience (Rosedale 2009).

A husband's response to the wife who suffers from breast cancer may provide security to the patient, through love and esteem despite the presence of significant illness (Holland \& Mastrovito 1980). The expression of mutual concern in relationships may form the sustaining dimensions of support (Lethborg et al. 2000, Schnipper 2001). However, even in well-established marital relationships, breast cancer often brings the relationship into sharp focus and husbands/partners are suddenly confronted with uncertainty about their common future (Harrow et al. 2008). Relatives strive to meet the patient' demand for support, but they often move from their conventional role to a more supportive role and feel less competent and confident than before (Lethborg et al. 2003). They may feel uncertain in reading the patient's signals to provide this ongoing concern after the cancer diagnosis, during treatment and also afterwards, and in finding strategies to address the patient's needs (Shands et al. 2006). Such problems may intensify distress and anxiety and intensify conflicts in the interpersonal relationship, factors in our studies which were related to the relatives' unmet needs (chapters 4,6 ). Therefore, easy access to health care profes- 
sionals who can satisfy the relatives' needs for information and offer discussions and counselling regarding their roles and relationship is vital to promote adjustment of relatives of patients with breast cancer.

Cancer and cancer treatment-related problems of the patients found in our studies, like fatigue, changes in body image and sexuality or psychological problems, such as anxiety and depression (chapters 5,6$)$ may also complicate relationships and social relatedness (Fobair et al. 2006, Holland \& Mastrovito 1980, Ozono et al. 2005).

Sexuality is an important part of human life and marital relationships. In our study, patients had a need for help with sexual issues (chapter 4). After a cancer diagnosis and under treatment, sexuality may be less important for the patients and possibly also for their partners. The wish for intimacy and loving may increase, and sexuality regains importance with recovery. Thus, the patient's treatment-related problems with sexuality can interfere with the patient's and/or their partner's wish for a sexual relationship (Fobair \& Spiegel 2009), which may influence belongingand esteem-needs.

The satisfaction of the patients' basic biological and physiological needs through adequate symptom management and the satisfaction of the patients' and their relatives' needs for more safety and security may also have a positive influence on the interpersonal relationships between the patients and their relatives. This increases the satisfaction of needs for belongingness.

\section{The tentative model}

The model developed from the literature review (chapter 3 ) is not comprehensive enough. Our research and systematic measurement allowed calculation of statistical models which brought the patients' and their relatives' needs into sharper focus. Our key findings from research are more relevant and give more specific but also more comprehensive insight in the patients' supportive care needs and mainly in their relatives' psychosocial needs. The factors developed in this research may identify patients and relatives who are in need of help. Communication is an aspect which we have not assessed in our research, but support, reciprocity and conflict in the interpersonal relationship can also be seen in a broader sense as signs of concordance and discordance in the interpersonal relationship. 


\section{METHODOLOGICAL REFLECTIONS}

\section{Research design}

The three cross-sectional surveys (chapters $4,5,6$,) were guided by a qualitative study (chapter 2) and by a tentative model developed from a literature-review (chapter 3). In our research, we investigated phenomena such as the patients' and their relatives' psychosocial needs, their psychological problems, their perception of the interpersonal relationship and the patients' cancer and cancer treatmentrelated symptoms. Either the patients' supportive care needs or the relatives' psychosocial needs were seen as the outcome variables. We could develop factors associated with the patients' needs, such as patients' physical and social impairment, impaired body image, distress, depression, anxiety, support and conflicts in the interpersonal relationship (chapter 5). Relatives' needs were associated with distress, anxiety and conflicts in the interpersonal relationship (chapter 6).

The cross-sectional data limit the possibility to generalise from the results. The relationships between the variables in the statistical models should therefore be seen as associations rather than causal relationships. The cross-sectional design can not assess changes and trends over time. To provide a deeper insight of the patients' and their relatives' needs, data were not only evaluated from patients under cancer treatment and their relatives, but also data of our own study from patients and their relatives within 1-22 months after completion of cancer treatment. A longitudinal design would have assessed changes over time, but the main problem of such studies is the loss of participants at different times during the study. In our study, the participants had to answer a relatively large number of questions. The drop-out of participants would have been high had we questioned them two or three times, and even intensified because we not only recruited patients, but also relatives, who were invited by the patients to participate. Such a longitudinal study would have been complex and costly to manage. Based on our study, a more limited questionnaire could be developed, which can be used in a longitudinal study to measure changes over time.

\section{Sample size}

The sample size of the study investigating the factors associated with supportive care needs of patients under cancer treatment (chapter 5) was relatively large ( $n=175)$; fewer relatives of patients under cancer treatment participated $(n=107)$ in the related study (chapter 6 ). The relatives recruited by patients may have provided a biased sample with data obtained from relatives in well-functioning relationships. The sample size of the study which assessed and compared psychosocial needs of patients with breast cancer and of their relatives (chapter 4 ) was not as high. Howe- 
ver, interesting in this study is that seventy-two patients participated with their relatives and we could show findings from patients and their relatives in the same study. The lower sample size must be considered when interpreting the findings of the regression models. The statistical models described in chapters 5 and 6 are therefore more accurate.

\section{Instruments}

German (Swiss) versions of self-reported instruments were used. The outcome variables, the patients' needs, were measured with the Supportive Care Needs Survey (SCNS-SF34) (Bonevski et al. 2000) and the relatives' needs with the Psychosocial Need Inventory (PNI) (Soothill et al. 2001, Soothill et al. 2003). When we started with the conceptualisation of the quantitative studies, no instrument was found which was appropriate to measure both the patients' and their relatives' needs. The $\mathrm{PNI}$ can be used for patients and relatives. But the PNI items did not exactly meet the patients' needs and was therefore not appropriate. The SCNS-SF34 is an instrument for cancer patients and cannot be used for relatives. For these reasons, two different instruments were used with the disadvantage that the direct comparison of the patients' and their relatives' needs was not possible. Hodgkinson et al. (2007a) started to develop instruments assessing unmet supportive care needs of cancer survivors and their relatives. In some part, these instruments have the same items for patients and their relatives and might be useful for further research projects (Hodgkinson et al. 2007a, Hodgkinson et al. 2007b, Hodgkinson et al. 2007d).

The Cancer and Cancer Treatment related Symptom Scale (CTSS) (Schmid-Büchi et al. 2009), the Hospital Anxiety and Depression Scale (HADS) (Zigmond \& Snaith 1983) and the Distress-Thermometer (DT) (Roth et al. 1998) are brief and easy to complete, and may, according to the factors evaluated in our research, identify more vulnerable patients and relatives at risk. The Pictorial Representation of Illness and Self-Measure (PRISM) (Buchi et al. 1998) which measures the burden of suffering, is important because it is a visual or graphic instrument which gives patients and relatives the opportunity to communicate their burden of suffering in a non verbal manner (chapter 4, figure 1 ).

The instruments who measured the patients' supportive care needs (SCNS), the patients' psychosocial needs (PNI) and the Interpersonal Relationship Inventory (IPRI) (Tilden et al. 1990) are also clinically useful, but mainly for patients and relatives who need more support and a more sophisticated assessment because these instruments are somewhat time-consuming to apply and analyse.

The German (Swiss) versions of the SCNS, PNI, CTSS and IPRI showed good internal consistency. The HADS and the DT are well established and proved instruments (chapters 4, 5). 


\section{IMPLICATIONS FOR NURSING, CLINICAL PRACTICE AND RESEARCH}

\section{The patients' and relatives' needs in the context of oncology nursing}

The impact of breast cancer is an individual experience for each patient and relative and must be seen in its personal context. Some patients or relatives are more resilient, others more vulnerable. The factors evaluated in our research (chapters 5, 6) may help to identify more vulnerable patients and relatives with unmet needs and with a higher need for help. Breast care nurses can contribute to effective symptom management and psychological care through systematic assessment, but also as nurse-initiated communication with patients and relatives. Nurses need to be sensitive in exploring the patients' or relatives' needs. Not all patients or relatives spontaneously mention their needs and concerns, such as conflicts in their interpersonal relationship or sexual issues. Nurses have to generate and create a caring atmosphere in which patients and relatives feel comfortable and confident enough to disclose their needs, feelings and concerns. The patients' and relatives' individual needs and experiences with the illness, also require individualised care which takes the patients' and their relatives' perspective into consideration. In clinical practice, basic, biological or physiological needs, needs for safety and security, belonging- and esteem needs often appear concurrently. Maslow's hierarchy of needs (1968) may help nurses to structure and prioritise the patients' and relatives' needs, not only in a hierarchical sense but rather to understand which needs are most relevant and most important for the patients and their relatives and to give them the appropriate care. The patients' recovery process may lead to a higher level of needs, e.g. belonging-or esteem needs or the need for self-actualisation become more important for patients and their relatives. Further, nurses should also support the process which brings patients and relatives towards self-actualisation and to a reformulation of self. Nurses play an important role in guaranteeing and coordinating consistent patient- and relative-centred and holistic, medical and psychosocial care.

\section{Implications for clinical practice}

The factors developed in this thesis may identify more vulnerable patients and relatives with a higher need for help and provide them with the required care, support and counselling.

The patients' high symptom burden requires breast cancer-specific symptom assessment and successful symptom management to resolve the patients' symptoms, to enhance their well-being and to facilitate their recovery process. This thesis can help to increase the nurses' and other health care professionals' awareness that many breast cancer patients suffer from several cancer and cancer treatmentrelated symptoms even in post-treatment, which impair their physical and social 
activities and femininity. Further, it is necessary to develop national guidelines and standards for breast cancer-related symptom assessment and management and to implement them in the clinical practice of Swiss breast care centres.

The relatives' role in the treatment and care process should be strengthened. Relatives often need to be invited to participate in the patients' illness- and treatment process which helps them to satisfy their high needs for information and access to health care professionals. It must always remain the patient's decision to invite her relative, but nurses can encourage patients to do so. Relatives often are in need of help. Nurses and other health care professionals should be sensitive to the relatives' specific and often unsatisfied needs and their psychological problems.

The patients' problems with sexuality and their impaired body image may negatively influence their interpersonal relationship with spouses or partners. Nurses and other health care professionals need specific training which enhances their ability to detect patients with sexual problems and to give them adequate counselling. Further, nurses should be knowledgeable in identifying patients and relatives who perceive conflicts in their interpersonal relationship.

This dissertation demonstrated the need for well-trained breast care nurses in Switzerland, who provide appropriate knowledge and experience to assess, understand, and interpret the needs of breast cancer patients and their relatives, to initiate the required interventions according to the patients' and their relatives' individual needs and provide counselling and support. Education programs which lead to a Master in Advanced Oncology Nursing (MAS) and specialisation in Breast Care Nursing have just been started. This dissertation provides a knowledge base for further development of clinical practice in Switzerland, the education of breast care nurses and for national standards for Breast Care Nursing. The findings of this dissertation also emphasize the importance and the role of nurses in the care and treatment process of breast cancer patients and their relatives in the Swiss health care system.

\section{Implications for future research}

Further research should focus on frequently-occurring symptom sets of breast cancer patients to gain more insight into the onset of concurrent symptoms, how they are related to each other and how they influence the patients' needs. More accurate knowledge would improve symptom management and enhance the patients' well-being.

More research is required to understand the full impact of breast cancer on the patients' relatives and for the full understanding of the specific needs of relatives not only living in a marriage or intimate relationship with the breast cancer patient, but also of other supportive groups of relatives. Further research is needed because we do not know if and how communication in the interpersonal relationship is related to the patients' and their relatives' needs. The statistical models which genera- 
ted factors associated with the breast cancer patients' supportive care needs and their relatives' psychosocial needs should be refined to determine which variables are most important in identifying patients and relatives with unmet needs.

Longitudinal studies are important to assess changes in patients' and their relatives' needs over time. We still do not know enough about the relatives' needs, their fears and psychological burden. The approaches to develop measurement instruments which can measure the patients' and their relatives' needs should be stimulated, because they allow direct comparison of the patients' and their relatives' needs, but research should also focus on the patients' and the relatives' interpersonal relationship. We need more knowledge of how perceived support and conflict in the interpersonal relationship may influence the patients' and their relatives' needs, and also about the communication in the interpersonal relationship in case of cancer. Further, we should gain more insight into how patients with breast cancer and their relatives overcome the existential threat of breast cancer and its consequences and how they can find spiritual and philosophical meaning towards post-traumatic growth. 


\section{REFERENCES}

Armes J, Crowe M, Colbourne L, Morgan H, Murrells T, Oakley C, Palmer N, Ream E, Young A \& Richardson A (2009) Patients' supportive care needs beyond the end of cancer treatment: a prospective, longitudinal survey. J Clin Oncol 27, 6172-6179.

Arndt V, Stegmaier C, Ziegler H \& Brenner H (2006) A population-based study of the impact of specific symptoms on quality of life in women with breast cancer 1 year after diagnosis. Cancer 107, 24962503.

Bender CM, Ergyn FS, Rosenzweig MQ, Cohen SM \& Sereika SM (2005) Symptom clusters in breast cancer across 3 phases of the disease. Cancer Nurs 28, 219-225.

Boehmke MM \& Dickerson SS (2006) The diagnosis of breast cancer: transition from health to illness. Oncol Nurs Forum 33, 1121-1127.

Bonevski B, Sanson-Fisher R, Girgis A, Burton L, Cook P \& Boyes A (2000) Evaluation of an instrument to assess the needs of patients with cancer. Cancer 88, 217-225.

Bower JE (2008) Behavioral symptoms in patients with breast cancer and survivors. J Clin Oncol 26, 768777.

Buchi S, Sensky T, Sharpe L \& Timberlake N (1998) Graphic representation of illness: a novel method of measuring patients' perceptions of the impact of illness. Psychother Psychosom 67, 222-225.

Burkett VS \& Cleeland CS (2007) Symptom burden in cancer survivorship. J Cancer Surviv 1, 167-175.

Chalmers K, Marles S, Tataryn D, Scott-Findlay S \& Serfas K (2003) Reports of information and support needs of daughters and sisters of women with breast cancer. Eur J Cancer Care 12, 81-90.

Cleeland CS (2000) Cancer-related symptoms. Semin Radiat Oncol 10, 175-190.

Cleeland CS (2007) Symptom burden: multiple symptoms and their impact as patient-reported outcomes. J Natl Cancer Inst Monogr, 16-21.

De Jong N, Candel MJ, Schouten HC, Abu-Saad HH \& Courtens AM (2004) Prevalence and course of fatigue in breast cancer patients receiving adjuvant chemotherapy. Ann Oncol 15, 896-905.

Fobair P \& Spiegel D (2009) Concerns about sexuality after breast cancer. Cancer J 15, 19-26.

Fobair P, Stewart SL, Chang S, D'Onofrio C, Banks PJ \& Bloom JR (2006) Body image and sexual problems in young women with breast cancer. Psychooncology 15, 579-594.

Girgis A, Boyes A, Sanson-Fisher RW \& Burrows S (2000) Perceived needs of women diagnosed with breast cancer: rural versus urban location. Aust N Z J Public Health 24, 166-173.

Hansen JA, Feuerstein M, Calvio LC \& Olsen CH (2008) Breast cancer survivors at work. J Occup Environ Med 50, 777-784.

Harrow A, Wells M, Barbour RS \& Cable S (2008) Ambiguity and uncertainty: the ongoing concerns of male partners of women treated for breast cancer. Eur J Oncol Nurs 12, 349-356.

Helms RL, O'Hea EL \& Corso M (2008) Body image issues in women with breast cancer. Psychol Health Med 13, 313-325.

Hodgkinson K, Butow P, Hobbs KM, Hunt GE, Lo SK \& Wain G (2007a) Assessing unmet supportive care needs in partners of cancer survivors: the development and evaluation of the Cancer Survivors' Partners Unmet Needs measure (CaSPUN). Psychooncology 16, 805-813.

Hodgkinson K, Butow P, Hunt GE, Pendlebury S, Hobbs KM, Lo SK \& Wain G (2007b) The development and evaluation of a measure to assess cancer survivors' unmet supportive care needs: the CaSUN (Cancer Survivors' Unmet Needs measure). Psychooncology 16, 796-804.

Hodgkinson K, Butow P, Hunt GE, Pendlebury S, Hobbs KM \& Wain G (2007c) Breast cancer survivors' supportive care needs 2-10 years after diagnosis. Support Care Cancer 15, 515-523.

Hodgkinson K, Butow P, Hunt GE, Wyse R, Hobbs KM \& Wain G (2007d) Life after cancer: couples' and partners' psychological adjustment and supportive care needs. Support Care Cancer 15, 405-415.

Holland JC \& Mastrovito R (1980) Psychologic adaptation to breast cancer. Cancer 46, 1045-1052.

Hoskins CN (1997) Breast cancer treatment-related patterns in side effects, psychological distress, and perceived health status. Oncol Nurs Forum 24, 1575-1583. 
Hoybye MT, Dalton SO, Christensen J, Larsen LR, Kuhn KG, Jensen JN, Carlsen K \& Johansen C (2008) Research in Danish cancer rehabilitation: Social characteristics and late effects of cancer among participants in the FOCARE research project. Acta Oncol, 1-9.

Kim Y, Kashy DA, Spillers RL \& Evans TV (2009) Needs assessment of family caregivers of cancer survivors: three cohorts comparison. Psychooncology.

Lavigne JE, Griggs JJ, Tu XM \& Lerner DJ (2008) Hot flashes, fatigue, treatment exposures and work productivity in breast cancer survivors. J Cancer Surviv 2, 296-302.

Lee-Jones C, Humphris G, Dixon R \& Hatcher MB (1997) Fear of cancer recurrence--a literature review and proposed cognitive formulation to explain exacerbation of recurrence fears. Psychooncology 6 , 95-105.

Lethborg CE, Kissane D, Bruns WI \& Snyder R (2000) "Cast Adrift": of Completing Treatment Among Women with Early Stage Breast Cancer. J Psychosocl Oncol 18, 73-90.

Lethborg CE, Kissane D \& Burns WI (2003) 'It's not the easy part': the experience of significant others of women with early stage breast cancer, at treatment completion. Soc Work Health Care 37, 63-85.

Lewis FM, Fletcher KA, Cochrane BB \& Fann JR (2008) Predictors of depressed mood in spouses of women with breast cancer. J Clin Oncol 26, 1289-1295.

Little M (2004) Chronic illness and the experience of surviving cancer. Intern Med J 34, 201-202.

Manne SL, Ostroff JS, Norton TR, Fox K, Goldstein L \& Grana G (2006) Cancer-related relationship communication in couples coping with early stage breast cancer. Psychooncology 15, 234-247.

Maslow AH (1968) Toward a Psychology of Being. D. Van Nostrand Company, New York, Cincinnati.

Morris SM \& Thomas C (2001) The carer's place in the cancer situation: where does the carer stand in the medical setting? Eur J Cancer Care (Engl) 10, 87-95.

Morris SM \& Thomas C (2002) The need to know: informal carers and information. Eur J Cancer Care 11, 183-187.

Nail LM (2001) Long-term persistence of symptoms. Semin Oncol Nurs 17, 249-254.

Ozono S, Saeki T, Inoue S, Mantani T, Okamura H \& Yamawaki S (2005) Family functioning and psychological distress among Japanese breast cancer patients and families. Support Care Cancer 13, 10441050.

Pistrang N \& Barker C (1995) The partner relationship in psychological response to breast cancer. Soc Sci Med 40, 789-797.

Rasmussen DM, Hansen HP \& Elverdam B (2009) How cancer survivors experience their changed body encountering others. Eur J Oncol Nurs.

Ribi K, Bernhard J, Rufibach K, Thurlimann B, von Moos R, Ruhstaller T, Glaus A \& Bohme C (2007) Endocrine symptom assessment in women with breast cancer: what a simple "yes" means. Support Care Cancer 15, 1349-1356.

Rosedale M (2009) Survivor loneliness of women following breast cancer. Oncol Nurs Forum 36, 175-183.

Roth AJ, Kornblith AB, Batel-Copel L, Peabody E, Scher HI \& Holland JC (1998) Rapid screening for psychologic distress in men with prostate carcinoma: a pilot study. Cancer 82, 1904-1908.

Schmid-Buchi S, Halfens RJ, Dassen T \& van den Borne B (2009) Psychosocial problems and needs of posttreatment patients with breast cancer and their relatives. Eur $J$ Oncol Nurs, 10.1016/j.ejon.2009.11.001.

Schnipper HH (2001) Life after breast cancer. J Clin Oncol 19, 3581-3584.

Segrin C, Badger T, Dorros SM, Meek P \& Lopez AM (2007) Interdependent anxiety and psychological distress in women with breast cancer and their partners. Psychooncology 16, 634-643.

Shands ME, Lewis FM, Sinsheimer J \& Cochrane BB (2006) Core concerns of couples living with early stage breast cancer. Psychooncology 15, 1055-1064.

So WK, Marsh G, Ling WM, Leung FY, Lo JC, Yeung M \& Li GK (2009) The symptom cluster of fatigue, pain, anxiety, and depression and the effect on the quality of life of women receiving treatment for breast cancer: a multicenter study. Oncol Nurs Forum 36, 205-214.

Soothill K, Morris SM, Harman J, Francis B, Thomas C \& Mclllmurray MB (2001) The significant unmet needs of cancer patients: probing psychosocial concerns. Support Care Cancer 9, 597-605. 
Soothill K, Morris SM, Thomas C, Harman JC, Francis B \& Mclllmurray MB (2003) The universal, situational, and personal needs of cancer patients and their main carers. Eur J Oncol Nurs 7, 5-13; discussion 14-16.

Tilden VP, Nelson CA \& May BA (1990) The IPR inventory: development and psychometric characteristics. Nurs Res 39, 337-343.

Wen K \& Gustafson D (2004) Need assessment for cancer patients and their families Health Qual. Life Outcomes 2, 2-12.

Yoon J, Malin JL, Tao ML, Tisnado DM, Adams JL, Timmer MJ, Ganz PA \& Kahn KL (2008) Symptoms after breast cancer treatment: are they influenced by patient characteristics? Breast Cancer Res Treat 108, 153-165.

Zigmond AS \& Snaith RP (1983) The hospital anxiety and depression scale. Acta Psychiatr Scand 67, 361370. 
Summary, Samenvatting \&

Zusammenfassung 


\section{SUMMARY}

Breast cancer changes the patients' life. The life-threatening nature of breast cancer and the consequences of the aggressive treatment regimes can result in a wide range of physical, emotional and social consequences which may influence the patients' needs. Breast cancer also places distress and strain on the patients' relatives and affects their needs. There is variability in how patients and their relatives react to breast cancer disease. Some patients and relatives have psychosocial care needs, while others have fewer or no needs. The experience with breast cancer can also change the relationship between the patients and their relatives. Understanding the impact of breast cancer on patients and their relatives early on during the illness and treatment process is clinically of prime importance, as it may help to give them appropriate care and support based on their needs.

In this dissertation we used an innovative approach in studying cancer patients' specific needs instead of focusing on the more general dimensions of quality of life. We addressed the supportive care needs of breast cancer patients under treatment and in their post-treatment phase, as well as their relatives' psychosocial needs. Further, we assessed the patients' cancer and treatment-related symptoms, the patients' and their relatives' psychological problems and their perception of their interpersonal relationship. We evaluated factors which are related to the patients' and their relatives' needs, and may identify patients and relatives who are more vulnerable and have unsatisfied psychosocial needs and therefore a higher demand for support.

To justify the research questions, chapter 1 provides a general introduction to the Swiss health care system, oncology-nursing and psychosocial needs of breast cancer patients and their relatives. The dissertation starts with a qualitative study which described the experiences of newly-diagnosed breast cancer patients (chapter 2) and with a review of the literature which provided a tentative model guiding the subsequent studies (chapter 3). The first of 3 quantitative studies focused on breast cancer patients' and their relatives' needs during the patients post-treatment phase (chapter 4). The second study investigated the breast cancer patients' supportive care needs during medical cancer treatment, and the third investigation evaluated the relatives' psychosocial needs of patients following breast cancer treatment (chapters 5 and 6).

Chapter 2 addresses the experiences of newly-diagnosed patients under treatment for breast cancer as derived from qualitative interviews. Ten patients were interviewed about their experiences, problems, fears and needs at the end of radiotherapy. The tape-recorded and transcribed interviews were analysed by content analysis and led to three main domains with two subtopics each. First: From living in 
fear of having breast cancer to the confirmation of its diagnosis with the subtopics shock and crisis. The women were deeply affected when they were confronted with the possibility that they might have breast cancer. The time until the diagnosis was established was often described as the most difficult time and the confirmed diagnosis was experienced as a shock. The disease was experienced as a sudden attack because the women had not felt ill before. They perceived the disease as an existential crisis. Some women associated the disease with death, they reacted with panic attacks, felt a total lack of energy, emptiness and often doubted whether they would have enough strength to get through the crisis. The second domain deals with: Experiencing therapy, with the subtopics impact of treatment on body and psyche, and being a patient and the relationship with health care professionals. The women did not perceive the operation (all ten women had breast-conserving surgery) as the most difficult part of the treatment; they suffered from the subsequent therapies. The treatment brought them to the brink of physical exhaustion, which also affected their emotional well-being. They were convinced that their psyche would recover along with their physical recovery. With the diagnosis, the women felt that they suddenly became a patient. The women were grateful for gentleness, because difficulties in contact with health care professionals led to a lack of confidence in their recovery and to helplessness, thus making it more difficult for them to bring their fears under control.

The third domain is: Endure and live with the two subtopics strengthen and protect yourself and mobilizing strength and finding coping strategies. The women felt that they had no choice; they had to deal with the disease and its treatment. The coherence and support from family helped in coping, but they felt that the cancer also affected their relatives. They often consciously spared their relatives and tried to create normality as soon as it was possible for them. Not giving up and believing in their inner strength was important, but it took time to gain new confidence.

In addition to these subjective experiences of women with breast cancer, we need to understand the psychosocial needs of these women and particularly of their relatives. Therefore, quantitative studies with standardized and structured data collection methods were performed in phases of treatment and after treatment.

Chapter 3 presents a literature review with the aim of reviewing the research on psychosocial needs of breast-cancer patients and their relatives and developing a tentative model considering both cancer patients' needs and the needs of their relatives to guide further research. The findings indicated that women with breast cancer had treatment-related needs both during active treatment and after such treatments. They felt physical impairments, suffered from treatment-induced menopausal symptoms and sexual problems and many suffered from a negative body image. The women's needs comprised also psychological and social needs. They 
perceived substantial distress, felt depressed and feared the spread or recurrence of breast cancer. Some women perceived improvements, others impairments in their social and familial relationships. They had high needs for information and professional support to help them manage their illness. Relatives needed more information about the patients' disease, the treatment and prognosis. On one side, they had a need to protect themselves from the threat of breast cancer and seemed on the other side to focus on the patients' illness and on the family. Many tried to subjugate their own feelings and needs to those of the patients. Factors such as familial or marital support, emotional distress, the communication flow and the patients' or the relatives' health condition influenced the interaction between the patients and their relatives. However, the literature review indicated a lack of knowledge concerning the patients' and particularly the relatives' needs. Only two of the studies in the review had an underlying definition of the concept of needs and used a specific need assessment instrument. More research is needed to evaluate the patients' and their relatives' specific needs and to determine which factors may influence the patients' and their relatives' needs. A tentative model was developed as a framework for further research.

Chapter 4 focuses on the psychosocial problems and needs of post-treatment patients with breast cancer and their relatives in Switzerland. The aim of this study was to assess the patients' and their relatives' met and unmet needs, their burden of illness, anxiety, depression and distress, further to assess the patients' cancer and cancer treatment-related symptoms and to identify factors which may influence the patients' and their relatives' needs. Using established measurement instruments, seventy-two newly-diagnosed breast cancer patients and their relatives were interviewed in this survey. The patients still had unmet care needs in their posttreatment phase mainly regarding psychological needs and sexual issues. The majority of the patients reported cancer and cancer treatment-related symptoms such as fatigue, pain, insomnia and endocrine symptoms. Nearly 50 percent felt impaired at work and in daily and leisure activities. Their relatives indicated high needs for information and were not satisfied with the access to health care professionals or the support they received. The relatives had higher levels of anxiety, depression, distress and higher burden of suffering than the patients. Depression, higher burden of suffering and more cancer and cancer treatment-related symptoms were associated with the patients' supportive care needs. Depression, younger age and having a disease themselves were related to the relatives' psychosocial needs. Patients and their relatives had substantial unmet needs even after completion of the patients' treatment. This study provides a basis for continued and specific assessment of the patients' and their relatives' needs and the patients' high symptom burden and for purposeful professional support and counselling. 
Chapter 5 reports research findings of patients $(n=175)$ under treatment for breast cancer. The aim of this study was 1 ) to gain insight into the patients' supportive care needs, insight into treatment-related symptoms, and in the patients' anxiety, depression and distress, 2) to identify how the patients perceive their interpersonal relationships and 3) to determine factors associated with supportive care needs. The patients' supportive care needs were predominately related to the domains physical daily living, health care system and information and psychological needs, less important were the needs related to the domains sexuality and care and support. The patients had high levels of cancer and cancer treatment-related symptoms. More than eighty percent suffered from fatigue and body strains, more than seventy percent felt impaired by hot flashes, at work, in daily or leisure activities and more than fifty percent suffered from changes in body appearance and body perception. The patients perceived social support and reciprocity in their interpersonal relationship but also conflicts. More than half of the patients suffered from clinically-evident distress. The most important factors which were associated with the patients' supportive care needs were the treatment-related symptoms, such as impaired body image and physical and social impairment. Distress, anxiety, depression and conflict in the interpersonal relationship were factors which predicted the patients' unmet needs, whereas perceived social support in the interpersonal relationship was associated with fewer unmet needs. The factors evaluated in this study may help to identify early more vulnerable patients at risk of psychosocial problems and with unmet needs.

Chapter 6 addresses the psychosocial needs of close relatives $(n=107)$ of women under treatment for breast cancer. The aim of the study was 1) to gain insight into the psychosocial needs, anxiety, depression and distress of close relatives, 2) to identify the relative's perception of his or her interpersonal relationship with the patient and 3) to determine factors associated with the close relatives' needs.

Between 34 and 50 percent of the relatives reported that they had problems in getting honest information, information about what to expect and about the patients' medication and its side effects. They needed help to develop hope for the future. They had difficulties with confidence in the health professionals, in being treated with respect by doctors and getting time from doctors to discuss problems with them. More than sixty percent suffered from clinically-evident distress and one-fourth had problems with anxiety. Relatives also perceived support and conflicts in their relationships with the patients. Distress, anxiety and conflict in the interpersonal relationship were the most important factors associated with the relatives' unmet psychosocial needs and may identify more vulnerable relatives who need more support and attention. The findings of this study enhance the knowledge of the psychosocial needs of relatives of breast cancer patients and provide a basis for purposeful support. 
Chapter 7 discusses the main findings of the studies and presents some methodological reflections. Important findings were that many patients reported unmet needs and high levels of cancer and cancer treatment-related symptoms during and in their post-treatment phase. Relatives had problems getting access to information and to health care professionals. The patients and their relatives perceived support, but also conflicts in their interpersonal relationship. However, not all patients and relatives have the same need for help. Therefore the factors evaluated in these studies are most important to identify patients and relatives with unmet needs and a higher demand for help and to conduct targeted support to those who actually need it.

Specific assessments in clinical routine enable health care professionals to provide appropriate information, purposeful symptom-management, support and counselling which may help patients to satisfy their unmet needs. Relatives of breast cancer patients need more attention from health care professionals who are key persons in contact with close relatives. Health care professionals can intensify the flow of information, help relatives to relieve anxiety and distress and can promote communication between the patient and their relatives. Further, the patients' and their relatives' interpersonal relationship should be addressed.

Methodological criticism may include that the studies were cross-sectional, and that no appropriate instrument was found to measure the patients' and their relatives' needs. Two different instruments were used with the disadvantage that a direct comparison of the patients' and their relatives' needs was not possible.

This dissertation demonstrates the need of well trained breast care nurses in Switzerland and provides a knowledge base for their education and for further development of clinical practice.

Further research should focus on frequently and concurrently occurring cancer and cancer treatment-related symptoms and how they are related to the patients' needs. More insight is needed to understand the full impact of breast cancer on the patients' relatives and their needs. Future research should also focus on the patients' and their relatives' interpersonal relationship. Longitudinal studies with large sample sizes are important to assess changes in patients' and their relatives' needs over time. 


\section{SAMENVATTING (Summary in Dutch)}

Borstkanker verandert het leven van de patiënt. Het levensbedreigende karakter van borstkanker en de gevolgen van het vaak agressieve behandelingsregime, kunnen een groot aantal fysieke, emotionele en sociale gevolgen hebben die van invloed kunnen zijn op de behoeften van de patiënt. Borstkanker veroorzaakt ook stress en spanning bij de familieleden van de patiënt en beïnvloedt ook hun behoeften. Er is een groot verschil in hoe patiënten en hun familieleden op borstkanker reageren. Sommige patiënten en familieleden hebben behoefte aan psychosociale zorg terwijl anderen weinig of geen behoefte hebben aan zorg. Borstkanker kan ook de relatie tussen patiënt en familieleden veranderen. Het vaststellen van de invloed van borstkanker op patiënten in de beginfase van de ziekte en het behandelingsproces en ook in de periode na afsluiting van de behandeling is van groot belang, aangezien dit kan helpen om zorg te verlenen die aansluit op de behoeften van patiënten.

In het onderzoek waarop dit proefschrift is gebaseerd, is een innovatieve benadering toegepast die met name was gericht op het vaststellen van de specifieke behoeften van de borstkankerpatiënten in plaats van het zich uitsluitend richten op het meten van de meer algemene dimensies van de kwaliteit van leven. Hierbij werd vooral aandacht besteed aan de behoeften aan ondersteunende zorg van borstkankerpatiënten tijdens de behandeling en de periode daarna, evenals aan de psychosociale behoeften van hun familieleden. Verder werden de aan de ziekte en behandeling gerelateerde lichamelijke symptomen van de patiënt gemeten, de psychische problemen van de patiënten en de familieleden en de percepties van hun inter-persoonlijke relaties. Eveneens werden factoren vastgesteld die samenhangen met de behoeften van patiënten en familieleden en die gebruikt kunnen worden om de meer kwetsbare patiënten en familieleden die behoeften hebben waarin niet is voorzien, te identificeren.

Voor de onderbouwing van de onderzoeksvragen wordt in Hoofdstuk 1 een algemene inleiding gegeven in het gezondheidszorgsysteem van Zwitserland, de oncologische verpleegkunde en de psychosociale behoeften van borstkankerpatiënten en hun familieleden.

Dit proefschrift begint met de beschrijving van een kwalitatief onderzoek waarin de ervaringen van recent gediagnosticeerde borstkankerpatiënten worden beschreven (hoofdstuk 2) en met een overzicht van literatuur hetgeen heeft geleid tot een tentatief model dat richtinggevend is geweest voor enkele kwantitatieve vervolgstudies (hoofdstuk 3). De eerste van 3 kwantitatieve studies was gericht op het beschrijven van de behoeften van patiënten en hun familieleden tijdens de behandeling voor borstkanker en op de behoeften in de periode daarna (hoofdstuk 4). In een tweede kwantitatief onderzoek werden de behoeften van borstkankerpatiënten 
aan ondersteunende zorg tijdens de medische behandeling onderzocht en in het derde kwantitatieve onderzoek werden de psychosociale behoeften van familieleden van patiënten die voor borstkanker werden behandeld, beschreven en geanalyseerd (hoofdstukken 5 en 6 ).

Hoofdstuk 2 is gericht op het beschrijven van de ervaringen van nieuw gediagnosticeerde patiënten die onder behandeling waren voor borstkanker. Tien patiënten werden geïnterviewd over hun ervaringen, problemen, angsten en behoeften na de beëindiging van de radiotherapie. De op een band opgenomen interviews werden na het uitschrijven geanalyseerd door middel van inhoudsanalyse wat resulteerde in een drietal domeinen met ieder een tweetal subtopics. Ten eerste: het leven met de vrees borstkanker te hebben tot de bevestiging van de diagnose met de twee topics schok en crisis. De vrouwen werden diep geraakt toen ze werden geconfronteerd met de mogelijkheid dat ze borstkanker zouden kunnen hebben. De tijd tussen het vermoeden dat er sprake kon zijn van borstkanker en de feitelijke diagnose, werd vaak beschreven als de moeilijkste tijd en de bevestiging van de diagnose werd ervaren als een grote schok. De ziekte werd ervaren als een plotselinge aanval omdat de vrouwen zich voordien niet ziek voelden. Ze ervaarden de ziekte als een existentiële crisis. Sommige vrouwen associeerden de ziekte met de dood, ze reageerden met paniekaanvallen, voelden leegheid en een totaal gebrek aan energie en ze twijfelden vaak of ze voldoende kracht zouden hebben om door deze crisis te komen.

Het tweede domein betrof: de ervaring van de behandeling met de subtopics invloed van de behandeling op lichaam en geest en het patiënt zijn en de relatie met de zorgverleners. De vrouwen hebben de operatie (alle vrouwen ondergingen een borstsparende operatie) niet als het moeilijkste deel van de behandeling ervaren; ze leden meer van de aansluitende chemotherapie, radiotherapie of endocriene behandeling. De behandeling bracht hen aan de rand van fysieke uitputting, die weer hun emotioneel welzijn beïnvloedde. Ze verwachtten dat na hun lichamelijk herstel ook psychisch herstel zou volgen. Met de diagnose voelden de vrouwen dat ze plotseling patiënt werden. De vrouwen waren dankbaar voor zachtheid en vriendelijkheid van zorgverleners omdat moeilijkheden in contacten met zorgverleners leidden tot een gebrek aan vertrouwen in het herstel en tot hulpeloosheid, waardoor het voor hen weer moeilijker werd om hun angsten onder controle te houden.

Het derde domein betrof: volhouden en blijven leven met de twee subtopics jezelf sterker maken en beschermen en kracht verzamelen en manieren zoeken om met problemen om te gaan. De vrouwen voelden dat ze geen keus hadden; ze moesten omgaan met de ziekte en de behandeling. Eensgezindheid en steun van familieleden hielp bij het omgaan met problemen maar ze merkten ook dat de kanker invloed had op hun familieleden. Vaak beschermden patiënten bewust hun familieleden en zodra het mogelijk was probeerden ze een zo normaal mogelijk 
leven te leiden. Niet opgeven en in de eigen innerlijke kracht geloven was belangrijk, maar het vereiste tijd om weer opnieuw zelfvertrouwen te ontwikkelen.

Behalve het vaststellen van de subjectieve ervaringen van vrouwen met borstkanker is het belangrijk dat de psychosociale behoeften van deze vrouwen worden gekwantificeerd en begrepen evenals de behoeften van hun naasten. Daarom werd bij patiënten en hun familieleden tijdens en na de behandeling ook kwantitatief onderzoek verricht met behulp van gestructureerde en gestandaardiseerde vragenlijsten.

In hoofdstuk 3 wordt een literatuurstudie beschreven met als doel een overzicht geven van onderzoek naar de psychosociale behoeften van patiënten met borstkanker en hun familieleden en het ontwikkelen van een tentatief model voor verder onderzoek naar de behoeften van patiënten en hun naasten. De resultaten wijzen er op dat vrouwen met borstkanker behoeften hadden die samenhingen met hun behandeling, zowel tijdens de behandeling als in de periode na afsluiting van de behandeling. Ze voelden zich fysiek gehandicapt, leden aan symptomen van menopauze als gevolg van de behandeling, hadden seksuele problemen en velen hadden een negatief lichaamsbeeld. Ze ervaarden ook veel stress, voelden zich depressief, waren bang voor uitzaaiingen of het terugkeren van de borstkanker. Sommige vrouwen ervaarden verbeteringen in hun sociale en familierelaties terwijl anderen daarentegen verstoringen ervaarden. Ze hadden veel behoefte aan informatie en professionele steun om hen te helpen bij het omgaan met hun ziekte. Familieleden hadden behoefte aan meer informatie over de ziekte van de patiënt, de behandeling en de prognose. Aan de ene kant hadden familieleden behoefte om zichzelf te beschermen tegen de bedreiging van de borstkanker terwijl ze aan de andere kant zich leken te richten op de ziekte van de patiënt en op hun gezin. Velen probeerden hun eigen gevoelens en behoeften te projecteren op die van de patiënt. Factoren zoals steun van de partner en familie, emotionele stress, en de gezondheidstoestand van de patiënt en van familieleden, waren van invloed op de communicatie over en weer tussen patiënten en hun familieleden. De literatuurstudie wees ook op een gebrek aan kennis over de behoeften van patiënten en speciaal over de behoeften van naasten van patiënten met borstkanker. Slechts twee van de studies in het overzicht van de literatuur gebruikten een definitie van het concept "behoeften" en gebruikten een instrument om door patiënten ervaren specifieke behoeften te meten. Meer onderzoek bleek nodig om de specifieke behoeften van patiënten en hun familieleden te bepalen en om vast te stellen welke factoren de behoeften van patiënten en familieleden kunnen bepalen. Als een raamwerk voor verder onderzoek werd een tentatief model ontwikkeld.

Hoofdstuk 4 is gericht op de psychosociale problemen en behoeften van patiënten met borstkanker en hun familieleden in Zwitserland in de fase na de behandeling. 
Het doel van dit onderzoek was om de behoeften van patiënten en hun familieleden waaraan werd voldaan en de behoeften waaraan niet werd voldaan te meten, evenals de belasting door de ziekte, de ervaren angst, depressie en stress. Verder werden de symptomen van de kanker en de behandeling daarvoor onderzocht en werden factoren geïdentificeerd die van invloed kunnen zijn op de behoeften van patienten en hun familieleden. In dit onderzoek werden 72 patiënten waarbij de behandeling recent was afgesloten onderzocht en hun familieleden, waarbij gebruik werd gemaakt van gevalideerde meetinstrumenten. In de fase direct na de behandeling hadden deze patiënten nog steeds behoefte aan zorg waarin niet was voorzien, vooral met betrekking tot psychische behoeften en seksuele onderwerpen. De meerderheid van de patiënten rapporteerden symptomen die aan de kanker of de behandeling daarvan waren gerelateerd, zoals moeheid, pijn en endocriene symptomen. Bijna 50 procent voelde zich gehandicapt bij hun werk, dagelijkse activiteiten en vrijetijdsbesteding. Bij de familieleden bleek een grote behoefte te bestaan aan informatie en ze waren niet tevreden over hun toegang tot zorgverleners of met de steun die ze ontvingen. Familieleden hadden een hoger niveau van angst, depressieve gevoelens, stress en ervaarden een hogere belasting dan de patiënten. Bij de patiënten waren depressie, ervaren belasting en meer symptomen van de kanker en de behandeling daarvoor, gerelateerd aan meer behoeften aan ondersteunende zorg. Bij de familieleden waren depressie, een jongere leeftijd en het zelf lijden aan een ziekte gerelateerd aan meer psychosociale behoeften. Patiënten en hun familieleden hadden substantiële behoeften waarin niet was voorzien, zelfs na afsluiting van de behandeling van de patiënt. De resultaten van dit onderzoek bieden een onderbouwing voor herhaald en specifiek meten van de behoeften van patiënten en hun familieleden en meten van de belasting door de symptomen van de patiënt ten behoeve van een doelgerichte, professionele ondersteuning en begeleiding.

In hoofdstuk 5 worden onderzoeksresultaten gerapporteerd van 175 patiënten die onder behandeling zijn voor borstkanker. Het doel van dit onderzoek was 1 ) inzicht verkrijgen in de behoeften van de patiënt aan ondersteunende zorg, in de aan de behandeling gerelateerde symptomen en in het voorkomen van angst, depressie en stress; 2) vaststellen hoe patiënten hun inter-persoonlijke relaties ervaren; en 3 ) vaststellen van factoren die geassocieerd zijn met de behoefte aan ondersteunende zorg. De behoeften van de patiënt aan ondersteunende zorg waren hoofdzakelijk gerelateerd aan de domeinen van het dagelijkse leven, behoeften met betrekking tot het systeem van de gezondheidszorg, behoefte aan informatie en aan psychosociale steun. Minder belangrijk waren de behoeften gerelateerd aan het domein van de seksualiteit en dat van zorg en ondersteuning. De patiënten hadden veel symptomen die gerelateerd waren aan de kanker en de behandeling daarvoor. Meer dan $80 \%$ leed aan vermoeidheid of voelde zich lichamelijk zwaar belast, meer dan $70 \%$ 
had last van opvliegers tijdens het werk of bij dagelijkse activiteiten of vrijetijdsbesteding en meer dan $50 \%$ had last van uiterlijke veranderingen van het lichaam en had een negatief lichaamsbeeld. De patiënten ervaarden sociale steun en wederkerigheid in hun inter-persoonlijke relaties, maar eveneens conflicten. Meer dan de helft van de patiënten leed aan klinische stress. De belangrijkste factoren die geassocieerd waren met de behoeften van de patiënt aan ondersteunende zorg waren de aan de behandeling gerelateerde symptomen, zoals een negatief lichaamsbeeld en fysieke en sociale problemen. Stress, angst, depressie en conflicten in interpersoonlijke relaties waren factoren die voorspelden of patiënten behoeften hadden waarin niet was voorzien, terwijl het ervaren van steun in inter-persoonlijke relaties gerelateerd was aan minder behoeften waarin niet was voorzien. Een aantal factoren die werden bestudeerd in dit onderzoek kunnen behulpzaam zijn bij het herkennen van kwetsbare patiënten met een risico voor het ontwikkelen van psychosociale problemen en van patiënten met behoeften waarin niet wordt voorzien.

In hoofdstuk 6 worden de psychosociale behoeften van nauw betrokken familieleden (meestal de partner) ( $n=107$ ) van patiënten die worden behandeld, beschreven. Het doel van dit onderzoek was 1 ) inzicht verkrijgen in psychosociale behoeften en angst, depressie en stress bij nauw betrokken familieleden; 2 ) identificeren van de percepties van naasten van hun inter-persoonlijke relatie met de patiënt; 3 ) bepalen van factoren die geassocieerd zijn met de behoeften van nauw betrokken familieleden.

Tussen de 34 en 50 procent van de familieleden rapporteerden dat ze problemen hadden met het krijgen van eerlijke informatie, zoals informatie over wat er gaat komen en over de medicatie van de patiënt en de bijverschijnselen daarvan. Zij hadden hulp nodig om weer hoop te krijgen met betrekking tot de toekomst. Zij hadden problemen met vertrouwen in de zorgverleners, met het niet met respect behandelt worden door artsen en met het krijgen van tijd en aandacht van dokters om problemen met hen te bespreken. Meer dan $60 \%$ ervaarde stress en $25 \%$ had angstproblemen. Familieleden ervaarden zowel steun als conflicten in hun interpersoonlijke relatie met patiënten. Stress, angst en problemen in de interpersoonlijke relatie waren de belangrijkste factoren die samenhingen met het hebben van psychosociale behoeften van familieleden waarin niet werd voorzien en deze kunnen gebruikt worden om kwetsbare familieleden die meer steun en aandacht nodig hebben, te identificeren. De resultaten van dit onderzoek dragen bij aan de kennis over de psychosociale behoeften van familieleden van patiënten met borstkanker en bieden een basis voor doelgerichte steun.

In hoofdstuk 7 worden de belangrijkste resultaten van het onderzoek in dit proefschrift besproken en wordt een methodologische beschouwing van het onderzoek gegeven. Belangrijke bevindingen waren dat borstkankerpatiënten in dit onderzoek 
in de periode na de behandeling veel behoeften rapporteerden waarin niet werd voorzien en dat zij veel symptomen hadden die samenhingen met de kanker en de behandelingen daarvoor. Familieleden van patiënten hadden vooral problemen met het krijgen van toegang tot informatie en tot zorgverleners. De patiënten en hun familieleden ervaarden steun, maar ook conflicten in hun inter-persoonlijke relatie. Een aantal factoren die werden bestudeerd in deze onderzoeken zijn belangrijk om patiënten en familieleden met behoeften waarin niet wordt voorzien, te identificeren evenals degenen die een grotere behoefte hebben aan hulp, teneinde doelgerichte steun te kunnen bieden. Door specifieke meting van behoeften van patiënten in de klinische praktijk kunnen zorgverleners de nodige informatie geven, doelgericht management van symptomen bieden en sociale steun en begeleiding geven, waardoor kan worden voorzien in de behoeften van patiënten. Familieleden van patiënten met borstkanker hebben meer aandacht nodig van zorgverleners die al een sleutelrol vervullen in de contacten met familieleden van de patiënt. Zorgverleners in de oncologische zorg kunnen meer informatie geven en familieleden helpen om angst en stress te verminderen en de communicatie tussen patiënt en familieleden te bevorderen. Verder is van belang dat aandacht wordt besteed aan de interpersoonlijke relatie tussen patiënt en familieleden.

Methodologische kanttekeningen bij het onderzoek: de onderzoeken die werden uitgevoerd waren cross-sectioneel en er was geen algemeen gevalideerd instrument beschikbaar om zowel de behoeften van patiënten als die van familieleden te meten. Er werden twee, deels verschillende instrumenten gebruikt, waardoor een directe vergelijking tussen de behoeften van patiënten en familieleden niet mogelijk was.

Dit proefschrift laat de duidelijke behoefte zien aan goed getrainde borstkankerverpleegkundigen in Zwitserland en biedt een basis voor de verdere ontwikkeling van hun opleiding en voor de klinische praktijk.

Verder onderzoek zou moeten worden uitgevoerd naar vaak voorkomende en onderling samenhangende symptomen bij borstkanker en de behandeling daarvan en hoe deze zich verhouden tot de behoeften van de patiënt. Meer inzicht is nodig om de invloed van borstkanker op de familieleden van patiënten en hun behoeften te begrijpen. Verder onderzoek zou zich ook moeten richten op de interpersoonlijke relatie tussen patiënt en familieleden. Longitudinaal onderzoek bij grote steekproeven van patiënten is van belang om de veranderingen in de behoeften van patiënten en hun familieleden met het verloop van de tijd te meten. 


\section{ZUSAMMENFASSUNG (Summary in German)}

Brustkrebs verändert das Leben der Patientinnen. Die Lebensbedrohung die von Brustkrebs ausgeht und die Folgen der aggressiven Therapieverfahren können zu physischen, emotionalen und sozialen Beeinträchtigungen führen, welche die Bedürfnisse der Patientinnen beeinflussen können. Brustkrebs verursacht auch Stress und Spannungen bei den Angehörigen der Patientinnen und beeinflusst deren Bedürfnisse. Es gibt Unterschiede wie Patientinnen und Angehörige auf die Brustkrebserkrankung reagieren. Einige der Patientinnen und Angehörigen haben psychosoziale Bedürfnisse, andere haben weniger oder keine Bedürfnisse. Auch die Beziehung zwischen den Patientinnen und ihren Angehörigen kann durch Brustkrebs verändert werden. Klinisch ist es von grosser Bedeutung, früh im Krankheits- und Therapieprozess zu verstehen, welchen Einfluss der Brustkrebs auf die Patientinnen und ihre Angehörigen hat. Das kann helfen, ihnen die angemessene Pflege und Unterstützung zu geben, welche auf ihren Bedürfnissen basiert.

Für diese Dissertation wählten wir einen innovativen Ansatz, der die spezifischen Bedürfnisse der Krebspatientinnen untersucht, anstatt sich an den eher generellen Dimensionen der Lebensqualität zu orientieren. Wir beschäftigten uns mit den Unterstützungsbedürfnissen der Brustkrebspatientinnen während der Krebstherapie und in der Zeit nach dieser Therapie, aber auch mit den psychosozialen Bedürfnissen ihrer Angehörigen. Weiter haben wir die Krankheits- und therapiebedingten Symptome der Patientinnen, die psychologischen Probleme der Patientinnen und ihrer Angehörigen, und die Einschätzung der zwischenmenschlichen Beziehungen der Patientinnen zu ihren engsten Bezugspersonen und der Angehörigen zu den Patientinnen erhoben. Wir haben Faktoren evaluiert, welche mit den Bedürfnissen der Patientinnen und deren Angehörigen in Zusammenhang stehen, und die verletzlichere Patientinnen und Angehörige mit nicht zufriedengestellten Bedürfnissen und mit einem höheren Unterstützungsbedarf identifizieren können.

Um die Forschungsfragen zu begründen, präsentiert das Kapitel 1 eine generelle Einführung in das Schweizerische Gesundheitssystem, die onkologische Pflege und die psychosozialen Bedürfnisse von Brustkrebspatientinnen und ihrer Angehörigen. Die Dissertation beginnt mit einer qualitativen Studie, welche die Erfahrungen von neu diagnostizierten Brustkrebspatientinnen beschreibt (Kapitel 2) und mit einer Literaturübersicht, die ein vorläufiges Modell zur Verfügung stellt, welches die nachfolgenden Studien leitete (Kapitel 3). Die erste der drei quantitativen Studien konzentrierte sich auf die Bedürfnisse von Brustkrebspatientinnen und ihrer Angehörigen während der Nachtherapie-Phase der Patientinnen (Kapitel 4). Die zweite Studie untersuchte die Unterstützungsbedürfnisse der Brustkrebspatientinnen während der medizinischen Therapie und die dritte Untersuchung evaluierte die psy- 
chosozialen Bedürfnisse der Angehörigen der Brustkrebspatientinnen während deren Therapie (Kapitel 5 und 6).

Das Kapitel 2 beschäftigt sich mit den Erfahrungen, die neu diagnostizierte Brustkrebspatientinnen während ihrer Krebstherapie gemacht haben, und welche durch qualitative Interviews erhoben wurden. Zehn betroffene Frauen wurden am Ende der Radiotherapie über ihre Erfahrungen, Probleme, Ängste und Bedürfnisse interviewt. Die Tonbandaufnahmen der Interviews wurden transkribiert und durch eine qualitative Inhaltsanalyse ausgewertet. Diese Analyse führte zu drei Hauptthemen mit je zwei Unterthemen. Erstens: Von der Angst an Brustkrebs zu leiden, zur Bestätigung der Diagnose, mit den Unterthemen Schock und Krise. Die betroffenen Frauen waren zutiefst betroffen, als sie mit der Möglichkeit, an Brustkrebs zu leiden, konfrontiert waren. Die Zeit bis zur Bestätigung der Diagnose wurde oft als die schwierigste Zeit beschrieben, und die definitive Diagnose wurde als Schock empfunden. Die Krankheit wurde als plötzliche Attacke erlebt, weil sich die Frauen vorher nicht krank gefühlt hatten. Sie erlebten eine existentielle Krise. Einige der Frauen assoziierten die Krankheit mit dem Tod, sie reagierten mit Panikattacken, fühlten sich energielos und total leer und zweifelten oft, genügend Kraft zu haben, um diese Krise zu überstehen. Das zweite Haupttema behandelt das Erleben der Therapie mit den beiden Unterthemen, der Einfluss der Therapie auf den Körper und die Seele und Patientin zu sein und die Beziehung zu den Gesundheitspersonen. Die Frauen erlebten nicht die Operation als den schwierigsten Teil der Behandlung (alle 10 Frauen wurden brusterhaltend operiert); sie litten unter den nachfolgenden Therapien. Die Therapien brachten sie an den Rand der physischen Erschöpfung, welche auch ihr psychisches Wohlbefinden beeinträchtigte. Sie waren überzeugt, dass sie sich mit der physischen Erholung auch psychisch wieder erholen würden. Mit der Diagnose wurden die Frauen plötzlich zu Patientinnen. Die Frauen waren sehr dankbar für Freundlichkeit, denn Schwierigkeiten im Kontakt mit Gesundheitspersonen führten zu mangelndem Vertrauen in ihren Gesundungsprozess und zu Hilfslosigkeit, welche es ihnen erschwerte, ihre Gefühle unter Kontrolle zu bringen.

Das dritte Hauptthema ist: Durchhalten und leben, mit den zwei Unterthemen, sich stärken und schützen und Kräfte zu mobilisieren und Wege zur Bewältigung zu finden. Die Frauen spürten, dass sie keine andere Wahl hatten, als sich mit der Krankheit und deren Behandlung auseinanderzusetzen. Der Zusammenhalt und die Unterstützung durch die Familie hatten ihnen bei der Bewältigung geholfen aber sie merkten auch, dass die Krebserkrankung auch ihre Angehörigen stark belastete. Sie versuchten oft bewusst, ihre Angehörigen zu schonen, und so schnell als möglich für diese wieder eine Normalität herzustellen. Nicht aufzugeben und an die eigenen inneren Kräfte zu glauben war wichtig. Aber es brauchte Zeit, um eine neue Zuversicht zu gewinnen. 
Nebst diesen subjektiven Erfahrungen der an Brustkrebs leidenden Frauen müssen wir auch die psychosozialen Bedürfnisse dieser Frauen, und vor allem die ihrer Angehörigen verstehen. Darum wurden quantitative Studien mit standardisierten und strukturierten Datenerhebungsmethoden in Phasen während der Therapie und nach der Therapie durchgeführt.

Kapitel 3 präsentiert eine Literaturübersicht mit dem Ziel, die Forschungsliteratur über die psychosozialen Bedürfnisse von Patientinnen mit Brustkrebs und von ihren Angehörigen zu analysieren, und ein vorläufiges Modell zu entwickeln, welches die Bedürfnisse von Frauen mit Brustkrebs und die Bedürfnisse ihrer Angehörigen berücksichtigt, und welches die zukünftige Forschung leiten kann. Die Ergebnisse zeigen, dass die Frauen mit Brustkrebs therapiebedingte Bedürfnisse hatten, sowohl während der Therapiezeit als auch nach diesen Therapien. Sie fühlten sich physisch eingeschränkt, litten unter Therapie induzierten menopausalen Symptomen und sexuellen Problemen, und viele hatten Probleme mit ihrem Body Image. Sie litten unter substantiellem Stress, fühlten sich depressiv und fürchteten, der Brustkrebs könnte sich ausbreiten oder zurück kommen. Einige der betroffenen Frauen nahmen eine Verbesserung, andere eine Verschlechterung der sozialen und familiären Beziehungen wahr. Sie hatten grosse Informationsbedürfnisse und Bedürfnisse nach professioneller Unterstützung durch Gesundheitspersonen, die ihnen helfen sollten, ihre Krankheit zu managen. Angehörige brauchten mehr Informationen über die Krankheit, die Therapie und die Prognose der Patientinnen. Einerseits hatten sie ein Bedürfnis, sich selbst vor der Bedrohung durch den Brustkrebs zu schützen, andererseits schienen sie ein Bedürfnis zu haben, sich auf die Erkrankung der Patientin und die Familie zu konzentrieren. Viele versuchten, ihre eigenen Gefühle und Bedürfnisse denjenigen der Patientinnen unterzuordnen. Faktoren, wie die Unterstützung in der Beziehung oder durch die Familie, emotionaler Stress, Kommunikationsfluss und der Gesundheitszustand der Patientinnen oder der Angehörigen, beeinflussten die Interaktion zwischen den Patientinnen und ihren Angehörigen. Allerdings zeigte die Literaturübersicht auch einen Mangel an Wissen über die Bedürfnisse der Patientinnen und vor allem der Angehörigen auf. Nur zwei der analysierten Studien wiesen eine zugrundeliegende Definition des Bedürfniskonzeptes auf und setzten ein spezifisches Instrument zur Erhebung der Bedürfnisse ein. Mehr Forschung ist nötig, um die spezifischen Bedürfnisse der Patientinnen und ihrer Angehörigen zu erheben, und um zu eruieren, welche Faktoren die Bedürfnisse der Patientinnen und ihrer Angehörigen beeinflussen könnten. Es wurde ein vorläufiges Modell als Grundstruktur für die spätere Forschung entwickelt.

Das Kapitel 4 fokussiert die psychosozialen Probleme und Bedürfnisse von Schweizer Brustkrebspatientinnen in der Zeit nach der Therapie und von ihren Angehörigen. Das Ziel dieser Studie war, die erfüllten und nichterfüllten Bedürfnisse von 
Patientinnen und ihren Angehörigen, deren Belastungen durch Krankheit, Angst, Depression, Stress und die Krankheits- und therapiebedingten Symptome der Patientinnen zu erheben, und Faktoren zu identifizieren, welche die Bedürfnisse der Patientinnen und ihrer Angehörigen beeinflussen könnten. Mittels etablierter Messinstrumente wurden 72 neu diagnostizierte Brustkrebspatientinnen und ihre Angehörigen in dieser Umfrage interviewt. Die Patientinnen hatten auch in ihrer Nachtherapiezeit immer noch nicht erfüllte Bedürfnisse, hauptsächlich psychologische, und solche, die ihre Sexualität betrafen. Die Mehrheit der Patientinnen litt unter Krankheits- und therapiebedingten Symptomen wie Fatigue (Müdigkeit), Schmerzen, Schlaflosigkeit und endokrinen Symptomen. Gegen $50 \%$ fühlten sich in ihrer Arbeitstätigkeit und den täglichen und Freizeitaktivitäten eingeschränkt. Ihre Angehörigen hatten hohe Informationsbedürfnisse, und waren nicht zufrieden mit dem Zugang zu Gesundheitspersonen oder der Unterstützung, die sie erhielten. Die Angehörigen hatten mehr Angst, Depressivität, Stress, und wiesen eine höhere Belastung und ein höheres Leiden durch die Krankheit aus, als die Patientinnen selbst. Depressivität, eine höhere Belastung und ein höheres Leiden durch die Krankheit und mehr krankheits- und therapiebedingte Symptome, hatten einen Zusammenhang mit erhöhten Unterstützungsbedürfnissen der Patientinnen. Depressivität, ein tieferes Lebensalter und selbst an einer Erkrankung zu leiden, hatten einen Zusammenhang mit erhöhten psychosozialen Bedürfnissen der Angehörigen. Die Patientinnen und ihre Angehörigen hatten auch nach dem Abschluss der Therapie substantielle, nicht zufriedengestellte Bedürfnisse. Die Ergebnisse dieser Studie liefern eine Grundlage für kontinuierliche und spezifische Assessments der Bedürfnisse der Patientinnen und deren Angehörigen, für die Erhebung der hohen Symptombelastung der Patientinnen und für die zielgerichtete und professionelle Unterstützung und Beratung.

Kapitel 5 zeigt Forschungsergebnisse von Patientinnen auf $(n=175)$, die wegen Brustkrebs behandelt werden. Das Ziel dieser Studie war 1) Erkenntnisse über die Unterstützungsbedürfnisse der Patientinnen, über ihre therapiebedingten Symptome, ihre Angst, Depressionen und über ihren Stress zu gewinnen, 2) zu evaluieren, wie die Patientinnen ihre zwischenmenschliche Beziehung zu ihrer engsten Bezugsperson erfahren, und 3) Faktoren zu identifizieren, welche mit ihren Unterstützungsbedürfnissen in Zusammenhang stehen. Die Bedürfnisse, in denen die Patientinnen Unterstützung brauchten, betrafen vorwiegend die Bereiche physische Bedürfnisse in den täglichen Aktivitäten, Gesundheitssystem und Information und psychologische Bedürfnisse, weniger wichtig waren Bedürfnisse in den Bereichen Sexualität und Betreuung und Hilfestellung. Die Patientinnen hatten viele krankheits- und therapiebedingte Symptome. Mehr als achtzig Prozent litten unter Fatigue und körperlichen Belastungen; mehr als siebzig Prozent fühlten sich durch Hitzewallungen, bei der Arbeit, in den täglichen und Freizeitaktivitäten eingeschränkt, 
und mehr als fünfzig Prozent litten unter der veränderten körperlichen Erscheinung und Körperwahrnehmung. Die Patientinnen erfuhren in ihrer Beziehung Unterstützung, Reziprozität, aber auch Konflikte. Mehr als die Hälfte der Patientinnen litt unter klinisch relevantem Stress. Die wichtigsten Faktoren, die mit den Unterstützungsbedürfnissen der Patientinnen in Beziehung standen, waren die therapiebedingten Symptome, wie beeinträchtigtes Body Image und physische und soziale Einschränkungen. Stress, Angst, Depressivität und Konflikte in der Beziehung waren Faktoren, welche mit den unerfüllten Bedürfnissen der Patientinnen assoziiert waren, während mehr soziale Unterstützung in der Beziehung mit weniger unerfüllten Bedürfnissen in Zusammenhang standen. Die in dieser Studie evaluierten Faktoren können helfen, frühzeitig verletzlichere Patientinnen mit einem höheren Risiko für psychosoziale Probleme und mit unerfüllten Bedürfnissen zu identifizieren.

Das Kapitel 6 befasst sich mit den psychosozialen Bedürfnissen der engsten Angehörigen ( $n=107)$ von Frauen, die wegen Brustkrebs in Behandlung sind. Das Ziel dieser Studie war, 1) Erkenntnisse über die psychosozialen Bedürfnisse, Angst, Depressivität und Stress der engsten Angehörigen zu gewinnen, 2) zu evaluieren, wie die Angehörigen ihre zwischenmenschliche Beziehung zur Patientin erfahren, und 3) Faktoren zu identifizieren, welche mit den Bedürfnissen der Angehörigen in Beziehung stehen.

Zwischen 34\% und 50\% der Angehörigen berichteten, Probleme zu haben, ehrliche Informationen und Informationen über die Medikamente der Patientinnen und deren Nebenwirkungen zu bekommen, und Informationen darüber zu erhalten, was sie zu erwarten hätten. Sie brauchten Unterstützung, um Hoffnung für die Zukunft zu entwickeln. Sie hatten Probleme mit dem Vertrauen in die Gesundheitspersonen, Schwierigkeiten, von Ärzten mit Respekt behandelt zu werden, und damit, dass sich Ärzte Zeit nahmen, um mit ihnen Probleme zu diskutieren. Mehr als sechzig Prozent litten unter klinisch evidentem Stress, und ein Viertel hatte Probleme mit Angst. Auch Angehörige hatten Unterstützung, aber auch Konflikte in der Beziehung zur Patientin erlebt. Stress, Angst und Konflikte in der Beziehung waren die wichtigsten Faktoren, welche mit den psychosozialen Bedürfnissen der Angehörigen in Zusammenhang standen, und welche verletzlichere Angehörige identifizieren könnten, die mehr Unterstützung und Aufmerksamkeit bräuchten. Die Ergebnisse dieser Studie erhöhen das Wissen über die psychosozialen Bedürfnisse von Angehörigen von Krebspatientinnen, und bilden eine Basis für deren gezielte Unterstützung.

Im Kapitel 7 werden die wichtigsten Ergebnisse der Studien und methodologische Belange diskutiert. Wichtige Ergebnisse waren, dass viele Patientinnen unerfüllte Bedürfnisse hatten und über viele krankheits- und therapiebedingte Symptome klagten, während dem sie wegen Brustkrebs behandelt wurden, aber auch in der Zeit nach ihrer Therapie. Angehörige hatten Probleme, Informationen und Zugang 
zu Gesundheitspersonen zu bekommen. Die Patientinnen und ihre Angehörigen hatten soziale Unterstützung, aber auch Konflikte in der Beziehung erfahren. Jedoch nicht alle Patientinnen und Angehörigen haben die gleichen Bedürfnisse nach Hilfe. Darum sind die Faktoren, welche in diesen Studien evaluiert wurden sehr wichtig, um Patientinnen und Angehörige mit unerfüllten Bedürfnissen und einem höheren Unterstützungsbedarf zu identifizieren, und denen gezielte Unterstützung zu geben, die sie auch wirklich benötigen.

Spezifische und in die klinische Routine integrierte Assessments ermöglichen Gesundheitspersonen angepasst $\mathrm{zu}$ informieren, ein gezieltes SymptomManagement, und gezielte Unterstützung und Beratung anzubieten, die den Patientinnen helfen, ihre unerfüllten Bedürfnisse zu befriedigen. Angehörige von Brustkrebspatientinnen benötigen mehr Aufmerksamkeit von Gesundheitspersonen, welche auch die Schlüsselpersonen im Kontakt mit den Angehörigen sind. Gesundheitspersonen können den Informationsfluss intensivieren, den Angehörigen helfen, ihre Angst und ihren Stress zu vermindern, und die Kommunikation zwischen den Patientinnen und ihren Angehörigen fördern. Weiter sollte die Beziehung zwischen den Patientinnen und ihren Angehörigen thematisiert werden.

Methodologische Kritik mag angebracht sein, weil ein Cross-Sektionales Forschungsdesign gewählt wurde, und weil kein angemessenes Messinstrument zur Verfügung stand, um die Bedürfnisse der Patientinnen und ihrer Angehörigen zu messen. Es mussten zwei verschiedene Instrumente eingesetzt werden, die den Nachteil hatten, dass der direkte Vergleich der Bedürfnisse der Patienten mit denen ihrer Angehörigen nicht möglich war.

Diese Dissertation zeigt die Notwendigkeit auf, dass wir in der Schweiz gut und speziell ausgebildete Pflegende für die Betreuung von Brustkrebspatientinnen brauchen, und sie stellt eine Wissensbasis für deren Ausbildung und für die weitere Entwicklung der klinischen Praxis bereit.

Zukünftige Forschung sollte sich auf die oft und gleichzeitig auftretenden krankheits- und therapiebedingten Symptome konzentrieren und untersuchen, wie sie mit den Bedürfnissen der Patientinnen in Zusammenhang stehen. Es müssen mehr Erkenntnisse gewonnen werden, um die ganzen Auswirkungen von Brustkrebs auf Patientinnen und deren Angehörige, und auf ihre Bedürfnisse zu verstehen. Die weitere Forschung sollte sich auch auf die zwischenmenschliche Beziehung zwischen den Patientinnen und ihren Angehörigen konzentrieren. Longitudinale Studien mit grossen Samples sind wichtig, um die Veränderungen der Bedürfnisse der Patientinnen und deren Angehörigen über längere Zeit zu untersuchen. 


\section{Acknowledgments}

I am indebted to numerous persons and institutions for their help and support during this project. Thanks are due to the patients and their relatives who participated in the studies for their valuable contribution.

Special thanks go to my promoters, Prof. Dr. Bart van den Borne, Maastricht University, Prof. Dr. Ruud JG Halfens, Maastricht University and Prof. Dr. Theo Dassen, Charité Berlin, for their guidance, expertise, constructive criticism and encouragement.

Thanks go further to persons in the following institutions, who provided resources, logistic support or contacted the patients: Prof. Dr. med. U.M. Lütolf, K. Betschart, B. Kissling, E. Salgueiro, N. Kaymaz, (Radio-Oncology, University Hospital Zurich); Prof. Dr. med. D. Fink, M. Schneebeli, and S. Müri, who died of cancer last summer, (Gynaecology, University Hospital Zurich); Dr. med. T.H. Hess (Gynaecology, Cantonal Hospital Winterthur) and M. Meyer; further to Dr. med. U.R. Meier (RadioOncology, Cantonal Hospital Winterthur) and B. Rutschmann; Prof. Dr. med. St. Büchi (Psychiatry, University Hospital Zurich, now Private Clinic Hohenegg, Meilen, $\mathrm{CH})$.

I am grateful to the Cancer League, Zurich for their financial support.

I thank my statistician, Prof. Dr. Marianne Müller for her excellent support, Dr. Joanne Eysell for competent proofreading, Astrid Maissen for data management and Marja Vissers for her warm and very helpful support with the administrative issues at the Maastricht University.

Special expressions of gratitude are extended to my colleagues, Susi Saxer, Horst Rettke, and Harry Hulskers for their help, inspiration and encouragement.

I am greatly indebted to my sister Doris Schmid Müller, to her sons and my nephews Philip and Flavio Müller, my father Max Schmid, also for his financial support, my mother, Margaretha Schmid-Wolf who passed away some years ago, my cousin Madeleine Wolf, my aunt Aline Wolf for proofreading and correcting the English text, Harry C. Hoeben, a close friend of the family and my best and closest friend Madeleine Schürch.

Finally I am greatly indebted to my husband Reto Büchi for his patience, encouragement, inspiration, support and love during all stages of this endeavour. 



\section{Curriculum Vitae}

Silvia Schmid Büchi was born August $13^{\text {th }} 1956$ in Thalwil, near Zurich, Switzerland. In 1977, she completed her professional training in Nursing Care at the Zurich School of Nursing, $\mathrm{CH}$. During the following years, she worked as a nurse in internal medicine and obstetric wards of the University Hospital Zurich and the City Hospital Triemli, Zurich. Between 1985 and 1987, she was an Assistant Teacher at the Zurich School of Nursing and from $1988-1996$ worked as a Clinical Tutor in surgery, internal medicine and obstetrics at the Regional Hospital Affoltern, $\mathrm{CH}$. During this period, she finished her training as a Clinical Nursing Expert at the WE'G Institute for Post Diploma Education in Health Professions, Aarau, Switzerland. In 1996, she commenced her master's studies at Maastricht University, NL and the University of Applied Sciences, Aarau, CH and obtained her Master's degree in Nursing Science in December 1999. During this time, she was a Tutor at the Educational Centre of the Swiss Nurses' Association, Zurich, CH. From 2000 - 2007, she worked as a Researcher and Project Leader at the Centre for Development and Nursing Research, University Hospital, Zurich. In 2003, she commenced her PhD studies presented in this dissertation at the Maastricht University, NL. She has been working as a Lecturer at several Nursing Education Centres in Switzerland since 2008. 